Transformação de espaços métricos otimizando a recuperação de imagens por conteúdo e avaliação por análise visual

Letrícia Pereira Soares Avalhais 


\section{Transformação de espaços métricos otimizando a recuperação de imagens por conteúdo e avaliação por análise visual ${ }^{1}$}

\section{Letrícia Pereira Soares Avalhais}

Orientadora: Profa. Dra. Agma Juci Machado Traina

Dissertação apresentada ao Instituto de Ciências Matemáticas e de Computação - ICMC-USP, como parte dos requisitos para obtenção do título de Mestre em Ciências - Ciências de Computação e Matemática Computacional. VERSÃO REVISADA

\section{USP - São Carlos}

Março de 2012

\footnotetext{
${ }^{1}$ Trabalho realizado com o apoio financeiro da FAPESP - Processo 2009/04232-8
} 
Ficha catalográfica elaborada pela Biblioteca Prof. Achille Bassi e Seção Técnica de Informática, ICMC/USP, com os dados fornecidos pelo(a) autor(a)

Avalhais, Letrícia Pereira Soares

Transformação de espaços métricos otimizando a recuperação de imagens por conteúdo e avaliação por análise visual / Letrícia Pereira Soares Avalhais; orientadora Agma Juci Machado Traina. -- São Carlos, 2012 .

$130 \mathrm{p}$.

Dissertação (Mestrado - Programa de Pós-Graduação em Ciências de Computação e Matemática Computacional) -Instituto de Ciências Matemáticas e de Computação, Universidade de São Paulo, 2012.

1. Transformação de espaço métrico. 2. Consultas por similaridade. 3. Realimentação de relevância. 4. Algoritmo genético. 5. Visualização. I. Traina, Agma Juci Machado, orient. II. Título. 


\section{Resumo}

O problema da descontinuidade semântica tem sido um dos principais focos de pesquisa no desenvolvimento de sistemas de recuperação de imagens baseada em conteúdo (CBIR). Neste contexto, as pesquisas mais promissoras focam principalmente na inferência de pesos de características contínuos e na seleção de características. Entretanto, os processos tradicionais de inferência de pesos contínuos são computacionalmente caros e a seleção de características equivale a uma ponderação binária. Visando tratar adequadamente o problema de lacuna semântica, este trabalho propõe dois métodos de transformação de espaço de características métricos baseados na inferência de funções de transformação por meio de algoritmo genético. O método WF infere funções de ponderação para ajustar a função de dissimilaridade e o método TF infere funções para transformação das características. Comparados às abordagens de inferência de pesos contínuos da literatura, ambos os métodos propostos proporcionam uma redução drástica do espaço de busca ao limitar a busca à escolha de um conjunto ordenado de funções de transformação. Análises visuais do espaço transformado e de gráficos de precisão vs. revocação confirmam que TF e WF superam a abordagem tradicional de ponderação de características. Adicionalmente, foi verificado que TF supera significativamente WF em termos de precisão dos resultados de consultas por similaridade por permitir transformação não lineares no espaço de característica, conforme constatado por análise visual. 



\section{Abstract}

The semantic gap problem has been a major focus of research in the development of content-based image retrieval (CBIR) systems. In this context, the most promising research focus primarily on the inference of continuous feature weights and feature selection. However, the traditional processes of continuous feature weighting are computationally expensive and feature selection is equivalent to a binary weighting. Aiming at alleviating the semantic gap problem, this master dissertation proposes two methods for the transformation of metric feature spaces based on the inference of transformation functions using Genetic Algorithms. The WF method infers weighting functions and the TF method infers transformation functions for the features. Compared to the existing methods, both proposed methods provide a drastic searching space reduction by limiting the search to the choice of an ordered set of transformation functions. Visual analysis of the transformed space and precision. vs. recall graphics confirm that both TF and WF outperform the traditional feature weighting methods. Additionally, we found that TF method significantly outperforms WF regarding the query similarity accuracy by performing non linear feature space transformation, as found in the visual analysis. 

Aos meus pais e à minha irmã. 



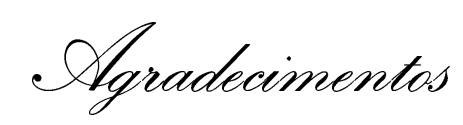

À Deus, que guia-me todos os dias e ilumina meu caminho, pelo dom da vida.

Aos meus queridos pais, Edima e Ramão, pelo incentivo, amor incondicional, carinho, apoio, pela dedicação e educação e por compreenderem a minha ausência durante o período do mestrado. À minha querida irmã Aryanne, pelo carinho, cumplicidade e incentivo que mesmo com a distância se fez sempre presente.

À minha orientadora, Profa. Dra. Agma J. M. Traina, agradeço a oportunidade, o apoio, a paciência, os valiosos ensinamentos e a sua orientação que foram fundamentais durante a elaboração deste trabalho.

Ao meu amigo e namorado Luciano, pelo seu jeito doce e especial de fazer dos meus dias os melhores ao seu lado, por compartilhar os momentos felizes e os não tão felizes.

Ao meu amigo Patrick, pela sua amizade, lealdade, companheirismo, espontaneidade e por estar sempre disposto a ajudar.

Às minhas amigas Giseli, Laís e Josi, que me fizeram sentir em casa desde que cheguei em São Carlos, pela amizade e compreensão.

A todos os meus amigos de Campo Grande, pelos momentos divertidos e descontraídos que passamos juntos.

Aos colegas do GBdI/ICMC, pelas discussões e conselhos, em especial aos amigos Sérgio e Mônica pelas revisões e sugestões deste texto.

Ao ICMC-USP, pelo apoio institucional.

Aos funcionários da secretaria da Pós-Graduação do ICMC-USP, pela atenção e competência.

À FAPESP, CAPES e CNPq, pelo apoio financeiro.

Meus sinceros agradecimentos. 

Agradecimento Especial

Ao meu coorientador, Prof. Dr. José Fernando Rodrigues Jr., pela orientação, pelas valiosas contribuições e pela disponibilidade em ajudar. 



\section{Sumário}

Lista de Figuras $\quad$ vii

Lista de Tabelas $\quad$ xi

Lista de Siglas e Acrônimos $\quad$ xiii

Lista de Símbolos $\quad$ Xv

1 Introdução 1

1.1 Considerações Iniciais $\ldots \ldots \ldots \ldots \ldots$

1.2 Motivação . . . . . . . . . . . . . . . . . . . 2

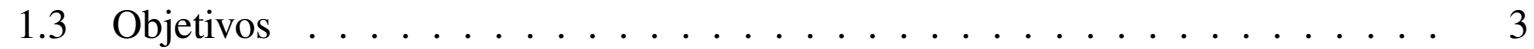

1.4 Organização do Documento . . . . . . . . . . . . . . . . . . 4

2 Dados Complexos e Recuperação Baseada em Conteúdo 5

2.1 Considerações Iniciais . . . . . . . . . . . . . . . . . . 5

2.2 Transformação e Representação de Dados Complexos . . . . . . . . . . . . . . 6

2.2.1 Extração de Características . . . . . . . . . . . . . . . . . . 7

2.2.2 Funções de Distância . . . . . . . . . . . . . . . . . . . 7

2.3 Consultas por Similaridade . . . . . . . . . . . . . . . . . . . 9

2.4 Espaços Métricos . . . . . . . . . . . . . . . . . . . . . . . . 11

2.5 Métodos de Acesso Métrico . . . . . . . . . . . . . . . . . . . . 12

2.6 Redução de Dimensionalidade . . . . . . . . . . . . . . . . . . . . . 12

2.7 Realimentação de Relevância . . . . . . . . . . . . . . . . . . . . . . . . . 14

2.8 Considerações Finais . . . . . . . . . . . . . . . . . . 16 
3 Otimização por Algoritmos Genéticos 19

3.1 Considerações Iniciais . . . . . . . . . . . . . . . . . . . . . . . . . . . . 19

3.2 Meta-heurística Evolutiva . . . . . . . . . . . . . . . . . 21

3.3 Algoritmos Genéticos . . . . . . . . . . . . . . . . . 21

3.3.1 Características Gerais dos AGs . . . . . . . . . . . . . . . . 22

3.3.2 Operadores Genéticos . . . . . . . . . . . . . . . . . . 24

3.3.2.1 Seleção . . . . . . . . . . . . . . . . . . 24

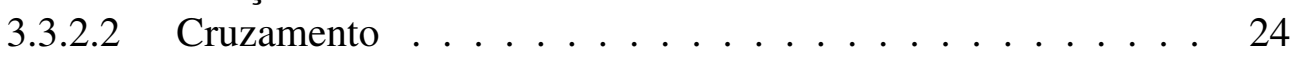

3.3.2.3 Mutação . . . . . . . . . . . . . . . . 26

3.3.3 Parâmetros Genéticos . . . . . . . . . . . . . . . . 26

3.4 Considerações Finais . . . . . . . . . . . . . . . . . . . . . . 27

4 Análise Visual de Dados 29

4.1 Considerações Iniciais . . . . . . . . . . . . . . . . . . . . . . . . . . . 29

4.2 Interação Visual sobre Bancos de Dados . . . . . . . . . . . . . . . . . . . . . . . . . . . . . .

4.3 Projeção Multidimensional . . . . . . . . . . . . . . . . . . . 32

4.4 Visualização de Informação . . . . . . . . . . . . . . . . . . . . . . 33

4.4 .1 Visão Geral e Objetivos . . . . . . . . . . . . . . . . . . . 33

4.4.2 Técnicas de Visualização de Informação . . . . . . . . . . . . . . . . . 34

4.4 .3 Classificação de Dados e Interação . . . . . . . . . . . . . . . . . . . . . . . . 40

4.5 Considerações Finais . . . . . . . . . . . . . . . . . . 43

5 Transformação de Funções de Similaridade e de Espaços de Características 45

5.1 Considerações Iniciais . . . . . . . . . . . . . . . . . . . 45

5.2 Definições e Formalização do Protótipo do Sistema CBIR Desenvolvido . . . . 46

5.3 Otimização por Funções de Ponderação . . . . . . . . . . . . . . . . . . . . 49

5.4 Otimização por Funções de Transformação . . . . . . . . . . . . . . . . 50

5.5 Considerações Finais . . . . . . . . . . . . . . . . . . . 51

6 Resultados Experimentais $\quad 53$

6.1 Considerações Iniciais . . . . . . . . . . . . . . . . . . . 53

6.2 Conjuntos de Imagens . . . . . . . . . . . . . . . . . . . . . 53

6.2.1 Domínio de Imagens Diversas . . . . . . . . . . . . . . . . 53

6.2 .2 Domínio de Imagens Médicas . . . . . . . . . . . . . . . . . . . . . . 54

6.3 Configurações dos Experimentos . . . . . . . . . . . . . . . . . . 56

6.4 Análise dos Resultados . . . . . . . . . . . . . . . . . . . . 58

6.4.1 Medidas de Precisão e Revocação . . . . . . . . . . . . . . . . . . . 58

6.4 .2 Visualização . . . . . . . . . . . . . . . . . . . 62

6.4.3 Discussões Gerais dos Resultados . . . . . . . . . . . . . . . . 64

6.5 Considerações Finais . . . . . . . . . . . . . . . . . 65

7 Conclusões $\quad 67$

7.1 Considerações Finais . . . . . . . . . . . . . . . . . . . 67

7.2 Principais Contribuições . . . . . . . . . . . . . . . . . 68

7.3 Trabalhos Futuros . . . . . . . . . . . . . . . . . . . 68 
7.4 Publicação . . . . . . . . . . . . . . . . . . . . . . . . . . . 69

$\begin{array}{ll}\text { Referências Bibliográficas } & 71\end{array}$

A Gráficos e Visualizações dos Resultados Experimentais $\quad 77$

A.1 Gráficos de Precisão e Revocação e Número de Relevantes por Ciclo . . . . . . 77

A.2 Visualização . . . . . . . . . . . . . . . . . . . . . . 99 



\section{Lista de Figuras}

2.1 Consulta por abrangência com três medidas de similaridade diferentes $\left(L_{1}, L_{2}\right.$ e $\left.L_{\infty}\right)$, de distância máxima $r_{q} \ldots \ldots \ldots \ldots \ldots \ldots$

2.2 Consulta pelos três vizinhos mais próximos ao objeto $s_{q}$ utilizando função de distância Euclidiana $L_{2} \ldots \ldots \ldots \ldots \ldots \ldots \ldots \ldots \ldots$

2.3 Recuperação de imagens utilizando Realimentação de Relevância. . . . . . . . 15

3.1 Ótimo global e ótimos locais de um problema de minimização não linear. . . . 20

3.2 Fluxograma de execução do Algoritmo Genético. . . . . . . . . . . . . . . 23

3.3 Exemplo de cruzamento de um ponto. . . . . . . . . . . . . . . 25

3.4 Exemplo de cruzamento de dois pontos. . . . . . . . . . . . . . . . 25

3.5 Exemplo de cruzamento uniforme. . . . . . . . . . . . . . . . . 26

4.1 Exemplo de visualização por Coordenadas Paralelas. . . . . . . . . . . . . 35

4.2 Exemplo de visualização por Scatter Plots. . . . . . . . . . . . . . . . . 36

4.3 Exemplo de visualização por Table Lens. . . . . . . . . . . . . . . . . . . 36

4.4 Exemplo de visualização por Star Glyphs. . . . . . . . . . . . . . . . . . 37

4.5 Exemplo de visualização por Dimensional Stacking. . . . . . . . . . . . . . . 38

4.6 Treemap com um milhão de dados. . . . . . . . . . . . . . . . . . . . . . . 39

4.7 Representação hierárquica por Árvore Hiperbólica. . . . . . . . . . . . . . . 40

4.8 Representação de dados hierárquicos utilizando Cone Tree. . . . . . . . . . . 40

5.1 Esquematização do protótipo CBIR apoiado por realimentação de relevância e algoritmo genético. . . . . . . . . . . . . . . . . . 47

5.2 Funções lineares e não lineares para otimização por ponderação e transformação do espaço de características. . . . . . . . . . . . . . . . . . . . . . . 49 
6.1 Amostra da base de imagens Corel 1000, composta por 10 classes: Africa, beach, buildings, buses, dinosaurs, elephants, flowers, food, horses e mountains.

6.2 Amostra da base de imagens Cenas composta por 5 classes: coast, forest, highway, mountain e tall buildings. . . . . . . . . . . . . . . . . 54

6.3 Amostra da base de imagens Exames Médicos composta por 12 classes: abdômen, cérebro axial, cérebro coronal, cérebro sagital, mama, tórax, pé, mão, joelho, pulmão, pélvis e espinha sagital. . . . . . . . . . . . . . .

6.4 Amostra da base de imagens Pulmão composta por 6 classes: normal, consolidação, enfisema, espessamento, favo de mel e vidro fosco. . . . . . . . . . . 55

A.1 Precisão vs. Revocação da consulta inicial para cada extrator. . . . . . . . . . . 78

A.2 Precisão vs. Revocação no ciclo 10 , (a) WG, $A=2$ (b) WG, $A=10$ (c) WG, $A=20$ (d) WF, $A=2$ (e) WF, $A=10$ (f) WF, $A=20$ (g) TF, $A=2$ (h) TF, $A=10$ (i) TF, $A=20 \ldots \ldots \ldots \ldots \ldots$

A.3 Precisão vs. Revocação para cada método e cada valor de $A$ utilizando os extratores (a) Momentos de Cor (b) SIFT (c) Sobel. . . . . . . . . . . . . . . . . 80

A.4 Número de Relevantes vs. Ciclos para cada método e cada valor de $A$ utilizando os extratores (a) Momentos de Cor (b) SIFT (c) Sobel. . . . . . . . . . . . . .

A.5 Número de Relevantes vs. Ciclos para cada método e cada valor de $A$ utilizando os extratores (a) Momentos de Cor (b) SIFT (c) Sobel. . . . . . . . . . . . . .

A.6 Precisão vs. Revocação do ciclo 1 ao ciclo 10 considerando o extrator Momentos de Cor (a) WG, $A=10$ (b) WF, $A=10$, e (c) TF, $A=10 \ldots \ldots 3$

A.7 Precisão vs. Revocação da consulta inicial para cada extrator. . . . . . . . . . . . 84

A.8 Precisão vs. Revocação no ciclo 10, (a) WG, $A=2$ (b) WG, $A=10$ (c) WG, $A=20$ (d) WF, $A=2$ (e) WF, $A=10$ (f) WF, $A=20$ (g) TF, $A=2$ (h) TF, $A=10$ (i) $\mathrm{TF}, A=20 \ldots \ldots \ldots \ldots \ldots$

A.9 Precisão vs. Revocação para cada método e cada valor de $A$ (a) Sobel (b) SIFT (c) Run Length. . . . . . . . . . . . . . . . . . . . . . . . . .

A.10 Número de Relevantes vs. Ciclos para cada método e cada valor de $A$ utilizando os extratores (a) Sobel (b) SIFT (c) Run Length. . . . . . . . . . . . . . . . . .

A.11 Precisão vs. Revocação do ciclo 1 ao ciclo 10 considerando o extrator Sobel (a) WG, $A=20$ (b) WF, $A=10$ e (c) TF, $A=10 \ldots \ldots \ldots 8$

A.12 Precisão vs. Revocação da consulta inicial para cada extrator. . . . . . . . . . . . 89

A.13 Precisão vs. Revocação no ciclo 10 , (a) WG, $A=2$ (b) WG, $A=10$ (c) WG, $A=20$ (d) WF, $A=2$ (e) WF, $A=10$ (f) WF, $A=20$ (g) TF, $A=2$ (h) TF, $A=10$ (i) TF, $A=20 \ldots \ldots \ldots \ldots \ldots$

A.14 Precisão vs. Revocação para cada método e cada valor de $A$ utilizando os extratores (a) Sobel (b) SIFT (c) Run Length. . . . . . . . . . . . . . . . . . . . .

A.15 Número de Relevantes vs. Ciclos para cada método e cada valor de $A$ utilizando os extratores (a) Sobel (b) SIFT (c) Run Length. . . . . . . . . . . . . . . . . .

A.16 Precisão vs. Revocação do ciclo 1 ao ciclo 10 considerando o extrator Sobel (a) WG, $A=20$ (b) WF, $A=10$ e (c) TF, $A=10 \ldots \ldots . \ldots 3$

A.17 Precisão vs. Revocação da consulta inicial para cada extrator. . . . . . . . . . . 94 
A.18 Precisão vs. Revocação no ciclo 10 , (a) WG, $A=2$ (b) WG, $A=10$ (c) WG, $A=20$ (d) WF, $A=2$ (e) WF, $A=10$ (f) WF, $A=20$ (g) TF, $A=2$ (h) TF, $A=10$ (i) $\mathrm{TF}, A=20 \ldots \ldots \ldots \ldots \ldots$

A.19 Precisão vs. Revocação para cada método e cada valor de $A$ utilizando os extratores (a) SIFT (b) Momentos de Cor (c) Sobel. . . . . . . . . . . . . . . . . 96

A.20 Número de Relevantes vs. Ciclos para cada método e cada valor de $A$ utilizando os extratores (a) SIFT (b) Momentos de Cor (c) Sobel. . . . . . . . . . . . . .

A.21 Precisão vs. Revocação do ciclo 1 ao ciclo 10 considerando (a) WG, $A=2$, Momentos de Cor (b) WF, $A=10$, Momentos de Cor e (c) TF, $A=20$, SIFT. .

A.22 Representação do espaço original da base Corel 1000 utilizando Mom. de Cor para (a) espaço completo (b) 50 elementos mais próximos ao centro de consulta. 99

A.23 Configuração do espaço da base Corel 1000 após o uso do método WG para (a) espaço completo (b) 50 elementos mais próximos ao centro de consulta. . . . .

A.24 Configuração do espaço da base Corel 1000 após o uso do método WF para (a) espaço completo (b) 50 elementos mais próximos ao centro de consulta. . . . . 99

A.25 Configuração do espaço da base Corel 1000 após o uso do método TF para (a) espaço completo (b) 50 elementos mais próximos ao centro de consulta. . . . . 100

A.26 Representação do espaço original da base Cenas utilizando Sobel para (a) espaço completo (b) 50 elementos mais próximos ao centro de consulta. . . . . . . 100

A.27 Configuração do espaço da base Cenas após o uso do método WG para (a) espaço completo (b) 50 elementos mais próximos ao centro de consulta. . . . . 100

A.28 Configuração do espaço da base Cenas após o uso do método WF para (a) espaço completo (b) 50 elementos mais próximos ao centro de consulta. . . . . . 101

A.29 Configuração do espaço da base Cenas após o uso do método TF para (a) espaço completo (b) 50 elementos mais próximos ao centro de consulta. . . . . . . . . 101

A.30 Representação do espaço original da base Exames Médicos utilizando Sobel para (a) espaço completo (b) 50 elementos mais próximos ao centro de consulta. 101

A.31 Configuração do espaço da base Exames Médicos após o uso do método WG para (a) espaço completo (b) 50 elementos mais próximos ao centro de consulta. 102

A.32 Configuração do espaço da base Exames Médicos após o uso do método WF para (a) espaço completo (b) 50 elementos mais próximos ao centro de consulta. 102

A.33 Configuração do espaço da base Exames Médicos após o uso do método TF para (a) espaço completo (b) 50 elementos mais próximos ao centro de consulta. 102

A.34 Representação do espaço original da base Pulmão utilizando SIFT para (a) espaço completo (b) 50 elementos mais próximos ao centro de consulta. . . . . . 103

A.35 Configuração do espaço da base Pulmão após o uso do método WG para (a) espaço completo (b) 50 elementos mais próximos ao centro de consulta. . . . . 103

A.36 Configuração do espaço da base Pulmão após o uso do método WF para (a) espaço completo (b) 50 elementos mais próximos ao centro de consulta. . . . . 103

A.37 Configuração do espaço da base Pulmão após o uso do método TF para (a) espaço completo (b) 50 elementos mais próximos ao centro de consulta. . . . . 104 



\section{Lista de Tabelas}

4.1 Classificação de técnicas de visualização por tipo de dados. . . . . . . . . . . . . . 41

6.1 Descrição sumarizada dos conjuntos de características utilizados. . . . . . . . . 56 



\section{Lista de Siglas e Acrônimos}

$1 D \quad$ Unidimensional ou 1-dimensional.

$2 D \quad$ Bidimensional ou 2-dimensional.

$3 D \quad$ Tridimensional ou 3-dimensional.

AG Algoritmo genético.

CBIR Content-based Image Retrieval ou

Recuperação de imagens por conteúdo.

GBdI Grupo de Bases de Dados e Imagens.

ICMC-USP Instituto de Ciências Matemáticas e de Computação -

Universidade de São Paulo.

$k \mathrm{NN} \quad k$-nearest neighbor query ou

Consulta aos $k$ vizinhos mais próximos.

LSP Least-square projection.

MAM Metric Access Method ou Método de Acesso Métrico.

$n \mathrm{D} \quad$ Multidimensional ou $n$-dimensional.

PCA Principal component analysis.

RR Realimentação de Relevância.

SGBD Sistema de Gerenciamento de Bases de Dados. 
SQL Structured Query Language.

SVM Support Vector Machines.

VisTree Visualization Tree. 


\section{Lista de Símbolos}

A Parâmetro do algoritmo genético.

C Conjunto de restrições.

$\mathrm{C}_{i} \quad$ Cromossomo.

d Função de distância ou função de dissimilaridade.

$d_{\mathbf{w}} \quad$ Função de distância.

$d_{C} \quad$ Função de distância Canberra.

$\mathfrak{D} \quad$ Domínio de objetos.

$\Delta \quad$ Função de transformação de espaço métrico.

$\delta_{\mathrm{w}} \quad$ Conjunto ordenado de funções de ponderação.

$\delta_{\mathbf{T}} \quad$ Conjunto ordenado de funções de ponderação.

$\epsilon \quad$ Extrator de características.

F Conjunto de funções de ponderação/transformação.

$g$ Geração da população.

$g_{i} \quad$ Restrições de igualdade.

$h_{j} \quad$ Restrições de desigualdade.

I Conjunto de imagens.

$k \quad$ Número de objetos retornados. 
k-Nearest Neighbor Query.

$L_{p} \quad$ Distância ou função Minkoswki.

$L_{1} \quad$ Distância ou função Manhattan ou City Block.

$L_{2} \quad$ Distância ou função Euclidiana.

$L_{\infty} \quad$ Distância ou função Chebychev.

$l \quad$ Ponto de cruzamento ou ponto de corte.

$\mathcal{M}$ Espaço métrico.

$m$ Dimensão do vetor/espaço de característica.

$n_{a} \quad$ Número de objetos relevantes.

$n_{b} \quad$ Número de objetos não relevantes.

$N_{g} \quad$ Número máximo de gerações.

$p_{i} \quad$ Probabilidade de seleção do cromossomo $\mathbf{C}_{i}$.

$P_{c} \quad$ Taxa de cruzamento.

$P_{m} \quad$ Taxa de mutação.

$r_{q} \quad$ Distância máxima.

$\mathbf{r}_{i} \quad$ Atributos dos objetos relevantes.

$\mathbf{R}_{q_{i}}^{+} \quad$ Conjunto de elementos positivos.

$\mathbf{R}_{q_{i}}^{-} \quad$ Conjunto de elementos negativos.

$S \quad$ Conjunto de objetos.

$s_{q} \quad$ Objeto de consulta $\left(s_{q} \in S\right)$.

$\mathbf{s}_{i} \quad$ Atributos dos objetos não relevantes.

$S_{p} \quad$ Tamanho da população.

T Ranking da consulta.

TF Método de transformação de espaço por funções de transformação.

$\mathbf{x}_{i}, \mathbf{y}_{i} \quad$ Vetor de características.

$\mathrm{X}, \mathrm{Y}$ Conjunto de vetores de caracterísiticas ou espaço de características.

$z \quad$ Atributo normalizado.

w Vetor de pesos.

WG Método de geração de pesos em intervalo contínuo.

WF Método de geração de pesos por funções de ponderação. 
$\mu(x) \quad$ Média dos valores do atributo $x$.

$\sigma(x) \quad$ Desvio padrão dos valores do atributo $x$.

$\Phi \quad$ Função de avaliação de qualidade ranking. 



\subsection{Considerações Iniciais}

O setor tecnológico tem conquistado expressivos avanços nos últimos anos, proporcionando meios mais eficientes e de custos cada vez menores para geração, propagação e armazenamento de grandes quantidades de dados. Em virtude do aumento do poder computacional de processamento e armazenamento, assim como da difusão da Internet, existe uma demanda de tecnologia para suporte ao gerenciamento de diversos tipos de dados por parte dos mais variados setores da atividade humana, como medicina, comércio, indústria, engenharia, agrometeorologia, educação, publicidade, entretenimento, entre outros.

Dentre a vasta gama de diversidade de dados gerados, muitos são considerados dados complexos, como por exemplo, cadeias de DNA, séries temporais, imagens, vídeos, podendo prover uma valiosa fonte de conhecimento. Entretanto, a capacidade de utilização destes dados está ainda aquém da capacidade de geração e propagação (Keim et al., 2008), o que inviabiliza a descoberta de conhecimentos úteis e possibilidade de tomadas de decisões.

Indexação e recuperação de dados complexos não são feitas de maneira trivial, pois normalmente são armazenados como uma sequência de bytes tratados como objetos passivos. Considerando o domínio de imagens, que é o foco deste trabalho, as duas principais maneiras para efetuar consultas (Lakdashti et al., 2008) sobre esses dados são: 1) utilizar descrições textuais 
feitas pelo usuário, imagem por imagem, o que pode introduzir inconsistências devido à imprecisão da informação introduzida, baseada na percepção humana; 2) consultas baseadas em conteúdo extraído automaticamente das imagens, sendo considerado características de baixo nível, que são usualmente realizadas por meio de consultas por similaridade.

Em um banco de imagens, uma consulta por similaridade deve retornar um conjunto de imagens como resposta à consulta. O processamento dessa consulta é feito por meio de uma estrutura de índices utilizada para o gerenciamento das imagens armazenadas no banco. O vetor de características extraído das imagens por um extrator de características e a função de distância para medir dissimilaridade são fundamentais para a realização de consultas por similaridade. Uma questão importante que deve ser considerada é o quanto os resultados dessas consultas refletem o que é esperado pelo usuário (Traina et al., 2006).

Em consultas baseadas em conteúdo, mais especificamente nas técnicas de CBIR (do inglês, Content-Based Image Retrieval), as imagens são indexadas pelo seu conteúdo visual como cor, textura e forma (Alemu et al., 2009). A utilização de descritores de imagem como distribuição de cor e tipo de textura para a sua indexação possui a desvantagem de não guardar nenhuma informação com relação à semântica dos dados, como demandam consultas sobre imagens. A inconsistência entre as características extraídas de uma imagem utilizadas para a sua descrição e a interpretação do usuário sobre a mesma é denominada lacuna semântica (semantic gap), pois usualmente as característica extraídas automaticamente não conseguem descrever todos os aspectos referentes a uma imagem.

Para tratar problemas como a lacuna semântica, existem metodologias que permitem o aprendizado de características que são mais representativas para as consultas. Uma dessas metodologias, denominada realimentação de relevância, é capaz de introduzir a percepção do usuário sobre os resultados de consultas por meio de mecanismos de aprendizagem que melhor reflete os interesses do usuário. De maneira geral, as metodologias para aprimorar consultas por similaridade devem fazer com que de alguma maneira as distâncias entre imagens semelhantes sejam menores e as distâncias entre imagens não semelhantes sejam maiores.

\subsection{Motivação}

As principais abordagens construídas para otimizar consultas por similaridade se dividem em técnicas que atuam sobre as funções de dissimilaridade e técnicas que atuam sobre o espaço de dados. Em geral, as técnicas que consideram funções de dissimilaridade visam a calibração destas funções por meio de vetores de pesos. Transformação de espaços de dados podem considerar, por exemplo, metodologias de seleção e transformação de características. 
Mecanismos dinâmicos de ponderação são utilizados para inferir vetores de pesos que modificam a função de distância de modo a aproximar melhor a noção perceptual de similaridade entre imagens semelhantes e imagens não semelhantes. Em (Rahman et al., 2011) é apresentado um framework para recuperação de imagens médicas que atribui pesos à distância Euclidiana baseado em avaliações positivas feitas pelo usuário na fase de realimentação de relevância, além de fazer uso de um classificador SVM (Suport Vector Machine) para predizer a classe das imagens.

Chen et al. (Chen et al., 2012) introduzem um método duplo de ponderação para dados de alta dimensão. As características são divididas em grupos e então os pesos são atribuídos simultaneamente para identificar a importância de cada grupo de características e a importância de cada característica dentro do grupo. Outros métodos de ponderação de função de dissimilaridade empregando o mecanismo de realimentação de relevância são apresentados em (Aksoy et al., 2000) (Bugatti et al., 2011).

Além do uso de vetores de pesos, existem outras técnicas para a aprendizagem de funções de distância. Composição de descritores é a estratégia de Torres et al. (Torres et al., 2009), onde um framework baseado em programação genética gera combinação de funções de similaridade de múltiplos descritores.

Técnicas baseadas em transformação de espaço de dados utilizando seleção de características são muito comuns na literatura (Sun and Bhanu, 2010) (Guldogan and Gabbouj, 2008) (Nguyen, 2010). Por exemplo, o trabalho apresentado em (da Silva et al., 2011) realiza a seleção das características baseado em funções de avaliação de rankings.

É importante salientar a limitação existente nessas abordagens. As técnicas de ponderação de atributos e seleção de características não são capazes de identificar correlações não lineares existentes nos espaços de dados, pois tais técnicas têm o efeito de realizar transformações lineares sobre os dados.

\subsection{Objetivos}

O objetivo principal deste trabalho foi desenvolver técnicas dinâmicas de transformação de espaços métricos visando inserir informação semântica dos dados na otimização de consultas por similaridade. Dessa forma, foram propostas duas técnicas para:

- inferir um vetor de pesos para ajustar a função de dissimilaridade por meio de funções de ponderação; 
- otimizar o espaço de características por inferência de vetores de funções de transformação, ajustando o espaço original para criar um novo espaço que represente melhor a relação dos dados no espaço.

Para gerar vetores de ponderação e transformação ótimos foi utilizada realimentação de relevância combinada com algoritmo genético. Esta combinação permite uma otimização guiada pelo interesse do usuário, o que possibilita a transferência semântica necessária para melhorar consultas por similaridade.

Técnicas de análise visual de dados podem ser usadas para inspecionar o comportamento dos dados num espaço métrico, como mostrado em (Rodrigues Jr. et al., 2005). Para este propósito, um dado espaço pode ser investigado usando-se, por exemplo, técnicas de projeção multidimensional. Com este tipo de análise, busca-se por padrões de comportamento, como aglomerados e exceções, que devem espelhar o que se conhece a priori sobre os dados. As inferências podem levar a conclusões a respeito de como um dado espaço métrico reflete a semântica de um conjunto de dados. Dado este cenário, foi empregada análise visual sobre os espaços resultantes com o objetivo de validar os métodos desenvolvidos.

\subsection{Organização do Documento}

Além deste capítulo introdutório, este documento possui outros seis capítulos organizados da seguinte forma:

- Capítulo 2: apresenta os conceitos básicos e técnicas relacionadas à recuperação de imagens por conteúdo.

- Capítulo 3: sumariza os conceitos e fundamentos de algoritmos genéticos.

- Capítulo 4: explora os conceitos e técnicas da análise visual de dados e visualização de informação.

- Capítulo 5: introduz as definições necessárias para a formalização e entendimento dos métodos e apresenta a visão geral do protótipo desenvolvido.

- Capítulo 6: descreve os resultados experimentais e apresenta as discussões sobre os resultados mostrados por meio de curvas de precisão vs. revocação e análise visual.

- Capítulo 7: sumariza as conclusões desta dissertação, apontando as principais contribuições e perspectivas de trabalhos futuros. 


\section{Dados Complexos e Recuperação Baseada em Conteúdo}

\subsection{Considerações Iniciais}

Extrair informações de dados complexos não é uma tarefa trivial. Por não se tratar de dados tradicionais, a maioria dos SGBDs não dispõem de suporte efetivo para lidar com estes. Operações como indexação, consultas, entre outras, só são possíveis mediante transformações no conjunto original de dados. A transformação necessária compreende desde a estruturação dos dados, até a redução do volume, eliminando tudo o que seja desnecessário ao real objetivo da aplicação.

Em sistemas de recuperação de imagens existem duas maneiras principais de representar imagens: a primeira é através de anotações textuais, que podem introduzir inconsistências devido ao poder pouco representativo de textos sobre a semântica de um domínio de imagens, e também devido à capacidade limitada da percepção humana em capturar e traduzir textualmente o conteúdo visual de imagens. A segunda abordagem é empregada em sistemas CBIR, a qual considera os atributos visuais como cor, textura e forma (Alemu et al., 2009) extraídas de forma automática por um extrator de características, fazendo com que cada imagem seja representada por um vetor de características. A similaridade entre imagens é então calculada 
por funções de dissimilaridade/distância, que devem refletir do modo mais preciso possível a percepção humana de similaridade.

A acurácia de consultas por similaridade está fortemente relacionada à combinação extrator de características x função de dissimilaridade, tópico de constante pesquisa. Algumas técnicas têm sido desenvolvidas para tentar obter melhor eficácia de sistemas CBIR. Este capítulo apresenta os principais conceitos e técnicas que estabelecem o cenário atual de pesquisas em recuperação baseada em conteúdo.

\subsection{Transformação e Representação de Dados Com- plexos}

Bancos de dados podem armazenar, além dos dados tradicionais, dados complexos, fazendo com que a manipulação destes resulte em considerações relevantes sobre o aspecto da capacidade e da eficiência de computar informações.

Dados complexos podem ser definidos como dados que não são auto-representativos em relação à sua semântica. São dados como, por exemplo, imagens, vídeos, áudios, séries temporais, entre outros, e são considerados em muitos casos como sendo adimensionais, podendo assim observar um número não determinado de atributos (dimensões), devido ao fato de serem tratados pelas suas características (features) extraídas. No caso de imagens, que é o foco deste trabalho, pode-se considerar além de outras características, a distribuição de cores observando o quão homogênea ou granulosa uma imagem é, ou mesmo a descrição das partes ou objetos que compõem essa imagem.

Dados adimensionais podem ser exemplificados por meio das características dos objetos presentes nas imagens. Inicialmente não se sabe quantos objetos estão contidos nas imagens, logo, o número de características a serem extraídas é indeterminado, dependendo de cada imagem analisada. Dessa forma, as características extraídas não podem ser diretamente indexadas em um banco de dados nem mesmo serem analisadas com técnicas tradicionais de análise visual de dados (Keim et al., 2006).

Um processo denominado mapeamento é necessário para que as características possam servir para serem processadas na etapa de análise visual, traduzindo-as para um formato mais adequado à computação. $\mathrm{O}$ mapeamento consiste em transformar um espaço adimensional em um espaço com número limitado de dimensões (espaço multivariado). Essa transformação resulta em um novo conjunto de dados, que representa o conteúdo derivado do conjunto original. Tais representações devem retratar a informação e o contexto semântico original o máximo possível. 


\subsubsection{Extração de Características}

A transformação de dados multidimensionais ou adimensionais em vetores numéricos representativos pode ser realizada por um processo de extração de características, sendo que as características extraídas devem capturar propriedades significativas dos dados. A extração de um conjunto de características é realizada por meio de cálculos de representações numéricas para caracterizar um determinado dado complexo, as quais são organizadas como um vetor de características, que pode ser interpretado como um ponto $m$-dimensional em um espaço vetorial. Supõe-se que cada vetor represente adequadamente um objeto segundo algum critério de interesse. Um determinado conjunto de características utilizado para a indexação de imagens é chamado de descritor.

No contexto de imagens, as características mais comuns empregadas são de fato características definidas como primitivas (Aslandogan and $\mathrm{Yu}, 1999$ ), consideradas como elementos fundamentais da composição de uma imagem, derivadas de aspectos visuais como distribuição de intensidade de cor, textura e forma. Embora as características baseadas em distribuição de intensidade de cor sejam as mais utilizadas em recuperação por conteúdo, principalmente devido ao reduzido custo computacional associado a esses tipos de extratores, muitas vezes não são satisfatórios em caracterizar corretamente as imagens. Uma alternativa para melhorar a eficácia de sistemas de recuperação de imagens é combinar outras características inerentes às imagens, como a textura e/ou forma (Zhang et al., 2000).

\subsubsection{Funções de Distância}

O uso de vetores de características é complementado pelo uso de funções de distância sobre os dados para medir a dissimilaridade entre eles. Uma função de distância, também chamada de função de dissimilaridade, compara dois objetos e retorna um valor maior ou igual a zero, que representa o grau de dissimilaridade entre esses objetos. Quanto maior o valor retornado, menor a similaridade entre os objetos comparados, ou seja, mais "distantes" eles estão entre si. Distância igual a zero reflete identidade ou similaridade total.

Funções de distância aplicadas aos vetores de características extraídas de duas imagens devem refletir, da melhor maneira possível, a percepção humana de similaridade entre elas. De forma geral, tais funções são baseadas na noção intuitiva de distância entre dois pontos.

A função de distância mais comum é a Euclidiana, conhecida também como $L_{2}$, sendo bastante frequente em buscas por similaridade em bancos de dados espaciais. É importante destacar que funções de distância devem ser fornecidas, sempre que possível, por um especialista do domínio, uma vez que para calcular e capturar as semelhanças ou diferenças entre os dados 
é preciso se fundamentar sobre um conhecimento prévio a fim de decidir os aspectos mais relevantes a serem comparados. São diversas as funções de distância propostas na literatura, dentre as mais clássicas podem-se destacar:

\section{Minkoswki}

As funções de distância da família Minkoswki, também conhecidas por distâncias $L_{p}$, são as mais amplamente utilizadas, podendo ser aplicadas em espaços vetoriais. Matematicamente, dados dois vetores de características $\mathbf{x}$ e $\mathbf{y}$ de dimensão $m$, essas funções são definidas da seguinte maneira:

$$
d(\mathbf{x}, \mathbf{y})=\sqrt[p]{\sum_{i=1}^{m}\left|x_{i}-y_{i}\right|^{p}}
$$

Para os seguintes valores particulares de $p=1,2$ e $\infty$, temos as conhecidas métricas:

- Manhattan ou City Block $\left(L_{1}\right)$ :

$$
L_{1}(\mathbf{x}, \mathbf{y})=\sum_{i=1}^{m}\left|x_{i}-y_{i}\right|
$$

- Euclidiana $\left(L_{2}\right)$ :

$$
L_{2}(\mathbf{x}, \mathbf{y})=\sqrt{\sum_{i=1}^{m}\left|x_{i}-y_{i}\right|^{2}}
$$

- Chebychev $\left(L_{\infty}\right)$ :

$$
L_{\infty}(\mathbf{x}, \mathbf{y})=\max _{i=1}^{m}\left(\left|x_{i}-y_{i}\right|\right)
$$

Uma propriedade interessante sobre a correlação destas métricas é dada pela desigualdade:

$$
L_{\infty}(\mathbf{x}, \mathbf{y}) \leq L_{2}(\mathbf{x}, \mathbf{y}) \leq L_{1}(\mathbf{x}, \mathbf{y})
$$

Esta propriedade ilustra o grau de seletividade, conforme a distribuição das distâncias que abrangem cada métrica. 


\section{Canberra}

A distância Canberra (Equação 2.6) é muito similar a distância Manhattan, com a diferença de que o módulo da diferença dos valores das características é dividido pela soma dos módulos dos mesmos.

$$
d_{C}(\mathbf{x}, \mathbf{y})=\sum_{i=1}^{m} \frac{\left|x_{i}-y_{i}\right|}{\left|x_{i}\right|+\left|y_{i}\right|}
$$

\subsection{Consultas por Similaridade}

Os SGBDs tradicionais manipulam domínios de dados que possuem relação de ordem entre os seus elementos. Estes dados compreendem basicamente números e pequenas cadeias de caracteres. Entretanto, quando dados complexos como imagens são os objetos de interesse, a relação ordem entre esses objetos é, na maioria das vezes, inexistente, portanto, buscas que utilizam operadores de igualdade ou baseadas em ordem neste domínio fazem pouco ou nenhum sentido.

Consulta por similaridade por sua vez, é apoiada pelo conceito de similaridade entre objetos, mecanismo mais adequado para realizar busca por imagens. Dado um critério de similaridade que determina uma função de distância, tais consultas são capazes de responder a requisições como as imagens mais "parecidas" a uma determinada imagem. As consultas por similaridade mais comuns são as consultas por abrangência e consultas aos $k$ vizinhos mais próximos, detalhadas a seguir.

\section{Consulta por Abrangência}

As consultas por abrangência (Range Query) consistem na busca de objetos que sejam similares a um dado objeto de referência em até um determinado grau. Isto é, dado um conjunto de objetos $S=\left\{s_{1}, s_{2}, \ldots, s_{n}\right\}$, pertencentes ao domínio $\mathfrak{D}$, uma função de distância $d$, um objeto de consulta $s_{q}$ e uma distância máxima $r_{q}$, o resultado de uma busca por abrangência é tal como descrito na Equação 2.7.

$$
\operatorname{Range}\left(s_{q}, r_{q}, d, S\right)=A=\left\{a \mid a \in S, d\left(s_{q}, a\right) \leq r_{q}\right\}
$$

A Figura 2.1, apresenta uma consulta por abrangência utilizando três medidas de similaridade: $L_{1}, L_{2}$ e $L_{\infty}$, com distância máxima $r_{q}$ em um espaço bidimensional. 


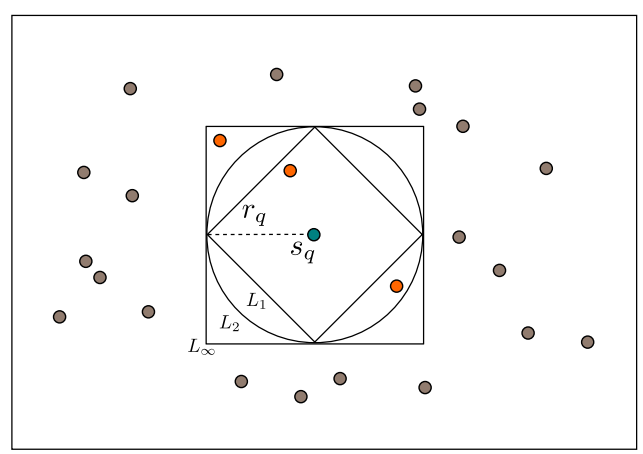

Figura 2.1: Consulta por abrangência com três medidas de similaridade diferentes $\left(L_{1}, L_{2}\right.$ e $\left.L_{\infty}\right)$, de distância máxima $r_{q}$.

\section{Consulta aos $k$ Vizinhos Mais Próximos}

As consultas aos $k$ vizinhos mais próximos $(k N N)$ consistem em retornar os $k$ objetos mais similares, ou mais próximos ao objeto de referência. Formalmente, seja $\mathfrak{D}$ um domínio, então dado um conjunto de objetos $S=\left\{s_{1}, s_{2}, \ldots, s_{n}\right\} \subset \mathfrak{D}$ e uma função de distância $d$, uma consulta $k N N$ sobre um objeto referência $s_{q}$ tal que $s_{q} \in S$ deve encontrar e retornar os $k$ objetos de $S$ com menor distância $d\left(s_{q}, s_{i}\right)$, onde $s_{i} \in S$. O conjunto resultante de uma consulta $k N N$ pode ser denotado pela Equação 2.8 (Zezula et al., 2006).

$$
k N N\left(s_{q}, k, d, S\right)=\left\{T \subseteq S,|T|=k \wedge \forall s_{i} \in T, s_{j} \in S \backslash T: d\left(s_{q}, s_{i}\right) \leq d\left(s_{q}, s_{j}\right)\right\}
$$

A Figura 2.2 ilustra uma consulta pelos $k$ vizinhos mais próximos a um objeto $s_{q}$ em um espaço bidimensional, onde $k=3$.

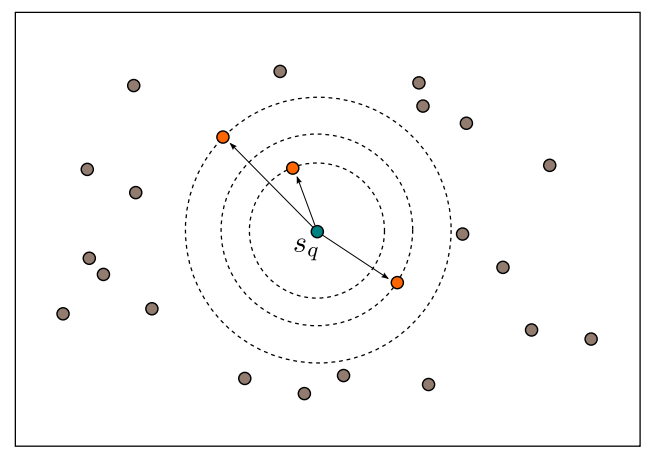

Figura 2.2: Consulta pelos três vizinhos mais próximos ao objeto $s_{q}$ utilizando função de distância Euclidiana $L_{2}$. 


\subsection{Espaços Métricos}

Algoritmos que respondem a consultas por similaridade dependem da existência de propriedades algébricas que possam fornecer uma relação entre o domínio de objetos e a função de distância. Um domínio de dados multidimensional ou adimensional com um processo de extração de características e uma função de distância podem definir um espaço métrico. Um espaço métrico (Ciaccia and Patella, 2002) é um par $\mathcal{M}=<\mathfrak{D}, d>$ onde $\mathfrak{D}$ é o domínio dos objetos e $d: \mathfrak{D} \times \mathfrak{D} \rightarrow \mathbb{R}^{+}$é uma função que associa uma distância para qualquer par $s_{i}, s_{j} \in \mathfrak{D}$. O par $\mathcal{M}=<\mathfrak{D}, d>$ é denominado espaço métrico se a função $d$ for métrica, ou seja, se $d$ atender aos seguintes axiomas para qualquer $s_{1}, s_{2}, s_{3} \in \mathfrak{D}$ :

1. Simetria: $d\left(s_{1}, s_{2}\right)=d\left(s_{2}, s_{1}\right)$

2. Auto-similaridade: $d\left(s_{i}, s_{i}\right)=0$

3. Não negatividade: $0<d\left(s_{1}, s_{2}\right)<\infty$ se $s_{1} \neq s_{2}$

4. Desigualdade triangular: $d\left(s_{1}, s_{2}\right) \leq d\left(s_{1}, s_{3}\right)+d\left(s_{3}, s_{2}\right)$

Quando os objetos do domínio considerado são vetores de coordenadas numéricas definidos em um espaço $m$-dimensional e a função de distância é métrica, tem-se um caso particular do espaço métrico denominado espaço vetorial. Portanto, pode-se dizer que espaços métricos englobam espaços vetoriais quando a função de distância é métrica.

O conceito de espaço métrico é bastante útil, podendo ser usado em bancos de dados complexos para indexação e para análise visual de dados. Um banco de dados pode se beneficiar do mapeamento de dados complexos de duas maneiras:

- um espaço métrico permite que dados adimensionais ou multidimensionais sejam indexados por Métodos de Acesso Métrico (MAMs) respondendo a consultas por similaridade (Traina et al., 2007);

- dados convencionais possuem relação de ordem, assim, eles podem ser representados visualmente. Da mesma maneira, dados adimensionais podem ter uma representação visual baseada em um espaço multidimensional de características, e respectivas distâncias entre si. 


\subsection{Métodos de Acesso Métrico}

Dados complexos não permitem a utilização de estruturas de indexação convencionais. Isso se deve ao fato de que imagens são dados de alta dimensionalidade e não possuem relação de ordem total. Definir um espaço métrico sobre o domínio dos dados faz com que esses dados adquiram propriedades algébricas, permitindo assim a indexação através de uma estrutura apropriada. Essas estruturas, baseadas no espaço métrico e suas propriedades são denominados Métodos de Acesso Métrico - MAM (Metric Access Method) (Chávez et al., 2001). A utilização de MAM requer que seja definido um espaço métrico, relacionando os objetos apenas por suas relações de similaridade.

Em um MAM os objetos são dispostos considerando-se uma relação de semelhança entre estes, permitindo assim que sejam realizadas consultas por similaridade. A fim de minimizar o número de comparações durante consultas, essas estruturas são, na maioria dos casos, implementadas utilizando árvores (Chino, 2004), permitindo o armazenamento de páginas em disco. A implementação utilizando árvores inicialmente escolhe alguns objetos e os utiliza para determinar a posição dos outros objetos, fazendo a indexação do conjunto de dados.

$\mathrm{Na}$ literatura é possível encontrar duas abordagens para MAM em árvores. As primeiras propostas são estáticas, necessitando previamente de todos os dados do conjunto para a indexação. As propostas estáticas não são de grande interesse para SGBDs, uma vez que não permitem a inserção e remoção de elementos posteriormente à indexação. Existem também as abordagens dinâmicas, que permitem a inserção e remoção de dados posterior à indexação.

As principais propostas para a abordagem dinâmica podem ser encontradas em (Ciaccia et al., 1997) com a M-Tree e em (Traina et al., 2000a) com a Slim-Tree. A M-Tree foi a primeira proposta a implementar uma estrutura dinâmica, onde pode-se inserir e remover elementos em qualquer momento na estrutura da árvore. A Slim-Tree é considerada uma evolução, por tratar de maneira mais aperfeiçoada a inserção de objetos e a manutenção da árvore, e por medir o grau de sobreposição entre subárvores e ainda minimizar essas sobreposições.

\subsection{Redução de Dimensionalidade}

O processo de extração de características de objetos complexos pode resultar em vetores de características de alta dimensão, especialmente nos casos em que cada vetor é uma combinação de dois ou mais vetores obtidos por diferentes extratores. Esta alta cardinalidade de características configura o que é conhecido pela comunidade científica como maldição da alta dimensionalidade (do inglês, dimensionality curse) (Berchtold et al., 1998). 
Implicações não desejáveis sobre o aspecto da maldição da dimensionalidade incluem a degradação de estruturas de indexação, redução da capacidade de representatividade das características e ineficiência no processo de indexação e recuperação de imagens. Além disso, é frequente a correlação entre características, o que introduz redundância de informações que prejudicam a capacidade de distinção entre objetos.

Se as características redundantes ou de menor discriminação podem ser ignoradas, então a redução desejada em dimensionalidade é alcançada. Os métodos de redução de dimensionalidade podem ser divididos em transformação de características e seleção de características. O processo de transformação de características transforma o espaço dos dados (espaço original) em um espaço de características que é de dimensão muito menor comparado com o espaço de dados original. As transformações consistem em gerar novas características a partir das originais, mantendo a maioria do conteúdo de informação intrínseca dos dados. Seleção de características, por outro lado, é guiada por algum critério de avaliação para encontrar o subconjunto de características mais relevantes do conjunto original, eliminando características de menor distinção.

Várias técnicas de redução dimensionalidade podem ser encontradas na literatura. Um exemplo é a técnica que utiliza a dimensão fractal (ou dimensão intrínseca) dos dados. A dimensão fractal é utilizada como uma forma de mensuração que caracteriza a essência e distribuição dos objetos naturais. Em (Traina et al., 2000b), a dimensão fractal de um conjunto de dados é utilizada como uma aproximação de sua dimensão intrínseca e para a redução de atributos necessários para representar e analisar objetos complexos sem perda de informação.

O algoritmo FastMap, proposto por Faloutsos e Lin em (Faloutsos and Lin, 1995), reduz a dimensionalidade de um conjunto $m$-dimensional buscando distribuir entre as dimensões originais a distorção ocasionada pela redução dimensional, baseando-se na Lei dos Cossenos da geometria. Outra técnica muito utilizada é a PCA (Principal Component Analysis), introduzida por Pearson (Pearson, 1901) e Hotelling (Hotelling, 1933), que transforma os dados de espaço de alta dimensão em um espaço de dimensão reduzida, preservando o máximo de informações relevantes possível. PCA realiza transformações lineares para gerar um novo espaço de tal forma que o novo conjunto de atributos são não correlacionados, obtidos por funções lineares dos atributos originais.

Em (Paulovich et al., 2008), os autores propõem o LSP (Least-Square Projection). O LSP utiliza aproximações de mínimos quadrados que computam as coordenadas de um conjunto de pontos projetados baseados nas coordenadas de um número reduzido de pontos de controle. Um número pequeno de cálculos de distância é necessário para efetuar a projeção e não há reposicionamento de pontos durante o processo. 
A ideia de aplicar a redução da dimensionalidade no conjunto de dados antes deste ser indexado é reduzir os efeitos da maldição da alta dimensionalidade na estrutura de indexação. A redução da dimensionalidade naturalmente gera perdas, consequentemente a precisão das respostas é afetada. Tal perda de informação depende especificamente do método utilizado e do conjunto de dados, e deve ser tratado caso a caso.

\subsection{Realimentação de Relevância}

Sistemas CBIR são projetados para responder a consultas recuperando imagens similares a uma determinada imagem. Para tanto, é necessário que algoritmos para extrair características sejam utilizados para obter os respectivos vetores de características. Apesar de lidar com informações derivadas das imagens, os resultados obtidos pelos sistemas CBIR são, na maioria das vezes, imprecisos, visto que é um grande desafio associar características de baixo nível a semântica de alto nível proveniente das imagens, causando muitos falsos positivos.

Este problema pode ocorrer, entre outros motivos, por considerar todas as características como igualmente representativas. De fato, é importante destacar que algumas características podem não contribuir para o cálculo da similaridade, pois são redundantes ou nunca contribuem efetivamente em capturar informações relacionadas à semântica do contexto, enquanto outras são mais importantes pois refletem mais diretamente as semelhanças.

A Realimentação de Relevância (RR) tem sido muito explorada para atuar no processo de recuperação de imagens tentando gradualmente diminuir o impacto da lacuna semântica. Inicialmente desenvolvida por (Salton, 1989), foi projetada para ser aplicada em recuperação de documentos (texto), mas facilmente e amplamente incorporada em recuperação de imagens.

Técnicas de RR possibilitam ao usuário indicar quais instâncias de um conjunto retornado por uma consulta são desejadas (relevantes) e quais são consideradas irrelevantes. Assim o usuário fornece ao sistema informações que auxiliam no cálculo das similaridades, refletindo o que se espera que seja retornado em consultas posteriores. Ou seja, a cada iteração o algoritmo de RR é capaz de "aprender" quais propriedades visuais representam melhor as imagens mais relevantes, de acordo com as informações obtidas da interação com o usuário (Figura 2.3).

Os passos gerais de um sistema CBIR que utiliza um algoritmo de RR são (Zhou and Huang, 2001):

1. Uma busca inicial é executada pelo sistema considerando um padrão de consulta fornecido pelo usuário, retornando um número pequeno de imagens. 


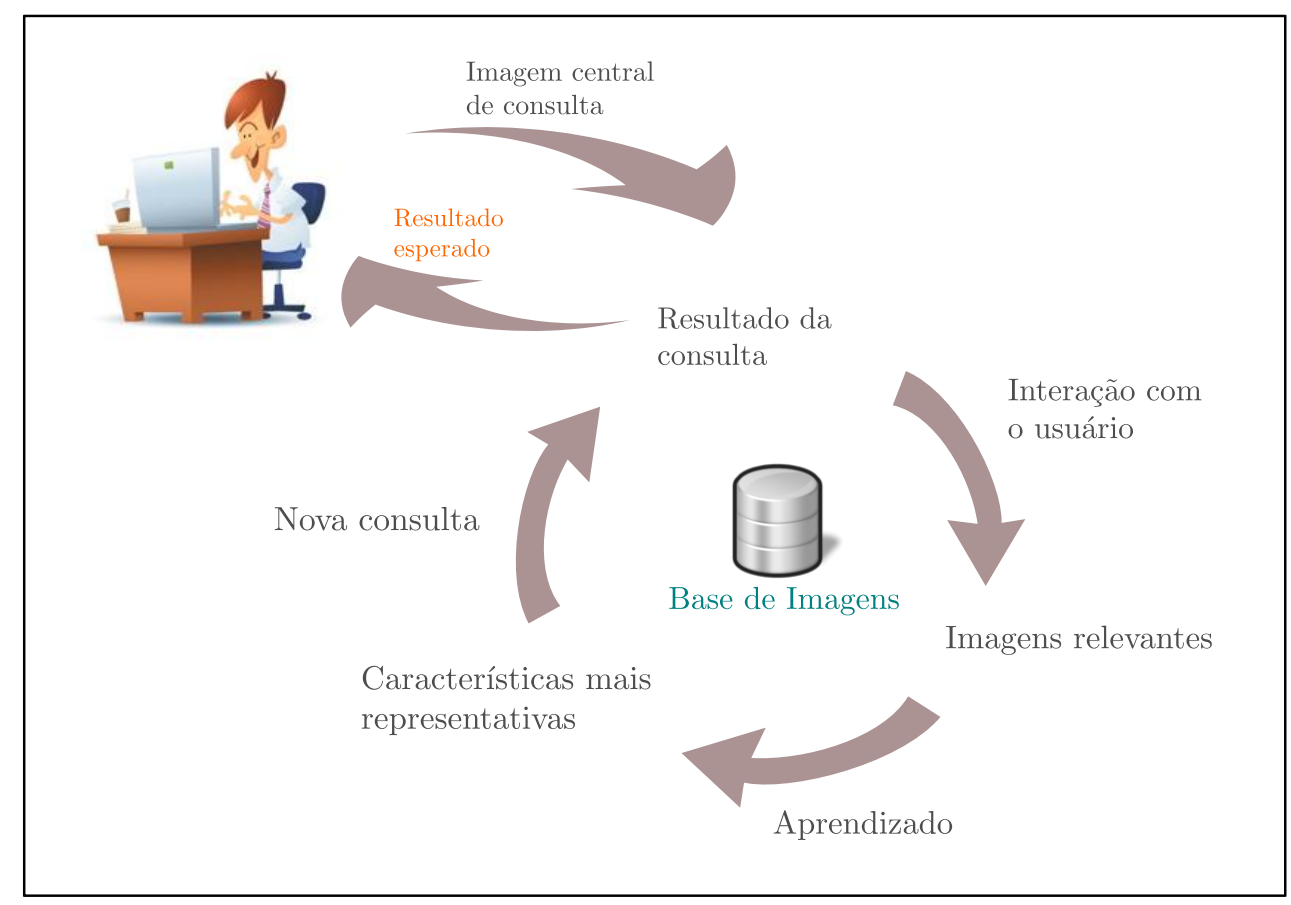

Figura 2.3: Recuperação de imagens utilizando Realimentação de Relevância.

2. O usuário interage com o sistema, julgando e indicando dentre o conjunto retornado quais imagens são mais relevantes (objetos positivos) e quais são menos relevantes (objetos negativos), considerando o grau de relevância.

3. Em seguida, o sistema "aprende" e realiza uma nova consulta e inicia um novo passo de aprendizagem considerando o julgamento do usuário no passo 2. Essa etapa é repetida até que um determinado número de iterações seja atingido ou até que o usuário alcance seu objetivo.

Em (Rocchio, 1971) o autor descreve uma das primeiras técnicas de realimentação de relevância, chamada Alteração do Centro de Consulta (Query Point Movement). Essa técnica consiste em mudar o elemento central da consulta, escolhendo um novo elemento tal que este seja mais próximo de objetos positivos (relevantes) e mais distante de objetos negativos (não relevantes). Mais detalhadamente, seja $\mathbf{q}_{0}$ o vetor de característica utilizado na consulta, e seja $\mathbf{q}_{1}$ o novo vetor de característica gerado para ser utilizado na próxima consulta. A Equação 2.9 descreve como o vetor $\mathbf{q}_{1}$ é calculado, sendo $n_{a}$ o número de objetos relevantes, $n_{b}$ o número de objetos não relevantes, $\mathbf{r}_{i}$ atributos dos objetos relevantes e $\mathbf{s}_{i}$ atributos dos objetos não relevantes. 


$$
\mathbf{q}_{1}=\mathbf{q}_{0}+\frac{1}{n_{a}} \sum_{i=1}^{n_{a}} \mathbf{r}_{i}-\frac{1}{n_{b}} \sum_{i=1}^{n_{b}} \mathbf{s}_{i}
$$

O problema dessa abordagem é não considerar a proporção entre as distâncias, pois objetos mais distantes ocasionam o deslocamento do centro de consulta prejudicando o processo de recuperação. Uma técnica que utiliza a ponderação é a chamada Refinamento da Medida de Similaridade. A atribuição de pesos é feita para as dimensões do espaço de dados. As dimensões que capturam melhor as similaridades na busca são as de maior importância, ao passo que para as dimensões de menor representatividade são atribuídos pesos para indicar menor significância. Em (Huang et al., 1997) a proposta é calcular o vetor de diferenças entre a imagem da consulta até uma certa imagem no conjunto de imagens relevantes. Os valores calculados no vetor diferença servem para determinar os pesos de cada dimensão, sendo que quanto maior a diferença calculada, menor é a importância da dimensão.

Outras aplicações importantes de RR incorporam diferentes tipos de conceitos, como Aprendizado de Máquina, que é a abordagem mais frequentemente adotada (MacArthur et al., 2002). Por meio do aprendizado de máquina, as técnicas mais comuns incorporam árvores de decisão, aprendizado Bayesiano, Suport Vector Machines (SVM) e Redes Neurais.

Segundo (MacArthur et al., 2002), um sistema de CBIR que utiliza RR deve atender a requisitos imprescindíveis para que suas funcionalidades possam ser executadas com um desempenho eficiente e não exigir muito esforço de seus usuários. Primeiramente, uma vez que um conjunto de imagens é retornado por uma consulta, o sistema precisa de uma quantidade razoável de informações. Se é necessário julgar e classificar uma numerosa quantidade de imagens para cada interação, o processo fica comprometido pela insatisfação do usuário. Em segundo lugar, o sistema deve produzir resultados aceitáveis exigindo o mínimo de interações, pois os usuários não estão dispostos a esperar muito pelas respostas. E, por último, entretanto não menos importante, a extração de característica e o processo de aprendizagem devem ser executados com um tempo reduzido para que na prática não seja considerado inviável.

\subsection{Considerações Finais}

Cada vez mais dados estão sendo gerados a uma taxa excessivamente grande, com tendência a aumentar a cada ano. O armazenamento por si só, principalmente de dados complexos como dados multimídia, não é capaz de estruturar esses dados devidamente para que possam ser utilizados em algum processo de exploração dos mesmos. Para que se possa responder a consultas embasadas no conteúdo intrínseco de tais dados, através das quais apenas a similaridade entre 
os objetos pode ser considerada, é de fundamental importância o desenvolvimento de métodos que permitam uma recuperação rápida e eficiente. Apesar do desenvolvimento de muitas técnicas encontradas na literatura para armazenamento e recuperação de imagens de forma eficiente, encontrar uma solução ótima é ainda um desafio.

Este capítulo abordou conceitos gerais a respeito de como tratar dados complexos, principalmente imagens. Foram delineados aspectos importantes sobre extração de características e redução de dimensionalidade, como etapas preliminares para o processamento desse tipo de dados. Foram introduzidos os conceitos de espaços métricos bem como de estruturas de indexação e recuperação de dados definidos em um espaço métrico. Foi introduzido também uma importante ferramenta para o auxílio na recuperação de dados, a Realimentação de Relevância. Esses conceitos constituem a base sobre a qual foi desenvolvido este trabalho. Mais especificamente, foi desenvolvida uma técnica de Realimentação de Relevância, baseada em Algoritmos Genéticos (ver Capítulo 3) para recuperação de imagens por conteúdo, que explora as duas principais estratégias de RR: a alteração do centro de consulta e o refinamento de medidas de similaridade. 



\section{Otimização por Algoritmos Genéticos}

\subsection{Considerações Iniciais}

Problemas de otimização são recorrentes em diversas áreas, como por exemplo, o "problema do caixeiro viajante" (Lawler, 1985) e o "problema da mochila" (Horowitz and Sahni, 1974) que configuram aplicações de cunho econômico. Em linhas gerais, problemas de otimização são modelados e aplicados para minimizar ou maximizar uma função objetivo, possivelmente atendendo a um conjunto de restrições.

O conjunto de possíveis soluções pode ser excessivamente grande para alguns problemas. Devido a esta propriedade, o elevado esforço computacional pode inviabilizar a busca da melhor solução (solução ótima global). Nos casos em que soluções aproximadas (soluções ótimas locais) são satisfatórias para o problema em questão, é preferível que sejam utilizados algoritmos de aproximação que, embora não garantam fornecer a solução ótima, são consideravelmente mais eficientes.

A otimização atende a propósitos específicos de minimização ou maximização numérica. A modelagem é o primeiro passo de qualquer sistema de otimização, sendo considerado em muitos casos o aspecto mais importante. O modelo depende do problema e requer a definição de uma (ou mais) função objetivo, de variáveis e suas restrições. A Definição 3.1 (Nocedal and Wright, 2000) representa a formulação matemática de um problema de otimização. 
Definição 3.1. Seja $f: \mathbb{R}^{m} \rightarrow \mathbb{R}$ uma função objetivo, $S \subseteq \mathbb{R}^{m}$ o conjunto que representa as soluções possíveis para o problema, denominado espaço de busca ou espaço de solução, o vetor de variáveis $x, x \in S$, e $C=\left\{g_{1}, \ldots, g_{p}, h_{1}, \ldots, h_{q}\right\}$ um conjunto de restrições as quais $x$ deve satisfazer. Um problema geral de otimização em que o objetivo é minimização é denotado como segue:

$$
\begin{array}{cl}
\min _{x} f(x) \text { sujeito a } & g_{i}(x)=0, i \in\{1, \ldots, p\} \\
& h_{j}(x) \geq 0, j \in\{1, \ldots, q\} .
\end{array}
$$

onde $g_{i}$ e $h_{j}$ são chamadas restrições de igualdade e desigualdade, respectivamente. Minimizar a função objetivo, em termos de busca, corresponde a encontrar $\mathrm{x}^{*} \in S$ tal que:

$$
f\left(\mathbf{x}^{*}\right) \leq f(x), \forall x \in S
$$

Problemas em que o objetivo é maximização são definidos de maneira análoga, substituindo $\min _{x} f(x)$ por $\max _{x} f(x)$ em 3.1 e $f\left(\mathbf{x}^{*}\right) \leq f(x)$ por $f\left(\mathbf{x}^{*}\right) \geq f(x)$ em 3.2.

Problemas de otimização não lineares podem admitir ótimos globais e ótimos locais. A solução ótima global é a solução que minimiza/maximiza a função objetivo com relação a todas as soluções possíveis do espaço de busca. Muitos algoritmos de otimização não linear são designados a encontrar soluções ótimas locais, devido ao alto custo de encontrar a solução ótima global. Uma solução ótima local é aquela que minimiza/maximiza a função objetivo entre todos os outros pontos possíveis dentro de uma determinada vizinhança (Sun and Yuan, 2006). A Figura 3.1 ilustra o ótimo global e os ótimos locais em uma representação de um problema de minimização não linear.

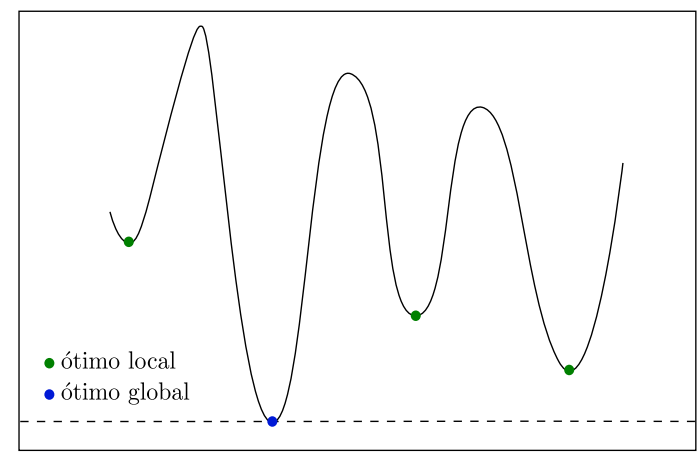

Figura 3.1: Ótimo global e ótimos locais de um problema de minimização não linear. 


\subsection{Meta-heurística Evolutiva}

Algoritmos de otimização podem ser determinísticos ( $A^{*}$, Branch and Bound, Programação Dinâmica) ou baseados em heurísticas que realizam buscas por soluções aproximadas. Uma classe especial de abordagem heurística, a meta-heurística, incorpora mecanismos para explorar eficientemente os espaços de busca para encontrar soluções ótimas ou próximas delas, evitando que o algoritmo fique "preso" a um ponto de ótimo local.

Um exemplo de meta-heurística baseada em população é a meta-heurística evolutiva. As meta-heurísticas lidam com uma população de possíveis soluções evoluindo ao longo da busca, ao invés de tratar uma única solução. Algoritmos evolutivos são uma classe de algoritmos de otimização meta-heurísticos evolutivos baseados na evolução biológica, que deram origem aos algoritmos genéticos (AGs) e aos algoritmos de programação genética (PG).

Algoritmos baseados em meta-heurística evolutiva são inspirados nos processos de seleção natural e sobrevivência do mais adaptado, estabelecendo-se como métodos bioinspirados. À medida que evoluem, esses algoritmos utilizam seleções competitivas para eliminar soluções de pouca qualidade. As soluções de boa qualidade são recombinadas com outras soluções.

\subsection{Algoritmos Genéticos}

Os algoritmos genéticos são uma das técnicas mais difundidas da computação evolutiva. Os AGs foram introduzidos por John Holland (Holland, 1975), que ainda na década de 60 juntamente com outros pesquisadores começaram a estudar os chamados sistemas adaptativos, modelados como sistemas de aprendizado de máquina.

A ciência genética estabelece que para ocorrer um processo evolutivo natural deve haver uma população de indivíduos (cromossomos) com capacidade de se reproduzir. Além disso, é necessário que exista diversidade e que a probabilidade de sobrevivência de um indivíduo esteja relacionada com a diversidade. Assim, dada a metáfora da evolução natural, os AGs foram criados como um modelo matemático para permitir que as máquinas também pudessem evoluir.

Uma otimização por AG parte de um conjunto de soluções candidatas possíveis, que constituem a população inicial. Esses indivíduos podem ser gerados ao acaso ou por meio de alguma heurística. Sobre cada indivíduo da população inicial são aplicados operadores genéticos artificiais de seleção e reprodução para determinar a sobrevivência dos mais aptos e promover a evolução genética. Antes de tudo, deve-se considerar a estrutura cromossômica do problema. Isto pode ser feito identificando o espaço de valores sobre os quais são definidos os parâmetros da busca. 
Ao longo do processo evolutivo é mantida uma população de indivíduos candidatos, um procedimento iterativo chamado geração. A cada geração são processados $S_{p}$ indivíduos (tamanho da população), avaliados por meio de uma medida de desempenho que indica a qualidade desses indivíduos como potenciais soluções. Dessa forma, pode-se dizer que os AGs empregam um paralelismo implícito por considerar uma população de candidatos em paralelo, o que aumenta as chances de se atingir áreas mais promissoras do espaço de busca. Os AGs diferem de outros métodos de busca e otimização por quatro características básicas:

- AGs podem trabalhar sobre um espaço de solução que representa o espaço de busca de maneira codificada (espaço de genótipo) bem como diretamente no espaço de busca (espaço de fenótipos);

- AGs empregam um paralelismo implícito por operar em um conjunto de soluções candidatas a cada geração, aumentando as chances de encontrar melhores soluções no espaço de busca;

- AGs utilizam somente uma estimativa de qualidade ou aptidão de indivíduo, não sendo necessárias quaisquer outras informações auxiliares;

- AGs são baseados em regras de transição probabilísticas e não determinísticas.

\subsubsection{Características Gerais dos AGs}

A representação de um dado problema que utiliza AGs é o primeiro aspecto a ser considerado. Deve-se estabelecer a representação das possíveis soluções do problema para determinar os cromossomos. Normalmente os cromossomos são vetores de dimensão finita, definidos sobre valores que podem ser binários, inteiros, reais ou caracteres. Cada valor que compõe um cromossomo é denominado gene.

Uma vez definidas as representações das soluções do espaço de busca, os AGs devem iniciar a busca gerando uma população inicial com $S_{p}$ indivíduos. Na maioria das vezes a forma com que é gerada a população inicial é aleatória. A vantagem da geração aleatória é poder gerar pontos diversos de tal maneira que eles estejam espalhados pelo espaço de busca. Isso acrescenta diversidade ao processo evolutivo, um fator fundamental para se alcançar a evolução.

Cada indivíduo é avaliado pela função de aptidão. Esta função é utilizada para atribuir notas aos indivíduos da população a cada geração. A nota atribuída por uma função de aptidão indica o quão bem adaptado ao ambiente um indivíduo está. A definição de medida de aptidão está fortemente relacionada ao problema, sendo crucial para o desempenho dos AGs. Medidas de aptidão pouco precisas podem prejudicar a manutenção e reprodução de soluções promissoras, 
ou no pior caso, podem terminar com soluções pouco satisfatórias. Inicialmente, os valores de aptidão obtidos geralmente são mais distribuídos, uma vez que a população inicial contém soluções de diversos pontos do espaço. A medida que a busca evolui, os valores de aptidão de uma população tem pouca variância, pois a busca tende a convergir para o solução ótima no espaço.

O fluxograma apresentado na Figura 3.2 mostra a sequência de operações realizadas pelos AGs. Após criada a população inicial, são realizados cálculos de aptidão para cada indivíduo da população. Se o critério de parada foi atingido, então a melhor solução é retornada. Caso contrário, é feita a seleção de alguns indivíduos para a reprodução, que consiste em operações de cruzamento e mutação.

Os indivíduos descendentes são submetidos à avaliação de aptidão, em seguida são selecionados $S_{p}$ indivíduos, considerando os indivíduos da população e os descendentes, para fazer parte da nova população (seleção para reinserção). Após a realização dessas operações, uma nova população é criada. É esperado que a nova população represente uma melhor aproximação da solução que a população anterior.

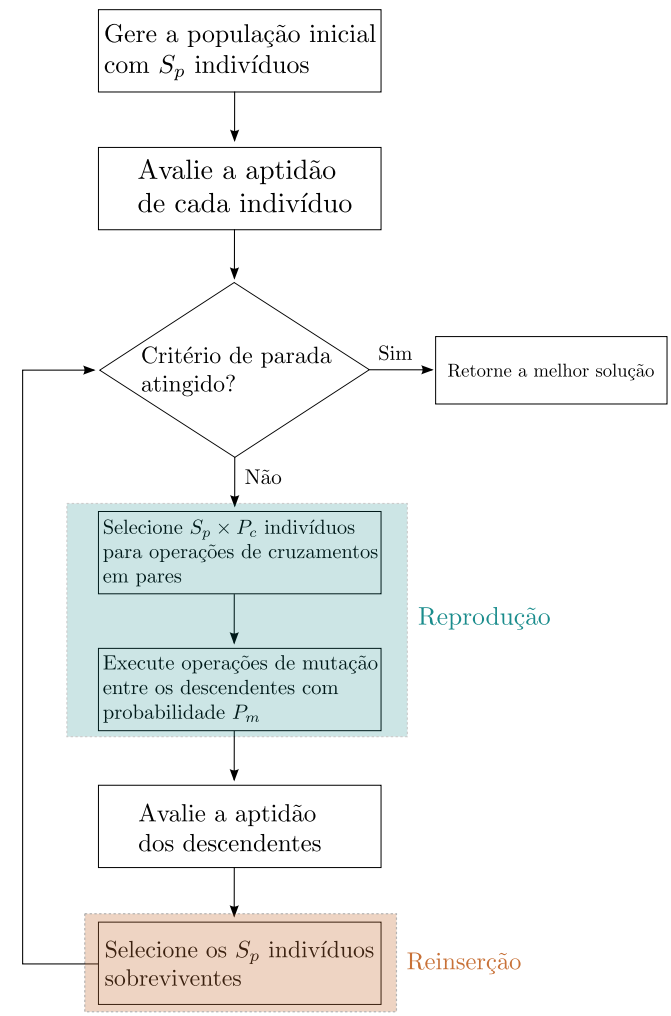

Figura 3.2: Fluxograma de execução do Algoritmo Genético, adaptada de (da Silva, 2011). 


\subsubsection{Operadores Genéticos}

A função dos operadores genéticos é criar novas populações ao longo das gerações, de modo a aproximar a busca da solução ótima. Os operadores genéticos são responsáveis por inserir diversidade ao mesmo tempo que devem manter o fator adaptativo da população adquirido nas das gerações anteriores.

\subsubsection{Seleção}

Operadores de seleção são responsáveis por escolher os indivíduos para reprodução. Preferencialmente devem ser escolhidos os indivíduos da população que estão mais bem adaptados ao ambiente. A maioria dos operadores de seleção são desenvolvidos de tal forma que selecionam uma pequena proporção de soluções de menor aptidão, para permitir a diversidade da população evitando uma convergência prematura da busca. Existem vários métodos de seleção, dentre as quais destacam-se:

- Seleção por ranking: os indivíduos são ordenados com relação ao seu valor de aptidão formando um ranking. A probabilidade de um indivíduo ser selecionado é dada conforme a posição deste indivíduo no ranking. As distribuições mais aplicadas para tal, são lineares e exponenciais.

- Seleção por roleta: este método atribui ao indivíduo uma probabilidade proporcional à sua aptidão. Essa probabilidade pode ser vista como uma fatia de uma roleta, sendo que para selecionar um indivíduo é sorteado um valor que irá corresponder ao giro da roleta.

- Seleção por torneio simples: são aleatoriamente formados grupos de $n$ indivíduos e selecionados os indivíduos com maior aptidão dentro de cada grupo.

- Seleção por torneio estocástico: similar a seleção por torneio simples, com a diferença de que para formar os grupos é utilizado o método da roleta.

- Seleção uniforme: seleciona-se um subconjunto de indivíduos com a mesma probabilidade.

- Seleção elitista: seleciona os indivíduos com melhor aptidão.

\subsubsection{Cruzamento}

Os operadores de cruzamento são responsáveis por recombinar os genes de dois indivíduos para gerar novos indivíduos. O cruzamento é inspirado na recombinação biológica, em que os filhos 
herdam características dos pais. Os pares de indivíduos escolhidos pela seleção são combinados para gerar pares descendentes. Os operadores tradicionais de cruzamento são:

- Cruzamento de um ponto: escolhe-se aleatoriamente um ponto $l$ do cromossomo. Então ao primeiro descendente é atribuído os primeiros genes até o ponto $l$ do pai $\mathrm{A}$ mais os genes do ponto $l$ ao último gene do pai B. De maneira análoga, o segundo descendente herda os primeiro $l$ genes do pai $\mathrm{B}$ e os últimos genes a partir do ponto $l$ do pai A. A Figura 3.3 ilustra um exemplo de cruzamento de um ponto.

\begin{tabular}{|c|c|c|c|c|c|c|c|c|c|c|}
\hline & \multicolumn{1}{c|}{ Ponto de cruzamento } \\
Pai A: & 0 & 1 & 0 & 0 & 1 & 1 & 1 & 0 & 0 & 1 \\
Pai B: & 1 & 0 & 0 & 1 & 0 & 1 & 0 & 1 & 0 & 0 \\
\hline
\end{tabular}

Figura 3.3: Exemplo de cruzamento de um ponto.

- Cruzamento multiponto: é uma generalização do cruzamento de um ponto, onde são escolhidos $n$ pontos de corte. Os genes entre os pontos de corte são trocados alternadamente entre os pais. A Figura 3.4 ilustra um exemplo de cruzamento considerando dois pontos de corte.

\begin{tabular}{|c|c|c|c|c|c|c|c|c|c|}
\hline \multicolumn{10}{|c|}{ Pontos de cruzamento } \\
\hline Pai A: 0 & 1 & 0 & 0 & 1 & 1 & & 0 & 0 & 1 \\
\hline Pai B: 1 & 0 & 0 & 1 & 0 & 1 & & & 0 & 0 \\
\hline Filho A: 0 & 1 & U & 1 & U & 1 & & & & 1 \\
\hline Filho B: 1 & 0 & 0 & 0 & 1 & 1 & & & & 0 \\
\hline
\end{tabular}

Figura 3.4: Exemplo de cruzamento de dois pontos.

- Cruzamento uniforme: é criada aleatoriamente uma máscara que indica para cada gene, de qual pai este gene será herdado. A Figura 3.5 ilustra um exemplo de cruzamento uniforme. 


Máscara: \begin{tabular}{ll|l|l|l|l|l|l|l|l|l|} 
& $\mathrm{A}$ & $\mathrm{B}$ & $\mathrm{B}$ & $\mathrm{A}$ & $\mathrm{B}$ & $\mathrm{A}$ & $\mathrm{A}$ & $\mathrm{B}$ & $\mathrm{A}$ & $\mathrm{A}$ \\
Pai A: & 0 & 1 & 0 & 0 & 1 & 1 & 1 & 0 & 0 & 1 \\
Pai B: & 1 & 0 & 0 & 1 & 0 & 1 & 0 & 1 & 0 & 0 \\
Filho A: & 0 & 0 & 0 & 0 & 0 & 1 & 1 & 1 & 0 & 1 \\
Filho B: & 1 & 1 & 0 & 1 & 1 & 1 & 0 & 0 & 0 & 0 \\
\hline
\end{tabular}

Figura 3.5: Exemplo de cruzamento uniforme.

\subsubsection{Mutação}

Operadores de mutação operam sobre indivíduos gerados por cruzamento, efetuando uma alteração em sua representação, com uma probabilidade pré-determinada. Esse operador é importante pois introduz diversidade genética que possibilita que diversos pontos do espaço de busca, antes não explorados, possam ser alcançados. Exemplos de operadores de mutação são dados a seguir:

- Mutação flip: os genes escolhidos para mutação recebem um novo valor válido, escolhido aleatoriamente.

- Mutação swap: os genes escolhidos para a mutação trocam seus valores entre si.

- Mutação creep: um valor aleatório é escolhido para ser somado ou subtraído ao valor do gene.

\subsubsection{Parâmetros Genéticos}

Além dos operadores genéticos, os AGs necessitam que sejam definidos os parâmetros genéticos que irão influenciar no desempenho e no mecanismo de busca. É importante estabelecê-los conforme as características do problema. Os parâmetros genéticos e suas implicações são descritos como segue:

- Tamanho da população $\left(S_{p}\right)$ : o tamanho da população afeta diretamente o desempenho e a eficiência dos AGs. O desempenho pode ser prejudicado se for escolhido um número pequeno de indivíduos, pois isso significa uma cobertura muito pequena do espaço 
de busca, gerando maiores possibilidades de convergência prematura em soluções ótimas locais. Por outro lado, se o tamanho for muito grande, a eficiência do algoritmo é prejudicada pelo alto custo computacional.

- Taxa de cruzamento $\left(P_{c}\right)$ : alta probabilidade de cruzamento implica que novas estruturas serão introduzidas na população rapidamente. Isso afeta a busca pois soluções promissoras podem ser destruídas mais rapidamente que a capacidade da seleção em mantê-las. Para evitar esse problema normalmente emprega-se elitismo, uma maneira de garantir que os melhores cromossomos não sejam eliminados da população após os cruzamentos.

- Taxa de mutação $\left(P_{m}\right)$ : essencialmente taxas de mutação são baixas, e ajudam a evitar que a busca fique estagnada em uma região do espaço de busca. Probabilidades altas de mutação tornam a busca essencialmente aleatórias.

\subsection{Considerações Finais}

Neste capítulo foram abordados os conceitos relacionados a algoritmos genéticos. AGs constituem técnicas de busca meta-heurística evolutiva, ou seja, é uma busca baseada em população que utiliza heurísticas para evitar a convergência em pontos de ótimos locais.

Os AGs são inspirados em conceitos provenientes da biologia, como o princípio da seleção natural, sendo muito utilizados em problemas de otimização. Sua natureza de fácil generalização, robustez e adaptabilidade fazem com que eles sejam aplicados em diversas áreas, inclusive otimização de consultas por similaridade, que é o escopo em que se insere este trabalho. 

CAPÍTULO

\section{4}

Análise Visual de Dados

\subsection{Considerações Iniciais}

Extrair informações relevantes contidas em um conjunto de dados é o problema alvo quando nos referimos à exploração de um banco de dados. Encontrar e explorar as informações presentes em um banco de dados é uma tarefa que pode ser exaustiva, dependendo de muitas consultas SQL que podem também ser de grande complexidade. O resultado dessas consultas é normalmente expresso por listas textuais de dados, resultados que podem não ser intuitivos e exigir grande dispêndio em tempo de leitura. Surge daí a necessidade de se empregar representações gráficas da estrutura e do conteúdo de bancos de dados tornando o aproveitamento destes mais simples e acessível. Representações visuais são eficazes para expressar diferentes tipos de conhecimento (Catarci, 1997), tornando-se assim um meio bastante promissor para se explorar bancos de dados (Siau and Tan, 2006).

O termo "explorar", no contexto de mineração de dados está geralmente associado à busca de padrões, descoberta de modelos ou estruturas novas que possam ser aplicadas a algum propósito. Os passos para se explorar um banco de dados compreendem seleção, processamento e transformação dos dados para que eles sejam usados como entradas na etapa de mineração de dados. Além disso, é necessário que o usuário esteja integrado a todo o processo, monitorando cada etapa para que os resultados desejados possam ser efetivamente alcançados. 
A exploração de dados tem como uma de suas linhas a utilização de recursos gráficos interativos para guiar o processo de mineração - denominada mineração visual de dados - ou para definir o próprio procedimento de mineração - realizando o que se denomina análise visual de dados. As metodologias baseadas no suporte gráfico para a exploração de dados visam estabelecer o conceito de diálogo analítico. O diálogo analítico (Thomas and Cook, 2005) refere-se ao estudo sistemático de como um conjunto de dados pode levar a avaliações, previsões e opções, com relação a um dado problema. Por meio de recursos computacionais, ele deve potencializar a capacidade humana de apreciação de dados ao desvendar artefatos de racionalização (Shrinivasan and van Wijk, 2008).

\subsection{Interação Visual sobre Bancos de Dados}

A combinação de algoritmos de transformação com técnicas de visualização, como objetivado pela Ciência Analítica Visual, resulta em metodologias que podem facilitar as etapas da análise de bancos de dados. Em um ambiente visual interativo, estas metodologias levam ao conceito de diálogo analítico (Thomas and Cook, 2005). O diálogo analítico é um processo em que partes de informação são combinados para que conclusões embasadas sejam alcançadas. Estas partes de informação, denominados artefatos de racionalização, são classificados em quatro classes: elementares (dados individuais, evidências, suposições), padrões (padrões e estruturas, temporais e espaciais), de ordem superior (argumentos, causa e efeito, modelos) e complexos (hipóteses e cenários).

A Ciência Analítica Visual assume que a pesquisa e o desenvolvimento em análise visual de dados não se resumem ao projeto gráfico. É objetivo da Ciência Analítica Visual a pesquisa considerando artefatos de racionalização mais elaborados. Uma das linhas sugeridas é a organização simultânea de múltiplos artefatos por meio de uma memória visual. Ou seja, um conjunto de entidades gráficas, cada qual representando uma informação que colabore para a formação de artefatos de ordem superior. No sistema VisTree (Rodrigues Jr. et al., 2005) desenvolvido no GBdI (Grupo de Bases de Dados e Imagens, ICMC-USP), esta organização é inicialmente experimentada segundo um arranjo de janelas com múltiplas técnicas. Cada janela de visualização pode ser filtrada originando outras janelas. Este ciclo pode evoluir sequencialmente ou paralelamente. O sistema gerencia automaticamente a evolução das janelas e o relacionamento entre elas como uma árvore de visualizações.

Formalmente, a Ciência Analítica Visual é constituída pela seguintes áreas de interesse: Representações e Transformações de Dados, Raciocínio Analítico, Representações Visuais e Interação; além de Produção, Apresentação e Disseminação da informação percebida. Os objetivos 
desta ciência são a representação versátil dos dados, a compreensão e a síntese das informações, e a percepção de padrões com a intenção de se alcançar o suporte à decisão.

Os vetores de características usados para a definição de um espaço métrico são, propriamente, dados multivariados. Na literatura, há intensa pesquisa a respeito da análise visual deste tipo de dado. As técnicas que fazem parte do sistema VisTree, como as coordenadas paralelas (Inselberg and Dimsdale, 1990) e as coordenadas estelares (Kandogan, 2000), servem a este propósito. Tais técnicas são exemplos das metodologias que podem ser usadas para a avaliação e potencial refinamento de técnicas de extração de características.

De acordo com (Keim, 2002), para que se possa realmente obter sucesso na mineração de dados, é indispensável incluir a interação com o usuário na exploração dos dados, combinando as características como flexibilidade, criatividade e conhecimentos humanos com o potencial elevado de armazenamento e processamento dos computadores. Ou seja, a exploração visual de dados objetiva a integração do ser humano no processo de exploração de dados, a fim de aplicar suas habilidades de percepção para auxiliar no processo de extrair conhecimento de grandes conjuntos de dados provenientes de sistemas computacionais atuais.

A ideia básica da exploração visual de dados é apresentá-los em alguma forma visual, permitindo ao usuário obter insights, tirar conclusões, e interagir diretamente com os dados. Técnicas de mineração visual têm provado ser de grande valor na análise exploratória, possuindo também um elevado potencial para explorar grandes bases de dados. A exploração visual de dados é especialmente útil quando pouco se sabe sobre os dados e os objetivos são vagos ou mesmo indeterminados. Visto que o usuário está envolvido no processo exploratório, os objetivos serão incorporados e ajustados automaticamente se necessário.

Um processo de geração de hipóteses pode ser observado na exploração visual de dados. A visualização gerada permite que o usuário obtenha insights e possa sugerir novas hipóteses. A verificação das hipóteses também pode ser dada através da exploração visual de dados, além de técnicas automáticas de estatística ou aprendizado de máquina (Keim, 2002). Em linhas gerais, as maiores vantagens da exploração visual de dados sobre técnicas automáticas de mineração de dados da estatística e aprendizado de máquina são:

- pode lidar com dados não homogêneos e dados com ruídos;

- é intuitiva, não requer do usuário conhecimentos sobre algoritmos complexos de matemática ou estatísticas. 


\subsection{Projeção Multidimensional}

A definição de um espaço métrico também prevê que um espaço adimensional de dados possa ser inspecionado por meio de representações visuais diretas de seus objetos. Tais representações são conseguidas por meio de técnicas de projeção multidimensional, nas quais é possível observar a distribuição dos dados de acordo com uma correspondência espacial intuitiva. Os objetos podem ser vistos contextualmente expondo representatividades específicas ou relativas ao conjunto de dados total.

Formalmente, a ideia de projeção multidimensional de um espaço métrico é definida da seguinte forma. Sejam $\mathbf{X}=\left\{\mathbf{x}_{1}, \mathbf{x}_{2}, \ldots, \mathbf{x}_{n}\right\}$ um conjunto de $n$ vetores $\mathbf{x}_{i}$ de características $m$-dimensionais, $m$ um valor inteiro geralmente maior do que 3 , e $\mathcal{D}\left(\mathbf{x}_{i}, \mathbf{x}_{j}\right)$ uma função que mede a similaridade entre dois vetores $\mathbf{x}_{i}, \mathbf{x}_{j} \in \mathbf{X}$. Sejam também $\mathbf{Y}=\left\{\mathbf{y}_{1}, \mathbf{y}_{2}, \ldots, \mathbf{y}_{n}\right\}$ um conjunto de $n$ pontos $p$-dimensional, $p$ geralmente igual a 2 ou a 3 , e $d\left(\mathbf{y}_{i}, \mathbf{y}_{j}\right)$ uma função que mede a distância Euclidiana entre dois pontos $\left\{\mathbf{y}_{i}, \mathbf{y}_{j}\right\} \in \mathbf{Y}$. Uma projeção multidimensional é descrita como uma função injetora $f: \mathbf{X} \rightarrow \mathbf{Y}$ que objetiva minimizar a diferença entre $\mathcal{D}$ e $d$, isto é:

$$
\min _{f}\left(\sum_{i, j}\left|\mathcal{D}\left(\mathbf{x}_{i}, \mathbf{x}_{j}\right)-d\left(f\left(\mathbf{x}_{i}\right), f\left(\mathbf{x}_{j}\right)\right)\right|\right)
$$

O algoritmo FastMap (Faloutsos and Lin, 1995) é um exemplo de técnica adequada a visualização e mineração de dados pois permite que dados de conjuntos de alta dimensão sejam projetados em espaços de duas ou três dimensões. Por procurar manter ao máximo as relações de distância entre os objetos do espaço original, as projeções baseadas baseadas no FastMap podem relevar a existência de clusters, correlações entre atributos, ou qualquer padrão que possa ser de interesse à mineração de dados.

A técnica de projeção multidimensional LSP (Paulovich et al., 2008) é capaz de projetar grandes conjuntos de dados de alta dimensão em tempo computacional satisfatório, reconstruindo bem as medidas de similaridade dada pelo conjunto. LSP foi projetado para preservar as relações de vizinhança entre os dados, o que o torna adequado para conjuntos esparsos. LSP e FastMap também são utilizadas para realizar redução de dimensionalidade em conjuntos de dados multidimensionais (ver Seção 2.6). 


\subsection{Visualização de Informação}

\subsubsection{Visão Geral e Objetivos}

A Visualização de Informação é utilizada para fornecer maior compreensão e possibilitar a análise de dados através de representações gráficas construídas sobre o conjunto de dados a ser investigado, sendo considerada uma modalidade de mineração de dados. Existem várias definições para a área, dentre as quais se destaca (Card et al., 1999):

"O uso de suporte computacional, interatividade e representações visuais de dados abstratos para ampliar a cognição.”

Segundo (Keim, 1997), os objetivos que competem a Visualização de Informação são divididos em três categorias:

- Análise Exploratória: não existem hipóteses formuladas sobre o conjunto de dados, sendo assim uma atividade que busca identificar padrões, informações e tendências.

- Análise Confirmativa: busca confirmar ou rejeitar as hipóteses formuladas previamente.

- Apresentação: fatos conhecidos sobre os dados guiam a ferramenta de visualização que deve prover um mecanismo eficiente de exibição.

Tipicamente, estruturas utilizadas em Visualização de Informação são obtidas através da organização dos dados brutos em uma tabela de dados, a partir da qual se constrói uma estrutura visual a fim de representar as informações ali presentes. Os artifícios visuais mais utilizados compreendem gráficos, setores, diagramas, esquemas e mapas. Para tanto, deve ser realizada uma transformação dos atributos para formas gráficas representativas, com o intuito de se obter uma estrutura visual que seja explorada pelo sistema perceptivo do usuário, que pode manipular a estrutura visual de várias maneiras, de acordo com os tipos de interação que se possa dispor sobre essas estruturas visuais. Ao observar graficamente os dados, pela representação visual gerada por uma técnica de visualização, o sistema perceptivo do usuário faz o uso da cognição para interpretar a representação gráfica e gerar inferências sobre ele, podendo assim obter novos conhecimentos (Card et al., 1983).

A maioria das técnicas existentes de Visualização de Informações são desenvolvidas visando, principalmente, aplicações que possuam um conjunto de dados de alta dimensionalidade. De acordo com (de Oliveira and Levkowitz, 2003), a caracterização de um conjunto de 
dados de alta dimensionalidade não é uma concepção de fato precisa. O limite entre baixa e alta dimensão está em torno de três ou quatro atributos. Ainda segundo os autores, é importante observar a diferença de capacidade perceptual do ser humano entre conjunto de dados de baixa dimensão (não mais que quatro dimensões) e de alta dimensão. Em se tratando da habilidade de compreensão humana, não há significativa diferença entre um conjunto de dados com cinco dimensões e um conjunto com cinquenta dimensões.

Uma área bastante similar a Visualização de Informações, denominada Visualização Científica, apresenta objetivos muito semelhantes. Ambas as áreas objetivam prover ferramentas para o processo de descoberta, de percepção e do auxílio a tomada de decisão, ampliando a habilidade cognitiva, melhorando o entendimento e aproveitamento do que é extraído, resultando na aquisição e solidificação do conhecimento.

Contudo, é importante apontar as suas diferenças. Essas residem no compêndio que compreende o domínio dos dados que processam. Na Visualização Científica, os dados geralmente correspondem a medidas de entidades físicas e que possuem intrinsecamente uma representação geométrica inerente. Exemplos de aplicação da Visualização Científica podem ser: visualização do fluxo de ar sobre as asas de um avião; comportamento de funções matemáticas; visualização de órgãos do corpo humano; escoamento de fluídos, etc.

Em Visualização de Informações, os dados não necessariamente possuem uma representação gráfica inerente. São dados com características multidimensionais, complexos e inerentemente abstratos. A geração de uma representação visual é feita com base nos relacionamentos ou informações que podem ser inferidos acerca dos dados. Assim, a Visualização de Informações, diferentemente da Visualização Científica engloba dados que não possuem uma representação para um espaço $\mathbb{R}^{n}(n \leq 3)$.

\subsubsection{Técnicas de Visualização de Informação}

A área Visualização da Informação busca desenvolver técnicas e ferramentas que possam representar de forma gráfica os dados de um determinado domínio de modo que a representação visual gerada explore a capacidade de percepção humana, onde o usuário a partir das relações espaciais exibidas, interprete e compreenda as informações apresentadas e deduza novos conhecimentos.

A seguir é feito um levantamento das principais técnicas de Visualização de Informação encontradas na literatura. 


\section{Coordenadas Paralelas}

A técnica de Coordenadas Paralelas, proposta por (Inselberg and Dimsdale, 1990), é considerada uma das técnicas mais conhecida e referenciada. $\mathrm{O}$ funcionamento é baseado no mapeamento de um espaço $k$-dimensional para as dimensões da tela de visualização utilizando $k$ eixos equidistantes a um dos eixos do dispositivo de exibição. Os eixos mapeiam os atributos e sua escala é linear de acordo com o menor e o maior valor dos atributos. A Figura 4.1 - extraída de (Rodrigues Jr., 2003) e gerada com o auxílio da ferramenta GBDIView - ilustra a aplicação da técnica sobre um conjunto de dados bastante comum na literatura, a base de dados Carros, que possui 406 registros e 8 atributos. Cada item da base de dados é representado pelas linhas que interceptam os eixos nos valores correspondentes. Essa técnica apresenta uma desvantagem sobre conjuntos de dados muito grandes, que na sua representação gráfica compromete a visualização.

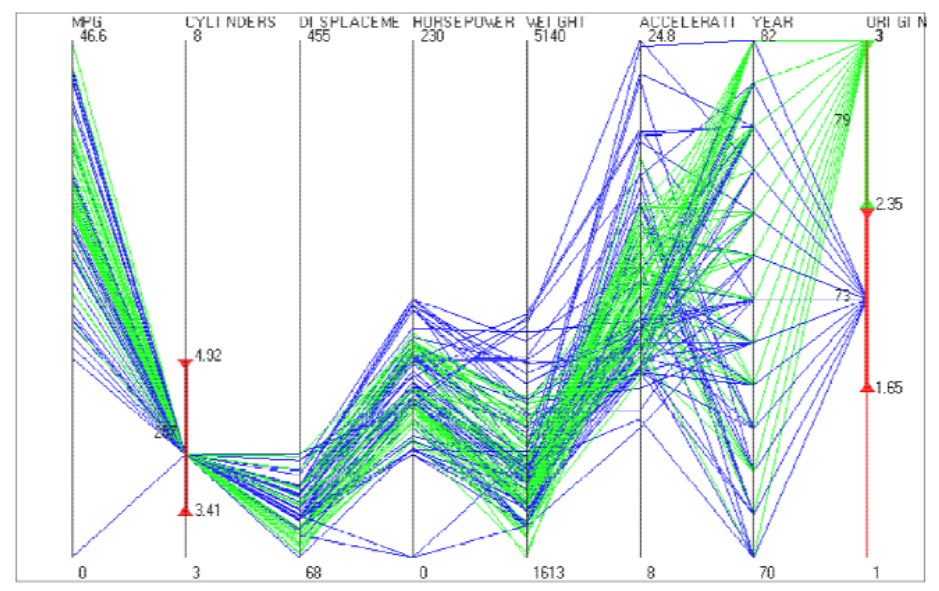

Figura 4.1: Exemplo de visualização por Coordenadas Paralelas.

\section{Scatter Plots}

Scatter Plots, (ou matriz Scatter Plot) é muito útil para visualizar a relação entre dois atributos, podendo projetar dados de alta dimensionalidade em um espaço de duas dimensões.

As dimensões são combinadas, duas a duas, e então projetadas uma em função da outra, formando uma grade, como mostra a Figura 4.2 (Rodrigues Jr., 2003). A correlação entre as dimensões resulta em clusters de pontos ao longo dos eixos de projeção.

\section{Table Lens}

Table Lens são bastante eficazes em ilustrar a grandeza dos valores dos atributos, comparando todo o conjunto de dados. Uma interação importante dessa técnica, chamada de ajuste-zoom 


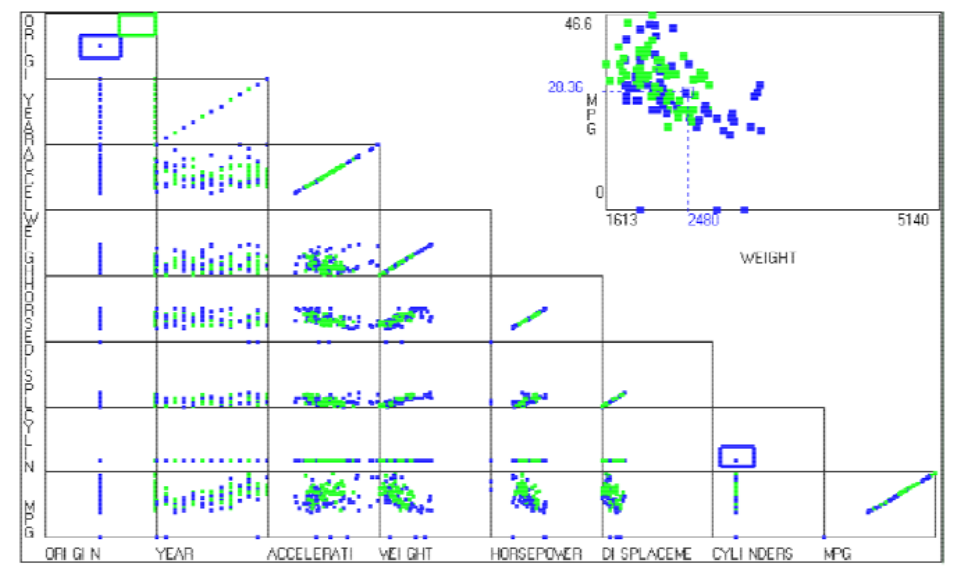

Figura 4.2: Exemplo de visualização por Scatter Plots.

(Rao and Card, 1994), permite aumentar/diminuir o número de células em foco, sem prejudicar seu tamanho. A técnica apresenta a distorção iterativa, que permite ao usuário visualizar todo o conjunto de dados e concentrar em elementos específicos, ao mesmo tempo. A Figura 4.3 (Rodrigues Jr., 2003) ilustra uma Table Len (gerada pela ferramenta GBDIView) com os elementos pertencentes a base de dados Carros.

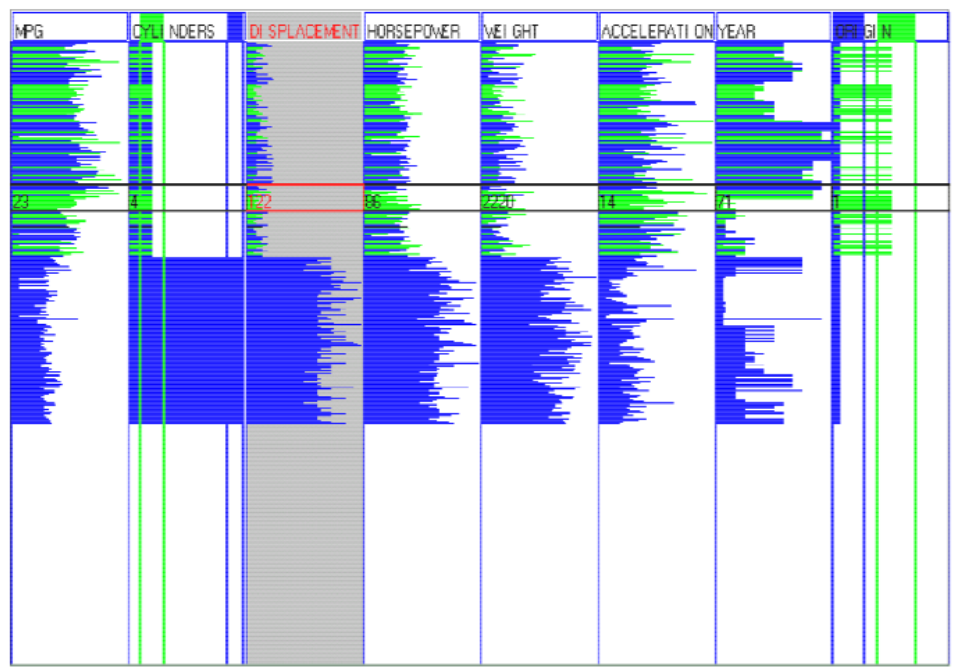

Figura 4.3: Exemplo de visualização por Table Lens.

\section{Star Glyphs}

Star Glyphs é uma técnica baseada em exibição orientada a ícones. Esta técnica tem como característica representar elementos por estrelas ou diagramas circulares. Um ícone de exibição representa um elemento do conjunto de dados, e possui $m$ eixos, representando $m$ dimensões, 
separados por ângulos iguais e tais que o comprimento representa a escala determinado pelos valores de cada dimensão. A Figura 4.4 (extraída de (Rodrigues Jr., 2003), gerada pela ferramenta XmdvTool (Ward, 1994)) ilustra uma aplicação dessa técnica.

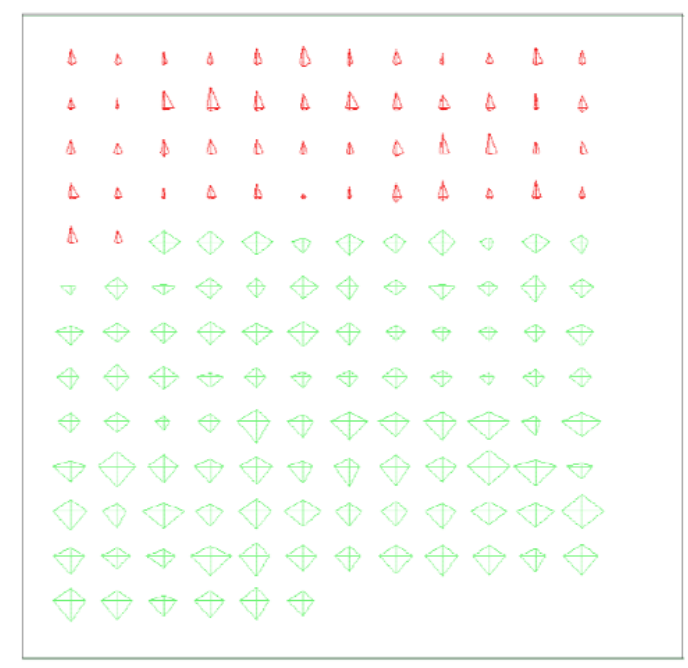

Figura 4.4: Exemplo de visualização por Star Glyphs.

\section{Dimensional Stacking}

Dimensional Stacking é uma técnica que projeta $m$ dimensões em um espaço bidimensional, utilizando eixos perpendiculares e mapeando uma dimensão dentro da outra. Como exemplo, a Figura 4.5 (extraída de (Rodrigues Jr., 2003), gerada pela ferramenta XmdvTool (Ward, 1994)) ilustra uma dimensional stacking sobre uma base de dados bastante conhecida, a base Íris, que possui 150 registros, 4 dimensões, representando três gêneros de uma espécie de flor denominada Íris.

\section{Treemaps}

Dentre as alternativas de representação utilizadas nas diversas técnicas para dados hierárquicos pode-se destacar dois grandes grupos: os que utilizam a abordagem de preenchimento do espaço e os baseados em diagramas de nós e arestas. No primeiro, o espaço disponível para a representação da estrutura é subdividido recursivamente, de forma que cada subárea representa um nó da hierarquia. No segundo, os nós são representados por figuras geométricas e os relacionamentos, por linhas. Dentro da abordagem de preenchimento de espaço podemos destacar a Treemap, introduzida por Shneiderman em (Shneiderman, 1991) e aperfeiçoada por (Bruls et al., 2000). Uma Treemap, ilustrada na Figura 4.6, é um espaço restrito a visualização de estruturas hierárquicas, muito eficaz em mostrar relação entre os atributos dos nós folha com 


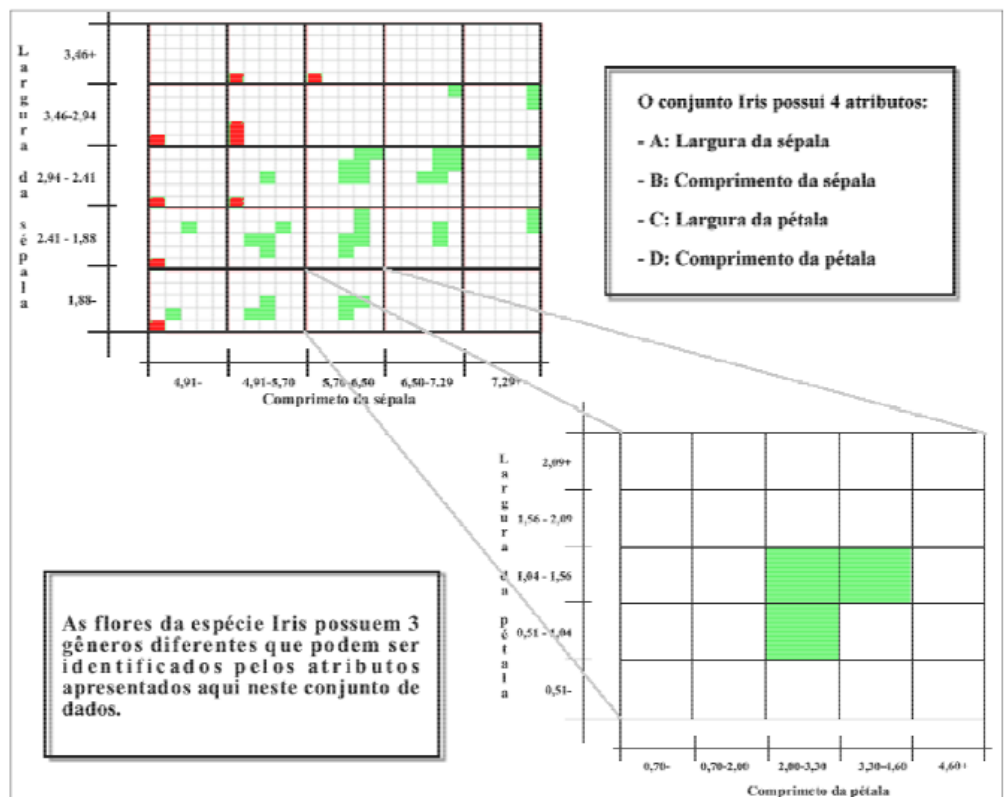

Figura 4.5: Exemplo de visualização por Dimensional Stacking.

tamanho e cor. Permite comparar nós e subárvores, mesmo com variações na profundidade da árvore e auxilia a detecção de padrões e exceções.

Cada item é representado por um retângulo. Cada retângulo por sua vez possui diferentes tamanhos, tal que sua área é proporcional a algum atributo definido pelo usuário. Como um exemplo, podemos considerar o conjunto de dados como sendo a descrição de uma estrutura de diretórios, e então podemos definir o tamanho dos arquivos e diretórios para ser representados pela área dos retângulos. Como a área não pode ser um valor negativo, e não será nesse exemplo pois tamanhos de arquivos também não o são, uma estratégia para lidar com dados negativos é ignorá-los na representação. Os retângulos são coloridos para representar outro atributo do conjunto de dados. No caso da estrutura de diretórios, o mais comum é associar a cor ao tipo do arquivo.

Existe uma grande quantidade de técnicas de visualização que podem ser utilizadas para o auxílio da busca pelo conhecimento. As técnicas de Visualização de Informação são classificadas por Keim (Keim, 2002) de modo a corresponder aos princípios básicos de visualização que podem ser combinadas para gerar um sistema de visualização específico. Uma breve descrição das classes em questão está descrita a seguir.

- Projeções 2D/3D tradicionais: técnicas simples e muito utilizadas como plotagem em planos e espaços e gráficos em geral. 


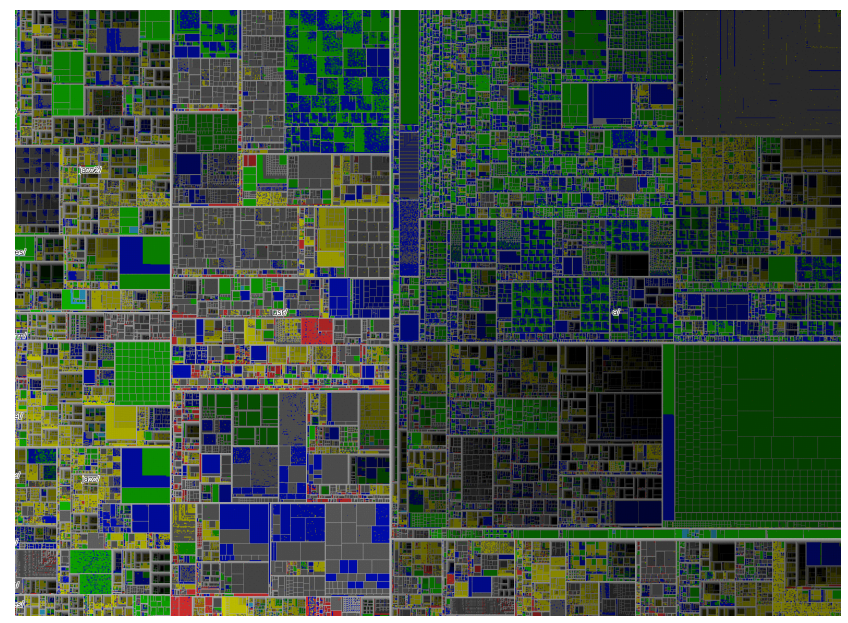

Figura 4.6: Treemap com um milhão de dados (fonte: http://www.cs.umd.edu/hcil/millionvis/ million-treemap.gif acessado em outubro de 2011).

- Projeções Geométricas: vislumbram técnicas que buscam encontrar "transformações" interessantes de dados multidimensionais. Como exemplo, as técnicas tais como Scatterplot (Ward, 1994), Coordenadas Paralelas (Inselberg and Dimsdale, 1990) e Coordenadas Estelares (Kandogan, 2000).

- Exibição Orientada a Ícones: mapeiam os valores dos atributos de dados multidimensionais a características de ícones, os quais podem ser arbitrariamente definidos. São técnicas como Faces de Chernoff (Chernoff, 1973) Stick Figures (Pickett and Grinstein, 1988) e Star Glyphs.

- Exibição Orientada a Pixel: cada valor de dimensão é mapeado em um pixel, considerando principalmente a disposição dos pixeis nas janelas, o mapeamento de cor e o formato das janelas. Como nesse caso costuma-se representar um dado por pixel, esse tipo de técnica é útil para representar um grande número de dados. Contudo, deve-se tomar o devido cuidado com o arranjo desses pixeis para não causar prejuízos à visualização.

- Técnicas Hierárquicas: utilizam uma estratégia que compreende em dividir o espaço $m$-dimensional e apresentar os subespaços resultantes de forma hierárquica. A hierarquia não ilustra importância ou subordinação, apenas ordem e detalhamento. Exemplos de técnicas hierárquicas: Treemaps (Shneiderman, 1991) (Bruls et al., 2000), Árvores Hiperbólicas (ilustrada na Figura 4.7) e Cone Tree (Robertson et al., 1991). Um exemplo de Cone Tree pode ser visto na Figura 4.8. 


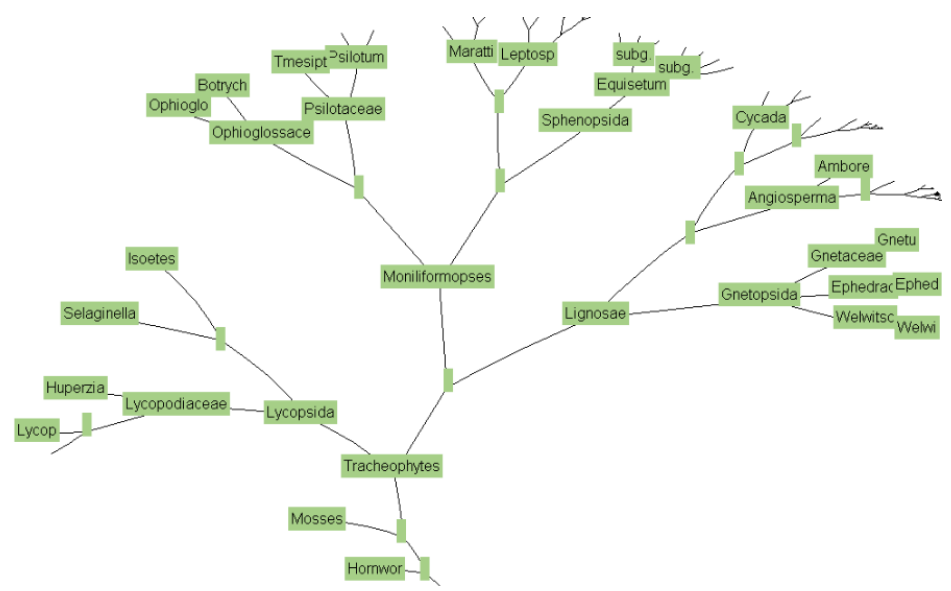

Figura 4.7: Representação hierárquica por Árvore Hiperbólica (fonte: http://ucjeps.berkeley.edu/map2.html acessado em outubro de 2011).

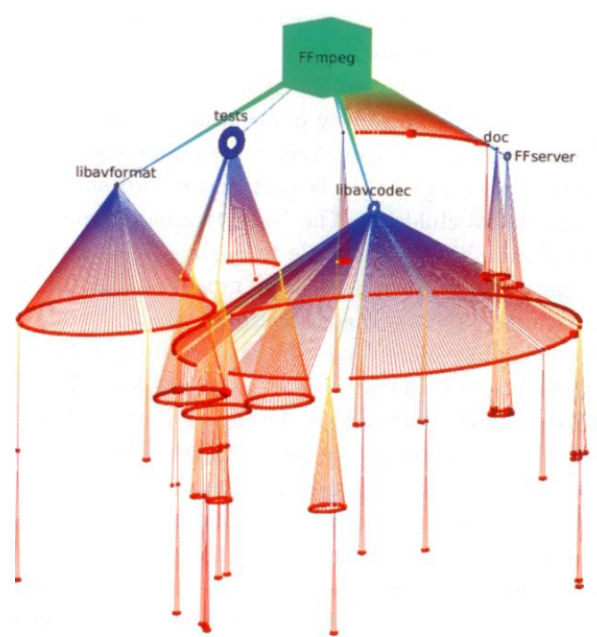

Figura 4.8: Representação de dados hierárquicos utilizando Cone Tree. Retirada de (Robertson et al., 1991).

Em (Ltifi et al., 2009), as técnicas de visualização são classificadas com base nos tipos de dados. A Tabela 4.1 ilustra essa classificação.

\subsubsection{Classificação de Dados e Interação}

Determinar uma técnica de visualização para ser empregada em uma aplicação é uma das principais considerações a ser analisada a fim de compor uma ferramenta de visualização. A escolha de tal técnica está fortemente relacionada a alguns aspectos importantes tais como o tipo de 
Tabela 4.1: Classificação de técnicas de visualização por tipo de dados (adaptada de (Ltifi et al., 2009)).

\begin{tabular}{|c|c|}
\hline Tipo de dados & Técnicas de Visualização \\
\hline \multirow{3}{*}{ Dados Lineares } & Tabelas \\
\hline & Perspective Wall \\
\hline & Linhas de Tempo \\
\hline \multirow[t]{2}{*}{ Dados Multidimensionais } & Matriz de Scatterplots \\
\hline & Sistema de Polilinhas \\
\hline \multirow{6}{*}{ Dados Hierárquicos } & Matrizes \\
\hline & Diagramas \\
\hline & Árvores \\
\hline & Treemaps \\
\hline & Abordagem Hiperbólica \\
\hline & Cone Tree \\
\hline \multirow{3}{*}{ Redes } & Redes de Hiperlinks \\
\hline & Redes de Co-citação \\
\hline & Redes Sociais \\
\hline \multirow[t]{2}{*}{ Dados Vetoriais } & Técnicas baseadas em similaridade \\
\hline & Técnicas baseadas em relevância \\
\hline
\end{tabular}

informação a ser tratada, o domínio ao qual pertencem os dados e as tarefas que podem ser efetuadas pelo usuário.

A fim de auxiliar na escolha entre técnicas de visualização, alguns trabalhos propostos na literatura foram desenvolvidos. A ideia é classificar as técnicas para que, através de suas características, o desenvolvedor possa determinar qual das técnicas melhor atende seus requisitos.

Em (Shneiderman, 1996), o autor classifica as técnicas de visualização pelos tipos de dados e pelas tarefas. Mais especificamente, as tarefas podem ser encaixadas em classes definidas como: obtenção de uma visão geral; obtenção de visão detalhada; zooming; filtragem; identificação de relacionamentos; manutenção de histórico de ações e extração de informações diversas. Já os dados são divididos em sete tipos:

- Unidimensional (1D): São tipos de dados lineares possuindo apenas uma dimensão, que inclui, entre outros, textos, código fonte de programas, lista de nomes, etc.

- Bidimensional (2D): Dados bidimensionais possuem duas dimensões distintas. Compreendem dados planares, mapas geográficos, entre outros. 
- Tridimensional (3D): Dados que possuem três dimensões distintas. Objetos do mundo real podem ser representados por esse tipo de dados.

- Multidimensional ( $n D)$ : Dados que possuem mais de três dimensões distintas. Como exemplo de dados multidimensionais temos as tabelas de bases de dados relacionais, que costumam ter muitos atributos.

- Temporal: Dados com uma dimensão, mas que diferentemente de dados unidimensionais, possuem um tempo de início e fim. Além disso, os dados podem ficar sobrepostos.

- Grafos (Árvores): São dados com comportamento hierárquico, ou seja, fazem uma ligação de um item com outro(s). É dividido em árvores, onde um item filho tem ligação para um item pai (exceto pelo item raiz).

- Grafos (Rede): Dados que possuem relações com outros dados, permitindo que exista uma ligação de um item com vários outros, diferentemente de dados do tipo árvore. Podemos tomar como exemplo redes sociais, a disposição de uma rede elétrica, etc.

Keim (Keim, 2002) classifica os dados em seis tipos: unidimensional; bidimensional; multidimensional; texto/web; hierárquicos/grafos e algoritmos/software. $\mathrm{O}$ autor ainda classifica as técnicas de interação da seguinte forma:

- Projeção Dinâmica: Interações que permitem redefinições dinâmicas de projeção para facilitar a exploração de conjuntos de dados multidimensionais.

- Filtragem Interativa: No processo de exploração de conjunto de dados muito volumosos é interessante particionar interativamente o conjunto de dados em subconjuntos e, então, dar foco nos subconjuntos de maior interesse. Pode ser feito pela seleção direta do subconjunto desejado, através de navegação, ou por uma especificação direta de propriedades desejadas do subconjunto, através de consultas. A navegação pode se tornar muito difícil em conjunto de dados muito grande e as consultas podem não retornar os elementos realmente esperados.

- Zoom Interativo: Outra maneira bastante utilizada para dar foco a diferentes porções da base de dados, entretanto, permitindo diferentes visões da distribuição dos dados, dependendo do grau do zoom aplicado. Como exemplo, os objetos podem ser representados por pixeis, quando o nível do zoom é baixo, por ícones, em um nível intermediário e como objetos rotulados em um nível maior de resolução. 
- Distorção Interativa: A ideia do funcionamento de técnicas de distorção interativa é exibir porções de dados com um alto grau de detalhamento em detrimento dos outros dados, que são exibidos com um baixo grau de detalhamento. Técnicas de distorção são frequentemente implementadas em árvores hiperbólicas e esféricas, podendo ser utilizada em qualquer outra técnica de visualização.

- Link \& Brush Interativo: A utilização do Link \& Brush Interativo serve para combinar diferentes métodos de visualização e tentar suprir as deficiências de técnicas simples. Por exemplo, scatterplots de diferentes projeções podem ser combinadas colorindo e ligando subconjuntos de pontos em todas as projeções. De forma semelhante, Link \& Brush pode ser aplicado a visualizações geradas por diversas técnicas de visualização.

\subsection{Considerações Finais}

A exploração visual de dados fornece uma maneira normalmente mais rápida e intuitiva para capturar informações de dados com bons resultados, especialmente nos casos em que algoritmos automáticos falham. Os resultados obtidos possuem um maior grau de confiança, uma vez que o processo é guiado pelo usuário, que possui as habilidades perceptivas necessárias.

Neste capítulo foram introduzidos vários conceitos que estabelecem a análise visual de dados. Termos relativos à área são descritos com o intuito de promover uma familiarização com relação aos desafios, técnicas e principais abordagens encontradas na literatura e que configuram o estado da arte.

Classificações sobre dados, interação e técnicas de Visualização de Informação foram brevemente introduzidas, bem como algumas técnicas, entre elas, Coordenadas Paralelas, Scatter Plots, Table Lens, Star Glyphs, Dimensional Stacking e Treemaps. Nota-se que técnicas de Visualização da Informação podem ser aplicadas em ferramentas de exploração de dados, de várias formas, atendendo a necessidades específicas, como será apresentado nesta dissertação, no Capítulo 6. 



\section{Transformação de Funções de Similaridade e de Espaços de Características}

\subsection{Considerações Iniciais}

Os métodos mais investigados para aprimorar resultados de recuperação de imagens por conteúdo consistem principalmente no ajuste da função de distância e transformação de espaço de dados como, por exemplo, seleção de características. Técnicas de ajuste de função de distância empregam vetores de pesos na tentativa de quantificar individualmente a contribuição de cada atributo ao representar um conjunto de imagens. Devido ao espaço de busca dos pesos ser normalmente um intervalo contínuo, a busca pelo vetor ótimo de pesos é dificultada, dado o grande número possível de combinações existentes.

Seleção de características transforma o espaço dos dados com o propósito de realizar redução de dimensionalidade. Tais técnicas buscam por um subconjunto de características em que seja minimizado o número de atributos irrelevantes e redundantes, ao mesmo tempo em que tenta minimizar a perda de informação. Todavia, seleção de características tem como limitação o fato de não considerar o grau de contribuição de cada característica selecionada como relevante. 
Neste trabalho foram propostos dois métodos que visam melhorar a eficácia de sistemas CBIR. O primeiro método, denominado WF, modifica a função de distância por intermédio de ponderação de atributos, utilizando funções de ponderação que permitem limitar o espaço de busca. O segundo método, denominado TF, realiza transformações no espaço original por meio de funções de transformação que visam capturar correlações não lineares sobre o espaço (Avalhais et al., 2012).

Foi também implementado um protótipo de sistema CBIR para dar suporte a consultas por similaridade. O mecanismo que produz as referidas transformações é baseado em realimentação de relevância e algoritmo genético, uma combinação de técnicas de êxito para buscas guiadas pelo interesse do usuário. Este capítulo introduz as definições necessárias para a formalização e entendimento dos métodos e também apresenta a visão geral do protótipo do sistema desenvolvido.

\subsection{Definições e Formalização do Protótipo do Sis- tema CBIR Desenvolvido}

Considere $\mathbf{X}=\left\{\mathbf{x}_{1}, \ldots, \mathbf{x}_{n}\right\}$ o conjunto de vetores de características extraídos da base de imagens $\mathbf{I}=\left\{\mathbf{i}_{1}, \ldots, \mathbf{i}_{n}\right\}$ pelo extrator $\varepsilon$, isto é, $\varepsilon\left(\mathbf{i}_{i}\right)=\mathbf{x}_{i}=\left\{x_{1}, \ldots, x_{m}\right\}, \mathbf{x}_{i} \in \mathbb{R}^{m}$. Denotamos por $\mathbf{x}_{q}$ o vetor de características da imagem de consulta $\mathbf{i}_{q}$. A função de distância $d: \mathbb{R}^{m} \times \mathbb{R}^{m} \rightarrow \mathbb{R}^{+}$calcula a dissimilaridade entre $\mathbf{x}_{q}$ e $\mathbf{x}_{i}$.

Uma representação esquemática do protótipo CBIR desenvolvido é ilustrada na Figura 5.1. Inicialmente, é feita uma consulta $k N N\left(\mathbf{x}_{q}, k, d, \mathbf{X}\right)$ (Equação 2.8), onde $k$ é previamente definido pelo usuário. $\mathrm{O}$ ranking inicial $\mathbf{T}_{1}=\left(\mathbf{t}_{1}, \ldots, \mathbf{t}_{k}\right)$, resultado da consulta $k N N$ inicial, é apresentado ao usuário, que deve avaliar as imagens recuperadas. Esta avaliação consiste em atribuir valores de relevância às imagens, mapeando a satisfação do usuário quanto ao ranking apresentado. Esses valores são representados por $r\left(\mathbf{t}_{j}\right), 1 \leq j \leq k$, tal que: $r\left(\mathbf{t}_{j}\right)=1$ se a imagem é relevante; $r\left(\mathbf{t}_{j}\right)=-1$ se a imagem é não desejável, ou seja, não deveria estar entre as primeiras $k$ imagens recuperadas; ou $r\left(\mathbf{t}_{j}\right)=0$ (não relevante) no caso em que eventualmente o usuário possa ter dúvidas sobre a classificação de tal imagem no contexto da consulta atual, ou simplesmente prefira não avaliá-la. A partir da avaliação inicial, é então iniciado o loop de ciclos de realimentação de relevância baseado em AG.

Os valores de relevância $r\left(\mathbf{T}_{i}\right)$ obtidos no $i$-ésimo ciclo de realimentação são utilizados para compor os conjuntos $\mathbf{R}_{q_{i}}^{+}$e $\mathbf{R}_{q_{i}}^{-}$, que representam o conjunto de elementos positivos (imagens relevantes), e elementos negativos (imagens não desejáveis), respectivamente. A composição destes conjuntos é apresentada na Definição 5.1. É pertinente ressaltar que o objetivo destes 


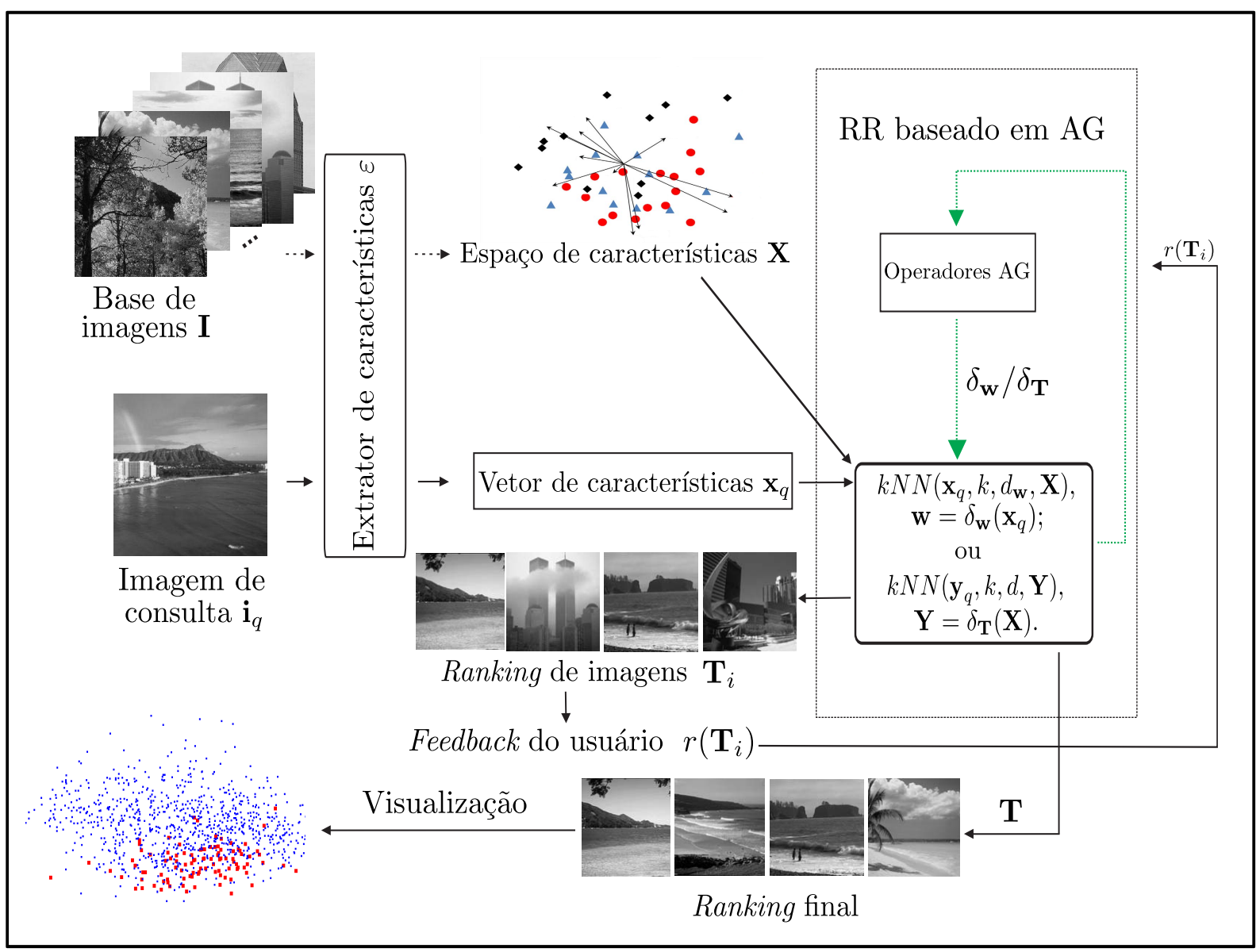

Figura 5.1: Esquematização do protótipo CBIR apoiado por realimentação de relevância e algoritmo genético.

conjuntos é armazenar a informação de todas as imagens avaliadas pelo usuário sobre a consulta em questão, inclusive em ciclos anteriores. Deste modo, o critério de avaliação de rankings pode considerar o "histórico" de elementos previamente recuperados estabelecendo um mecanismo mais robusto para a aprendizagem.

Definição 5.1. Seja $r\left(\mathbf{T}_{i}\right)=\left(r\left(\mathbf{t}_{1}\right), \ldots, r\left(\mathbf{t}_{k}\right)\right)$ a avaliação obtida no $i$-ésimo ciclo de realimentação. O conjunto de elementos positivos (relevantes) $\mathbf{R}_{q_{i}}^{+}$e o conjunto de elementos negativos (não desejáveis) $\mathbf{R}_{q_{i}}^{-}$são:

$$
\begin{aligned}
& \mathbf{R}_{q_{i}}^{+}=\left\{\mathbf{R}_{q_{i-1}}^{+} \cup\left\{\mathbf{t}_{j}\right\} \mid \forall \mathbf{t}_{j} \in \mathbf{T}_{i}, r\left(\mathbf{t}_{j}\right)=1\right\} ; \\
& \mathbf{R}_{q_{i}}^{-}=\left\{\mathbf{R}_{q_{i-1}}^{-} \cup\left\{\mathbf{t}_{j}\right\} \mid \forall \mathbf{t}_{j} \in \mathbf{T}_{i}, r\left(\mathbf{t}_{j}\right)=-1\right\} .
\end{aligned}
$$

A princípio, $\mathbf{R}_{q_{0}}^{+}=\mathbf{R}_{q_{0}}^{-}=\emptyset$. 
O AG executa buscas por vetores de funções de ponderação para alterar a medida de similaridade ou de funções de transformação para redefinição do espaço, tentando obter o maior valor de aptidão, ou seja, maximizar a função objetivo. Empregamos a função de avaliação de qualidade de ranking apresentada na Definição 5.2 como função objetivo para o AG. Esta função de avaliação considera a ordem dos elementos retornados no ranking, bastante adequada para o uso de realimentação de relevância (López-Pujalte et al., 2003). Outro aspecto importante desta função é poder utilizar elementos classificados negativamente no cálculo da medida de qualidade, possibilitando uma avaliação mais precisa de cada cromossomo da população.

Definição 5.2. Dados $\mathbf{R}_{q_{i}}^{+}, \mathbf{R}_{q_{i}}^{-}$e o ranking $\mathbf{T}_{i}=\left(\mathbf{t}_{1}, \ldots, \mathbf{t}_{k}\right)$ em resposta à consulta $k N N_{i}\left(\mathbf{x}_{q}, k, d, \mathbf{X}\right)$, a função de avaliação da qualidade de $\mathbf{T}_{i}\left(\Phi\left(\mathbf{T}_{i}\right)\right)$ é calculada como segue:

$$
\Phi\left(\mathbf{T}_{i}\right)=\sum_{j=1}^{k} \frac{r\left(\mathbf{t}_{j}\right)}{A} \cdot\left(\frac{(A-1)}{A}\right)^{j-1}
$$

onde $r\left(\mathbf{t}_{j}\right)=1$, se $\mathbf{t}_{j} \in \mathbf{R}_{q_{i}}^{+}$, ou $r\left(\mathbf{t}_{j}\right)=-1$, se $\mathbf{t}_{j} \in \mathbf{R}_{q_{i}}^{-}$, ou ainda $r\left(\mathbf{t}_{j}\right)=0$, caso contrário; $A \geq 2$ é o parâmetro de ajuste que expressa a importância da posição dos elementos no ranking. Valores $A$ baixos indicam que é supervalorizada a posição dos elementos relevantes mais próximos ao topo do ranking. Com valores maiores, a fração $\frac{A-1}{A}$ tende a 1 , o que significa que está sendo mais valorizado o número de elementos relevantes do que a posição deles em si. Dessa forma, é importante atribuir valores adequados ao propósito da busca para este parâmetro, uma vez que esta função é determinante para a convergência do AG.

Os vetores de funções de ponderação/transformação inferidos pelo AG podem ser considerados como operadores que realizam transformação de espaço métrico (Definição 5.3). De fato, o espaço de características e a função de distância adotada neste trabalho formam o espaço métrico que é redefinido a cada geração do AG.

Definição 5.3. Seja $\mathcal{M}=<\mathfrak{D}, d>$ um espaço métrico. Uma função $\Delta: \mathcal{M} \rightarrow \mathcal{M}^{\prime}$ realiza uma transformação sobre o espaço métrico $\mathcal{M}$ se:

$$
\begin{aligned}
& \mathcal{M}^{\prime}=<\mathfrak{D}^{\prime}, d>, \mathfrak{D}^{\prime}=\Delta(\mathfrak{D}) \text { ou } \\
& \mathcal{M}^{\prime}=<\mathfrak{D}, d^{\prime}>, d^{\prime}=\Delta(d), d^{\prime} \text { é métrica. }
\end{aligned}
$$

Isto é, uma transformação em espaço métrico é obtida quando existir uma função que transforma o espaço do domínio original ou quando a função de distância é redefinida para aquele espaço, com a condição de continuar sendo métrica. 
Os ciclos de realimentação e busca por AG são repetidos até que seja encontrada a solução desejada, o que significa que todos os elementos do ranking são relevantes para o usuário, ou até que um número máximo de iterações seja atingido.

\subsection{Otimização por Funções de Ponderação}

A construção de metodologias que empregam AGs na busca de vetores de pesos para ajuste de funções de similaridade tem alcançado resultados promissores, conforme discutido anteriormente. Com base neste conceito, uma das propostas desenvolvidas foi otimizar consultas por similaridade por meio de vetores de ponderação.

Ao invés de considerar um espaço contínuo para os pesos, como por exemplo o intervalo $[0,1]$, os pesos são gerados por funções matemáticas de vários tipos. Desta forma, o conjunto de pesos possíveis é reduzido e limitado, permitindo uma considerável redução do espaço de busca e, consequentemente, possibilitando que a busca tenha maior probabilidade de alcançar a solução ótima. A Figura 5.2 ilustra os gráficos de algumas funções de comportamento linear e não linear utilizadas para gerar o vetor de pesos.

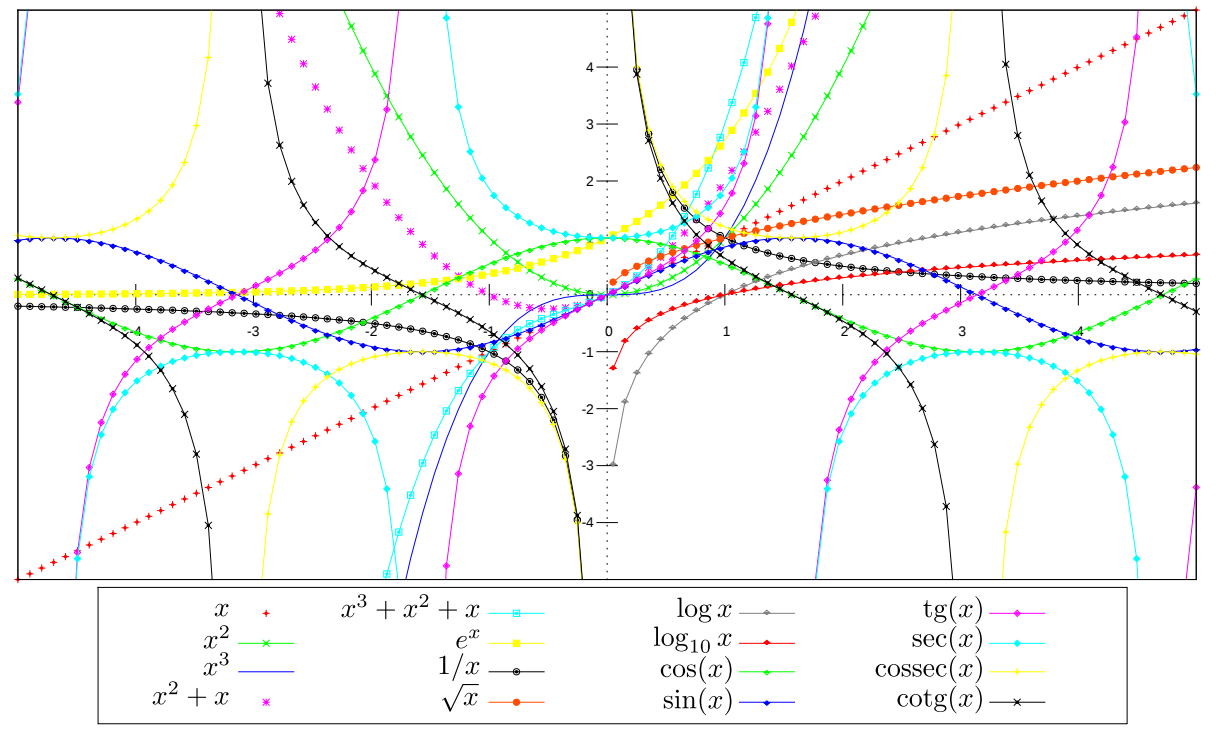

Figura 5.2: Funções lineares e não lineares para otimização por ponderação e transformação do espaço de características.

O mecanismo de realimentação de relevância baseado em AG, neste caso, é responsável por realizar transformações na função de distância. Pelo fato destas transformações serem obtidas apenas por ponderação nos atributos, e que os pesos possíveis são normalizados no intervalo 
$[0,1]$, podemos dizer que as funções de distância resultantes também são métricas, uma vez que continuam a satisfazer aos axiomas necessários.

O problema de otimizar consultas por similaridade por meio de funções de ponderação é formalmente apresentado pela Definição 5.4, e consiste em encontrar uma sequência de funções que geram o vetor de pesos mais adequado para uma consulta específica. Diferentemente da grande maioria das estratégias de busca de vetores de pesos por AG, onde é atribuído ao genótipo valores reais que correspondem aos pesos em si, neste caso são atribuídos para o genótipo valores inteiros que correspondem aos identificadores das funções de ponderação que geram os pesos.

Definição 5.4. Seja $\mathbf{F}=\left\{f_{1}, \ldots, f_{\rho}\right\}$ um conjunto de funções e $\delta_{\mathbf{w}}=\left(f_{1}^{\prime}, \ldots, f_{m}^{\prime}\right)$, $f_{i}^{\prime} \in \mathbf{F}$ o conjunto ordenado de funções de ponderação inferido pelo AG. Então seja $\mathbf{w}=\delta_{\mathbf{w}}\left(\mathbf{x}_{q}\right)=\left\{f_{1}^{\prime}\left(x_{q_{1}}\right), \ldots, f_{m}^{\prime}\left(x_{q_{m}}\right)\right\}$ o vetor de ponderação para a função de distância $d_{\mathbf{w}}$. O problema de otimização de consultas por similaridade por meio de funções de ponderação é encontrar um conjunto $\delta_{\mathbf{w}}$ tal que $\Phi(\mathbf{T})$ seja máximo. Ou seja, queremos encontrar:

$$
\underset{\delta_{\mathbf{w}}}{\arg \max } \Phi(\mathbf{T})
$$

onde $\mathbf{T}=k N N\left(\mathbf{x}_{q}, k, d_{\mathbf{w}}, \mathbf{X}\right)$.

A vantagem em lidar com as funções para ponderação é que o espaço de busca para o AG é significativamente reduzido. Isto porque o espaço de busca de um intervalo contínuo é consideravelmente maior que o espaço de busca $\mathbf{F}$, que é finito e discreto.

\subsection{Otimização por Funções de Transformação}

A segunda metodologia desenvolvida está relacionada com a transformação do espaço de característica. Todo o espaço original é redefinido por meio de funções de transformação, como detalhado na Definição 5.5. As funções de transformação, assim como as funções de ponderação, são funções matemáticas de vários tipos, como ilustradas na Figura 5.2. A diferença é que, aplicadas diretamente nos atributos, estas funções admitem, além de transformações lineares, transformações não lineares, que é uma tentativa de capturar também correlações não lineares sobre o espaço de característica.

As transformações são realizadas utilizando AG para inferir a sequência ótima de funções que serão aplicadas no espaço de características original. A cada sequência de funções de transformação gerada pelo AG, um novo espaço é obtido sobre os valores originais das características, e em seguida, são feitas novas consultas $k N N$. 
Definição 5.5. Dado F, como mencionado anteriormente, seja $\delta_{\mathbf{T}}$, definido analogamente a $\delta_{\mathbf{w}}$, um conjunto ordenado de funções de transformação inferido e $\mathbf{Y}=\left\{\mathbf{y}_{1}, \ldots, \mathbf{y}_{n}\right\}$ o novo espaço de característica, tal que $\mathbf{y}_{i}$ corresponde a $\mathbf{x}_{i}$ redefinido pelas funções de transformação em $\delta_{\mathbf{T}}$, isto é, $\mathbf{y}_{i}=\delta_{\mathbf{T}}\left(\mathbf{x}_{i}\right)=\left\{f_{1}^{\prime}\left(x_{i_{1}}\right), \ldots, f_{m}^{\prime}\left(x_{i_{m}}\right)\right\}$. O problema de otimização de consultas por similaridade por meio de funções de transformação consiste em encontrar um conjunto $\delta_{\mathbf{T}}$ de tal maneira que $\Phi(\mathbf{T})$ seja máximo. Ou seja, queremos encontrar:

$$
\underset{\delta_{\mathbf{T}}}{\arg \max } \Phi(\mathbf{T})
$$

onde $\mathbf{T}=k N N\left(\mathbf{y}_{q}, k, d, \mathbf{Y}\right)$.

\subsection{Considerações Finais}

Neste capítulo foram apresentados formalmente as duas principais contribuições deste trabalho de mestrado. Com o objetivo de aprimorar os resultados de consultas por similaridade sobre o domínio de imagens, os métodos aqui propostos transformam o espaço métrico original induzido por sequências de funções obtidas pelo algoritmo genético.

A avaliação do usuário nos ciclos de realimentação de relevância formam a base de referência do algoritmo genético na busca pela sequência ótima das funções de ponderação e transformação. As funções de ponderação contribuem para para a redução do espaço de busca na determinação dos pesos para a função de distância e as funções de transformação permitem uma melhor distorção do espaço de características por meio das transformações não lineares feitas sobre ele.

As técnicas para transformação de espaço métrico desenvolvidas atuam diretamente na atenuação do problema da lacuna semântica, uma vez que incorpora diretamente os interesses do usuário. Os experimentos e resultados são descritos e discutidos no capítulo seguinte. 



\section{CAPÍTULO \\ 6 \\ Resultados Experimentais}

\subsection{Considerações Iniciais}

Este capítulo apresenta os resultados experimentais a fim de validar os métodos propostos neste trabalho, definidos no Capítulo 5. Também são descritos os conjuntos de dados, extratores de características e função de distância utilizados nos experimentos, assim como os parâmetros e configurações considerados. Os métodos propostos são avaliados por meio de gráficos precisão vs. revocação e por visualização dos espaços de dados resultantes.

\subsection{Conjuntos de Imagens}

Nesta seção são descritos os conjuntos de imagens utilizados para a realização dos experimentos. Com o propósito de avaliar a aplicabilidade dos métodos propostos, os experimentos foram conduzidos sobre bases reais, em dois domínios distintos: imagens diversas e imagens médicas.

\subsubsection{Domínio de Imagens Diversas}

Para permitir uma avaliação mais rigorosa, utilizamos dois conjuntos de imagens diversas, uma delas colorida e outra em preto e branco. A base Corel $1000^{1}$ (Li and Wang, 2003) contém

\footnotetext{
${ }^{1}$ Disponível em: http://wang. ist.psu.edu/docs/related/; Acessado em 23/agosto/2011.
} 
1000 imagens coloridas, categorizadas em 10 classes com 100 imagens cada: Africa, beach, buildings, buses, dinosaurs, elephants, flowers, food, horses e mountains. A Figura 6.1 apresenta uma imagem de cada classe deste conjunto.

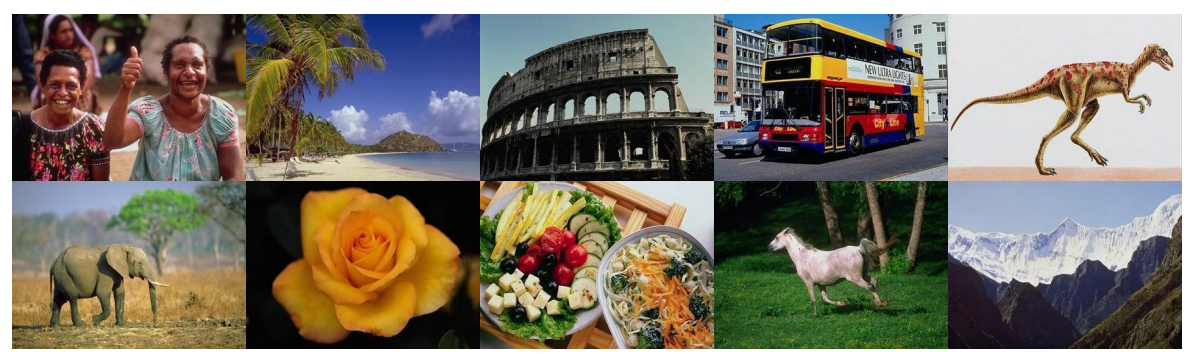

Figura 6.1: Amostra da base de imagens Corel 1000, composta por 10 classes: Africa, beach, buildings, buses, dinosaurs, elephants, flowers, food, horses e mountains.

A segunda base utilizada nos experimentos é denominada Cenas (Oliva and Torralba, 2001), que contém 1678 imagens em preto e branco. As imagens são distribuídas em 5 classes, sendo duas classes de cenas de ambientes urbanos: highway com 260 imagens e tall buildings com 356; e três classes de cenas de ambientes naturais: coast com 360 imagens, forest com 328 e mountain com 374, totalizando uma média aproximada de 336 imagens por classe. A Figura 6.2 ilustra uma amostra de cada classe desta base.

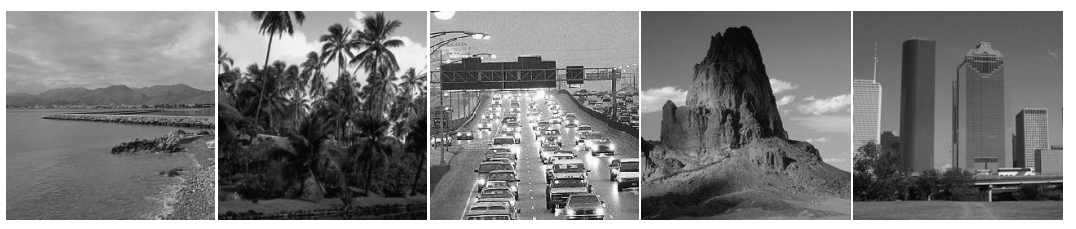

Figura 6.2: Amostra da base de imagens Cenas composta por 5 classes: coast, forest, highway, mountain e tall buildings.

\subsubsection{Domínio de Imagens Médicas}

Para o domínio de imagens médicas realizamos experimentos sobre um conjunto de exames variados, Exames Médicos e um conjunto mais específico, Pulmão. As imagens médicas foram fornecidas pelo Hospital das Clínicas da Faculdade de Medicina de Ribeirão Preto - USP.

O conjunto de Exames Médicos contém 2400 imagens de várias partes do corpo humano, extraídas por exames de raio X e ressonância magnética, classificadas conforme a parte do corpo e tipo de corte. A base é composta por 12 classes (abdômen, cérebro axial, cérebro coronal, 
cérebro sagital, mama, tórax, pé, mão, joelho, pulmão, pélvis e espinha sagital) sendo que cada classe contém 200 imagens. A Figura 6.3 ilustra uma amostra de cada classe desta base.

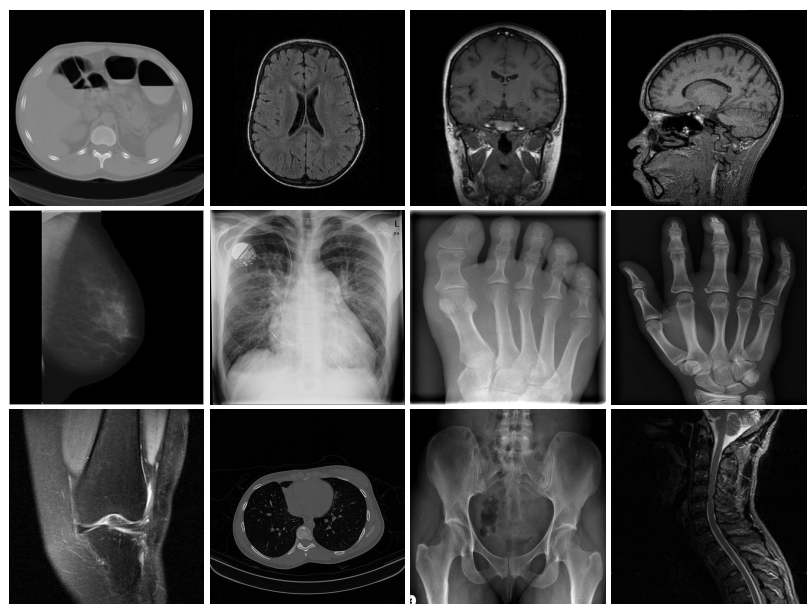

Figura 6.3: Amostra da base de imagens Exames Médicos composta por 12 classes: abdômen, cérebro axial, cérebro coronal, cérebro sagital, mama, tórax, pé, mão, joelho, pulmão, pélvis e espinha sagital.

A base Pulmão é formada por 246 imagens de ressonância magnética. Esta base é dividida em 6 classes, sendo uma normal, com 40 imagens e 5 patológicas: consolidação com 40 imagens, enfisema com 44, espessamento com 42, favo de mel com 39 e vidro fosco com 41, totalizando uma média de 41 imagens por classe. Um exemplo de cada classe pode ser vista na Figura 6.4 .
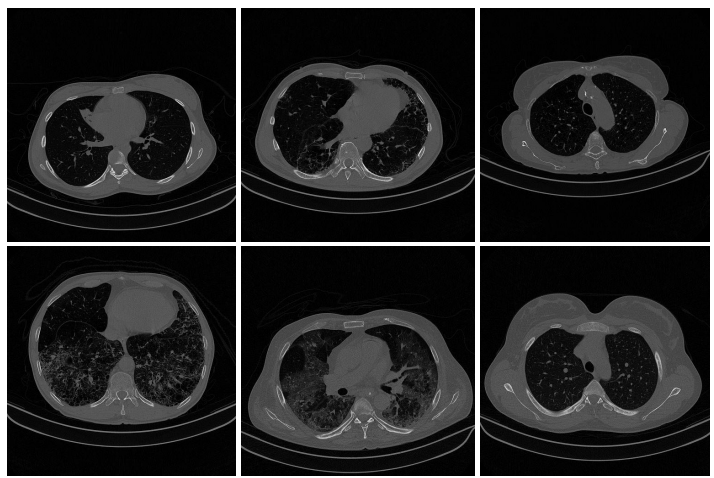

Figura 6.4: Amostra da base de imagens Pulmão composta por 6 classes: normal, consolidação, enfisema, espessamento, favo de mel e vidro fosco. 


\subsection{Configurações dos Experimentos}

Esta seção descreve todos os parâmetros e configurações utilizados para os experimentos.

\section{Extratores de Características e Função de Distância}

Para cada conjunto de imagens, foram utilizados os seguintes extratores de características: Momentos de Cor (Stricker and Orengo, 1995), Co-ocorrência (Haralick et al., 1973), Sobel (Brandt, 1999), Histograma (Bugatti et al., 2008), Run Length (Loh et al., 1988), e SIFT (Lowe, 1999). Os extratores Momentos de Cor e Sobel particionam as imagens em 16 regiões retangulares de tamanhos iguais, sendo as respectivas características extraídas de cada região e combinadas em um único vetor. A Tabela 6.1 mostra o número de características e o tipo de informação capturada para cada extrator.

Tabela 6.1: Descrição sumarizada dos conjuntos de características utilizados.

\begin{tabular}{|c|c|l|}
\hline Extrator de características & Número de características & Tipo \\
\hline Momentos de Cor & 144 & Cor \\
\hline Co-ocorrência & 88 & Textura \\
\hline Sobel & 128 & Forma \\
\hline Histograma & 256 & Cor \\
\hline Run Length & 44 & Textura \\
\hline SIFT & 128 & Forma \\
\hline
\end{tabular}

Como os atributos de imagens possuem diferentes escalas, que pode introduzir bias no cálculo de distância, cada conjunto de características foi normalizado por $z$-score. O valor normalizado $z$ de um atributo $x$ é calculado de acordo com a sua média $\mu(x)$ e desvio padrão $\sigma(x)$, como mostrado na Equação 6.1.

$$
z=\frac{x-\mu(x)}{\sigma(x)}
$$

Esta normalização é mais adequada do que normalizações em intervalo de variação, devido esta ser pouco sensível a outliers. O resultado da normalização é uma média igual a 0 e desvio padrão igual a 1 para todos os atributos.

A função de distância utilizada para os cálculos de dissimilaridades foi a Euclidiana $\left(L_{2}\right)$. Para o método de ajuste de função de distância foi utilizada a versão ponderada da distância Euclidiana onde, para a consulta inicial, os pesos são iguais a 1 para todas as dimensões do vetor. 


\section{Parâmetros do Algoritmo Genético}

Os valores dos parâmetros e escolha dos operadores são decisivos para a eficácia do algoritmo genético. Tais escolhas foram feitas empiricamente, de acordo com uma análise das melhores performances obtidas em experimentos preliminares.

- Codificação do cromossomo: em ambos os métodos propostos, o cromossomo foi codificado como um vetor de dimensão $m$ de valores inteiros, $\mathbf{C}=\left(g_{1}, \ldots, g_{m}\right)$, tal que $g_{i}$ corresponde ao identificador de uma função em F. Semanticamente, na abordagem de função de ponderação, o cromossomo gera o vetor de pesos $\mathbf{w}$, enquanto que na abordagem de funções de transformação o cromossomo gera o novo espaço de características $\mathbf{Y}$.

- Função fitness: como função objetivo, foi empregada a função de avaliação de qualidade de ranking da Equação 5.2.

- Operador de seleção para cruzamento: foi utilizada a seleção por ranking exponencial a fim de selecionar pares de indivíduos para reprodução. A probabilidade de seleção $p_{i}$ de um indivíduo $\mathrm{C}_{i}$ é dada pela Equação 6.2:

$$
p_{i}=\frac{c^{S_{p}-i}}{\sum_{j=1}^{S_{p}} c^{S_{p}-j}}, 0 \leq c \leq 1
$$

onde $i \in\left\{1, \ldots, S_{p}\right\}, S_{p}$ é o tamanho da população e $c=0.9$.

- Operador de seleção para reinserção: elitismo foi escolhido para selecionar os cromossomos sobreviventes para a próxima geração. Esta escolha é devido ao elitismo garantir que o melhor indivíduo da população em uma geração $g$ estará presente na população da geração $g+1$, que por sua vez garante que a melhor solução em gerações posteriores será sempre melhorada ou no mínimo mantida.

- Operador de cruzamento: foi empregado o cruzamento uniforme. Uma máscara randomicamente gerada indica quais cromossomos irão suprir cada gene do primeiro filho, sendo que o segundo filho é gerado pelo complemento da mesma máscara.

- Operador de mutação: a mutação uniforme é aplicada nos cromossomos filhos. Os genes selecionados com probabilidade $P_{m}$ e seus valores são substituídos por valores válidos escolhidos aleatoriamente.

- Tamanho da população $\left(S_{p}\right): 50$ indivíduos. 
- Número máximo de gerações $\left(N_{g}\right)$ : 100 gerações.

- Taxa de cruzamento: 0,8 .

- Taxa de mutação: 0,02 por gene.

\subsection{Análise dos Resultados}

Nesta seção são apresentados os resultados dos experimentos realizados, com o objetivo de demonstrar a acurácia dos métodos propostos nesta dissertação: ajuste de função de distância por funções de ponderação (WF) e redefinição do espaço de características por funções de transformação (TF). Os resultados dos métodos são comparados com a abordagem clássica de ponderação (WG) que explora o espaço de busca contínuo (Zhang et al., 2003) (Wettschereck et al., 1997).

Para as consultas $k N N$ foi empiricamente escolhido $k=30$. Foram aleatoriamente selecionadas uma imagem de cada classe, deste modo, os resultados de cada base são relativos à média das consultas para estas imagens. É também feita uma análise sobre a influência do parâmetro $A$ da função de aptidão escolhida para o AG, para o qual escolhemos os valores 2,10 e 20 . O número máximo de ciclos de realimentação foi 10.

Os resultados são avaliados por meio de gráficos de precisão vs. revocação e número de relevantes vs. ciclos. É também apresentada a análise visual da projeção do espaço resultante de cada método. As figuras referentes aos resultados dos experimentos descritos nesta seção estão disponíveis no Apêndice A.

\subsubsection{Medidas de Precisão e Revocação}

As análises sobre os resultados em medidas de precisão e revocação seguem os seguintes critérios: (i) os três extratores com melhor resultado global, ou seja, com o melhor resultado considerando todos os métodos e os valores de ajuste do parâmetro $A$; (ii) para cada método, o extrator que obteve o melhor resultado.

\section{Base Corel 1000}

Dados os resultados das consultas iniciais referentes à base Corel 1000, observou-se que Momentos de Cor foi o extrator que obteve os melhores resultados, devido a esta ser uma base colorida, recuperando uma média de 18 imagens relevantes entre as 30 primeiras posições do ranking. O extrator Histograma recuperou uma média de 10 imagens relevantes entre as 30 
primeiras imagens do ranking, obtendo o pior resultado entre todos os extratores. A Figura A.1 mostra o resultado médio das consultas iniciais para cada extrator em um gráfico de precisão vs. revocação.

Após dez ciclos de realimentação, verificamos que TF supera significativamente WF e WG para todos os extratores e configurações do parâmetro $A$. Também, sobre as mesmas condições, verificamos que WF obteve resultados equivalentes ou superiores a WG. Os métodos WG, WF e TF alcançaram maior precisão ao considerar $A=10$. Os gráficos da Figura A.2 representam os resultados do último ciclo de realimentação para cada extrator. A Figura A.2(a) mostra os resultados obtidos pelo método WG, a Figura A.2(b) mostra os resultados obtidos por WF e a Figura A.2(c) mostra os resultados obtidos por TF, utilizando $A=10$. Considerando revocação em $20 \%$, a precisão do método WG foi de $97 \%$ e a precisão de WF foi $98 \%$, enquanto que TF resultou em precisão máxima em até $26 \%$ de revocação.

Considerando as três abordagens de otimização e os valores de $A$ empregados, os três extratores que produziram os melhores resultados foram: Momentos de Cor, SIFT e Sobel. As Figuras A.3(a), A.3(b) e A.3(c) ilustram os resultados de cada método e valor $A$ para esses extratores. Analisando os gráficos, podemos ver que os melhores resultados foram alcançados pelo método de transformação, que produziu níveis maiores de precisão comparado aos métodos de ponderação. O gráfico da Figura A.3(a) mostra que TF obteve $100 \%$ de precisão até a faixa de aproximadamente $26 \%$ de revocação, enquanto que a melhor resposta de otimização por ponderação (WF e $A=10$ ) obteve $100 \%$ de precisão em até $16 \%$ de revocação. A Figura A.3(b) mostra que a precisão máxima obtida por TF alcançou $16 \%$ de revocação, ao passo que WG e WF alcançaram em média somente $2 \%$ de revocação com precisão máxima. Considerando o extrator Sobel, o método TF novamente alcançou $16 \%$ de revocação com $100 \%$ de precisão quando $A=10$, e o melhor resultado de ponderação (WG e $A=20$ ) obteve $100 \%$ de precisão em até $10 \%$ de revocação (Figura A.3(c)).

Com relação ao de número de imagens relevantes recuperadas em cada ciclo, apresentado na Figura A.5, considerando as 30 primeiras posições do ranking, nota-se que cada método apresenta um maior número de imagens relevantes quando $A=20$, seguido de $A=10$. A média de imagens relevantes recuperadas ao utilizar Momentos de cor e $A=20$ é 30 para o método de transformação, 28 para WF e 27 para WG (Figura A.5(a)). A média de relevantes no décimo ciclo para o extrator SIFT e $A=20$ é 28 para TF, 24 para WF e 25 para WG (Figura A.5(b)). Considerando o extrator Sobel, a média é de 28 relevantes para TF, 25 para WF e 24 para WG (Figura A.5(c)).

A Figura A.6 apresenta os gráficos de precisão vs. revocação para ilustrar a evolução dos métodos através dos ciclos de realimentação. As Figuras A.6(a), A.6(b) e A.6(c) são respectivas aos métodos WG, WF e TF, sobre a melhor combinação extrator e valor de $A$, que para os três 
métodos foi Momentos de Cor e $A=10$. Nota-se pelos gráficos que, em média, os resultados tendem a convergir após o quinto ou sexto ciclo de realimentação.

\section{Base Cenas}

Nos experimentos realizados com a base Cenas, Co-ocorrência atingiu o melhor resultado inicial, com média de 20 imagens relevantes recuperadas e Histograma, com o pior resultado, recuperou em média 11 imagens relevantes, considerando as 30 primeiras imagens do ranking. O gráfico de precisão vs. revocação médio das consultas iniciais é apresentado na Figura A.7.

O resultado médio das consultas no décimo ciclo de realimentação foram mais precisos em todos os métodos de otimização quando utilizado o extrator Sobel. O método WG produziu melhores resultados ao utilizar $A=20$, enquanto que para WF e TF, $A=10$ foi a melhor configuração. As Figuras A.8(a), A.8(b) e A.8(c) mostram os resultados médios no décimo ciclo para os métodos WG, WF e TF, respectivamente, para cada extrator. Considerando a revocação em $20 \%$, a precisão atingida por TF é de $67 \%$, sendo superior a precisão atingida por WF, que foi $64 \%$ e, por sua vez, superando a precisão resultante de WG, que foi $61 \%$.

Os extratores com os melhores resultados considerando todas as técnicas e ajuste de $A$, foram Sobel, SIFT e Run Length. Utilizando Sobel (Figura A.9(a)), os métodos TF ( $A=2,10$ e 20) e WF ( $A=10)$ alcançaram $100 \%$ de precisão até uma faixa média de $8 \%$ de revocação, e WF até uma faixa de 6\%. Com o extratores SIFT e Run Length (Figuras A.9(b) e A.9(c)), TF alcançou novamente $8 \%$ de revocação com precisão 100\%, entretanto, WF e WG chegaram ao máximo de $2 \%$ de revocação com a mesma precisão.

Os gráficos de número de imagens relevantes recuperadas em cada ciclo são apresentados na Figura A.10. Na maioria dos casos, o parâmetro $A$ com valor igual a 20 permitiu um maior número de elementos relevantes recuperadas para cada método, seguido de $A=10$. No décimo ciclo, o método TF recuperou em média 30 imagens relevantes utilizando Sobel e SIFT e 28 utilizando Run Length. O método WF recuperou 29, 24 e 23 enquanto que WG recuperou 28, 26 e 25 relevantes em média para Sobel, SIFT e Run Length, respectivamente.

A Figura A.11 apresenta as curvas de precisão vs. revocação da média dos resultados obtidos após cada ciclo de realimentação utilizando o extrator Sobel. Pode-se observar pelos gráficos que WG e WF convergem em torno do terceiro ciclo e TF entre o terceiro e quarto ciclo.

\section{Base Exames Médicos}

O resultado médio de precisão vs. revocação das consultas iniciais da base Exames Médicos para cada extrator é dado pela Figura A.12. O melhor extrator foi Momentos de Cor, que 
recuperou uma média de 26 imagens relevantes, ao passo que o pior foi o Histograma, com 17 imagens relevantes entre as 30 primeiras imagens recuperadas.

Os métodos de ponderação e o método de transformação produziram melhores resultados com a utilização do extrator Sobel. A Figura A.13 apresenta as curvas de precisão vs. revocação dos resultados após dez ciclos de realimentação. Para WG, o melhor valor atribuído a $A$ foi 20 (Figura A.13(a)), e para WF e TF o melhor valor foi 10 (Figuras A.13(b) e A.13(c)). Considerando a revocação em $20 \%$, pode-se notar que para o extrator Sobel, TF, WF e WG obtiveram precisão média de 95\%. Para os extratores baseados em textura, (Co-ocorrência e Run Length), o método TF revelou resultados superiores a WF e WG.

Os gráficos de precisão vs. revocação dos extratores que obtiveram melhores resultados são apresentados na Figura A.14. Na Figura A.14(a), referente aos resultados utilizando Sobel, pode-se observar que os três métodos alcançaram precisão máxima até a faixa de $14 \%$ de revocação. Considerando SIFT (Figura A.14(b)), os métodos de ponderação alcançaram até no máximo $10 \%$ de revocação, enquanto TF alcançou até no $14 \%$ de revocação, com $100 \%$ de precisão. Considerando Run Length (Figura A.14(c)), WG e WF obtiveram 100\% de precisão até $3 \%$ de revocação e TF até $14 \%$.

Na Figura A.15 considera-se os gráficos de relevantes recuperados por ciclo. Todos os métodos recuperaram 30 imagens relevantes entre as 30 primeiras posições do ranking no quinto ciclo ao utilizar o extrator Sobel (Figura A.15(a)). Para o SIFT (Figura A.15(b)), TF recuperou 30 relevantes, superando WG e WF que recuperaram em média 28 relevantes. Com o extrator Run Length (Figura A.15(c)) TF também recuperou 30 relevantes, WG recuperou 28 (para $A=$ 10 e 20 ) e WF recuperou 27 (para $A=10$ e 20 ).

Na Figura A.16 são apresentadas as curvas de precisão vs. revocação em cada ciclo das combinações de extrator e ajuste de $A$ que geraram melhores resultados para cada método. A Figura A.16(a) é referente ao método WG com o parâmetro $A=20$. Os métodos WF e TF são configurados com o parâmetro $A=10$ e os gráficos precisão $v$ s. revocação são ilustrados pelas Figuras A.16(b) e A.16(c), respectivamente. As curvas apresentadas mostram que os métodos convergem em torno do ciclo 5 .

\section{Base Pulmão}

Para os experimentos realizados com a base Pulmão foram consideradas seis imagens de consulta, providas da seleção aleatória de uma imagem de cada classe da base. As consultas iniciais considerando o extrator Momentos de Cor recuperaram o maior número de relevantes que o restante, aproximadamente 13. Consultas com Run Length recuperaram o menor número de relevantes, em média 7. Na Figura A.17 é ilustrado gráfico de precisão vs. revocação ilustra a média dos resultados das consultas iniciais. 
Momentos de Cor obteve melhor desempenho em relação a precisão das consultas resultantes dos métodos de otimização WG, com $A=2$, e WF com $A=10$ (Figuras A.18(a) e A.18(b)). Para otimização por TF, o SIFT obteve o melhor desempenho, com $A=20$ (Figura A.18(c)). Tomando-se $65 \%$ de revocação, WF obteve $32 \%$ de precisão, superando WG, com média de $23 \%$. Com um resultado significativamente superior, o método TF obteve $96 \%$ de precisão, sendo $64 \%$ mais preciso que WF e $73 \%$ mais preciso que WG.

Gráficos de precisão vs. revocação para os três extratores que obtiveram os melhores resultados em relação a precisão máxima são apresentados na Figura A.19. Considerando a revocação em $60 \%$ e o resultados ao utilizar SIFT, Momentos de Cor e Sobel, TF obteve precisão de $100 \%$, enquanto que a média para WF e WG foi $30 \%$, ou seja, TF foi $70 \%$ superior a WF e WG em termos de precisão.

Com relação ao número de relevantes por ciclo, podemos ver na Figura A.20 que, em geral, observando-se cada método individualmente, o número de relevantes recuperados foi maior quando $A=20$. Utilizando o SIFT, TF recuperou no décimo ciclo de realimentação uma média de 28 relevantes, enquanto WG e WF recuperaram apenas 16. Utilizando Momentos de Cor e Sobel, TF novamente recuperou 28 relevantes e WG e WF recuperaram cerca de 22 em média.

Os gráficos da Figura A.21 apresentam os resultados em cada ciclo de realimentação da melhor combinação de extrator e configuração para o parâmetro $A$. Observa-se que até o ciclo 3 , WG e WF tem resultados superiores à TF. A partir do ciclo 4, TF é consideravelmente superior à WG e WF.

\subsubsection{Visualização}

As visualizações apresentadas nesta seção foram realizadas pela ferramenta Metric Space Platform (ou MetricSplat), que combina os benefícios das técnicas de visualização com metodologias para a recuperação de dados baseada em conteúdo, desenvolvida por Rodrigues Jr. (Rodrigues Jr. et al., 2009). Para ilustrar as configurações dos espaços resultantes foi utilizada a projeção FastMap.

Os resultados apresentados a seguir são referentes à visualização de exemplos de consultas sobre uma imagem aleatoriamente selecionada de cada base, utilizando o extrator com o melhor resultado considerando todos os métodos e ajustes do parâmetro $A$, conforme descrito na Seção 6.4.1. São comparados os resultados dessas consultas com otimização dada pelos métodos desenvolvidos, WF e TF, como também o método WG. Para facilitar a análise visual, consideram-se os espaços contendo todos os elementos como também os 50 mais próximos ao centro de consulta para efeito de zoom. Os pontos em vermelho de cada projeção representam 
os elementos da mesma classe semântica do centro de consulta, e os pontos em azul representam elementos de outras classes.

\section{Base Corel 1000}

A representação do espaço original dado pelo extrator Momentos de Cor da base Corel 1000 é ilustrada pela Figura A.22. A configuração do espaço otimizado pelo método WG é mostrada na Figura A.23, e o espaço otimizado por WF é mostrado na Figura A.24. As Figuras A.23(a) e A.24(a) permitem observar que os espaços resultantes conservam a distribuição esparsa dos dados, similar ao espaço original, representado na Figura A.22(a). As Figuras A.23(b) e A.24(b) mostram que WG obteve 16 elementos relevantes e WF obteve 17 relevantes entre os 50 mais próximos ao centro de consulta, melhorando o resultado inicial de 9 relevantes, ilustrado pela Figura A.22(b).

Comparando o método de transformação com as abordagens de ponderação, pode ser visto na Figura A.25(a) que o espaço resultante é mais "denso", com uma concentração maior de elementos relevantes próximos ao centro. Como ilustrado na Figura A.25(b), TF resultou em 33 elementos relevantes entre os 50 primeiros elementos, aproximadamente $94 \%$ mais elementos positivos do que o resultado por WF.

\section{Base Cenas}

O espaço original obtido pelo extrator Sobel para a base Cenas é representado na Figura A.26. Após a otimização por WG, a configuração resultante é apresentada pela Figura A.27. As Figuras A.28 e Figuras A.29 mostram as representações resultantes dos métodos WF e TF, respectivamente.

A configuração dada por WF apresenta uma maior dispersão dos dados do que a configuração inicial, como pode ser visto pelas Figuras A.26(a) e Figuras A.27(a). Quanto a configuração dada por TF, foi relativamente mantida a distribuição dos elementos não relevantes, enquanto que houve uma aproximação dos elementos relevantes entre si e mais próximo ao centro de consulta.

É possível perceber que todos os métodos aumentaram o número de elementos relevantes entre os 50 mais próximos ao centro, como mostrado nas Figuras A.27(b) para WG (25 relevantes), A.28(b) par WF (36 relevantes) e A.29(b) para TF (36 relevantes), comparados ao resultado inicial (21 elementos relevantes). Percebe-se também que WF e TF obtiveram melhores resultados pois retornaram um menor número de falsos positivos entre os 50 mais próximos do elemento de consulta. 


\section{Base Exames Médicos}

As visualizações geradas para a base Exames Médicos correspondem ao espaço gerado pelo extrator Sobel, que obteve, em geral, o melhor resultado em termos de precisão e revocação nos experimentos para esta base. A representação do espaço inicial é dada pela Figura A.30.

A Figura A.31 mostra o espaço resultante otimizado por WG. O espaço final obteve uma distribuição dos dados mais regular do que a apresentada na configuração inicial (Figura A.30(a)), como pode ser visto pela Figura A.31(a). Os métodos WF e TF obtiveram uma distribuição em que os elementos positivos se concentraram de forma mais densa no centro do espaço (Figuras A.32(a) e A.33(a)). Com relação aos 50 elementos mais próximos, podemos ver pelas Figuras A.31(b), A.32(b) e A.33(b) que WF (com 34 elementos relevantes recuperados) e TF (com 36 relevantes recuperados) foram superiores à WG (com 25 relevantes recuperados) por obterem menos falsos positivos.

\section{Base Pulmão}

O SIFT foi utilizado para representar o espaço para a análise visual da base Pulmão, mantendo a escolha do extrator com melhor desempenho de precisão e revocação. A Figura A.34 ilustra a configuração do espaço original gerado pelo extrator. Os espaços resultantes da otimização pelos métodos WG, WF e TF são ilustradas pelas Figuras A.35, A.36 e A.37, respectivamente.

De maneira geral, pelas Figuras A.35(a), A.36(a) e A.37(a) pode-se perceber que os três métodos geraram uma distribuição aparentemente similar, onde os elementos não relevantes tendem a formar um agrupamento (ou cluster) e os elementos relevantes se encontram mais espalhados. A melhor configuração entretanto é a gerada por TF, em que os elementos negativos ficaram mais próximos entre si e mais distantes do centro. Dentre os 50 elementos mais próximos ao centro, onde a consulta inicial recuperou 13 elementos relevantes, o melhor resultado foi obtido por TF que recuperou 31 elementos relevantes, seguido por WF, com 22 elementos relevantes e por último WG, com 18 elementos relevantes, como mostrado pelas Figuras A.35(b), A.36(b) e A.37(b).

\subsubsection{Discussões Gerais dos Resultados}

Os resultados apresentados na Seção 6.4.1, considerando curvas de precisão e revocação, mostram que os métodos propostos foram eficazes em melhorar os resultados das consultas por similaridade. Os resultados dos experimentos mostram que o método de transformação (TF) obteve acurácia muito superior aos métodos de ponderação (WF e WG) em todos os casos, com precisão até $70 \%$ maior (Figura A.19). 
As visualizações apresentadas na Seção 6.4.2, que comparam a configuração dos espaços de dados originais com os espaços resultantes das otimizações, mostram que o método de transformação (TF) foi mais eficaz em agrupar os dados relevantes de maneira a aproximá-los do centro de consulta considerado. O método de ponderação de atributos por funções (WF), comparado à ponderação clássica analisada (WG), foi mais eficaz em representar as dissimilaridades dos dados considerando os elementos mais próximos ao centro de consulta. Este fato confirma a hipótese de que a busca por pesos em um espaço de busca discreto pode levar a uma solução mais precisa do que a busca de pesos em espaços contínuos de busca (Seção 5.3).

Os experimentos foram conduzidos considerando vários extratores (Momentos de Cor, Co-ocorrência, Sobel, Histograma, Run Length e SIFT). Para as bases de Exames Médicos e Cenas, o extrator de forma Sobel obteve os melhores resultados em precisão após feitas as otimizações. Considerando a base Corel 1000, o extrator que obteve maior precisão nos experimentos foi Momentos de Cor, enquanto que para a base Pulmão, o SIFT obteve melhor precisão.

Outra configuração para os experimentos considerou o ajuste de valores para o parâmetro $A$ da função de aptidão do algoritmo genético. Como discutido anteriormente, valores maiores para este parâmetro diminuem a influência da posição dos elementos relevantes nas primeiras posições do ranking. Analisando os gráficos apresentados na Seção 6.4.1, na maioria dos casos o melhor valor de ajuste para o parâmetro foi $A=20$, considerando consultas $k N N$ com $k=30$.

Com o objetivo de comprovar a generalidade da aplicação dos métodos, os experimentos foram realizados considerando domínios de imagens diversas e domínio de imagens médicas. De fato, a análise dos gráficos de precisão e revocação bem como a análise visual (visualização) dos espaços resultantes comprovaram que as metodologias de otimização propostas podem ser aplicadas em contextos gerais de domínio de imagens. Considerando os experimentos da base Pulmão, que obtiveram melhorias muito significativas, principalmente com o método de transformação, foi mostrado que mesmo conjuntos de imagens de difícil classificação até mesmo para especialistas do domínio, podem se beneficiar desta metodologia.

\subsection{Considerações Finais}

Neste capítulo foram apresentados os resultados dos métodos propostos que buscam aprimorar a recuperação de imagens por conteúdo. Os resultados das técnicas de otimização por funções de ponderação e funções de transformação foram comparados à técnica clássica de ponderação. 
Gráficos de precisão vs. revocação foram utilizados para demonstrar a precisão dos métodos, considerando os extratores utilizados e o parâmetro da função de aptidão do algoritmo genético.

As visualizações apresentadas foram importantes para mostrar, de maneira mais natural e direta, a influência de cada método na distribuição dos dados após a otimização. Além disso, foi realizada uma discussão geral sobre os resultados obtidos nos experimentos. O capítulo seguinte sumariza as contribuições e conclusões deste trabalho, bem como propõe perspectivas de trabalhos futuros. 


\section{Capítulo

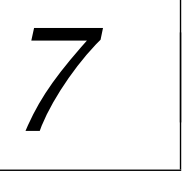

Conclusões

\subsection{Considerações Finais}

A recuperação de imagens baseada em conteúdo tem sido alvo de pesquisas para desenvolvimento de técnicas que objetivam atenuar o problema da lacuna semântica. Uma abordagem muito comum presente nessas pesquisas é a adequação de medidas de similaridade ao conjunto de imagens do domínio. A adequação de medidas de similaridade na maioria dos casos é obtida por vetores de ponderação para quantificar a contribuição de cada atributo nos cálculos de distância. Por considerar um intervalo contínuo para os pesos possíveis, a busca pelos vetores de pesos é prejudicada pelo tamanho (infinito) do espaço de busca para o problema.

Outras metodologias existentes atuam diretamente no espaço de características realizando transformações sobre este. Um exemplo para esta abordagem são as técnicas de seleção de características. O conjunto de características resultante possui dimensão reduzida, e é equivalente a ponderação de atributos considerando pesos binários. A principal limitação dessas técnicas é considerar apenas as relações lineares sobre o espaço de dados.

Um dos métodos desenvolvidos neste trabalho de mestrado permite que as buscas por vetores de ponderação sejam feitas em espaços de tamanho reduzidos (finitos). O uso de funções para a redução do espaço de busca permitiu resultados mais precisos. Outro método desenvolvido faz transformações não lineares nos espaços de características como forma de considerar as possíveis relações não lineares inerentes destes espaços. 
Os resultados mostraram que o método de transformação obteve precisão muito superior aos métodos de ponderação, o que nos leva a concluir que as correlações não lineares podem descrever melhor as relações semânticas entre os dados. Além disso, as visualizações geradas para os espaços resultantes das otimizações mostraram que o método de transformação gerou espaços que melhor refletiram à semântica dos dados em sua configuração espacial por agrupar e aproximar os objetos relevantes ao centro de consulta.

\subsection{Principais Contribuições}

Neste projeto foram desenvolvidos dois métodos para otimizar consultas por similaridade e melhorar a eficácia de sistemas CBIR. A otimização é feita por meio de algoritmos genéticos com o suporte de realimentação de relevância. Resumidamente, as principais contribuições deste projeto de mestrado são:

- Definição e desenvolvimento do método de ponderação por funções ponderadoras (WF) para o ajuste dinâmico de funções de dissimilaridade.

- Definição e desenvolvimento do método de transformação de espaço de características por funções de transformação não lineares (TF).

- Desenvolvimento de um protótipo para sistema CBIR, apoiado por realimentação de relevância e otimização de consultas por similaridade por meio de transformações em espaços métricos.

- Análise dos desempenhos obtidos por diferentes extratores de características.

- Análise da influência do parâmetro da função de avaliação de qualidade de ranking para consultas por similaridade considerando diferentes extratores de características e os métodos de otimização desenvolvidos.

- Análise visual dos espaços resultantes dos métodos de ponderação e transformação desenvolvidos para observar a configuração espacial dos objetos.

\subsection{Trabalhos Futuros}

Durante o desenvolvimento e experimentação dos métodos desenvolvidos surgiram algumas possibilidades de trabalhos futuros, dentre as quais apresentamos a seguir: 
- Combinar as técnicas de ponderação e transformação, avaliando o desempenho dessas técnicas aplicadas em conjunto.

- Aplicar outras funções de distância nos cálculos de similaridade e avaliar a influência de cada função nos métodos de otimização desenvolvidos.

- Permitir que a avaliação dos resultados das consultas feitas pelo usuário nos ciclos de realimentação de relevância possa considerar diferentes graus de relevância para as imagens a fim de obter resultados mais precisos.

- Investigar possíveis aplicabilidades de transformação de espaços métricos para otimizar consultas por similaridade como etapa de pré-processamento, tornando os métodos independentes de centros de consultas.

\subsection{Publicação}

O desenvolvimento deste projeto de mestrado resultou em um artigo científico intitulado: "Image Retrieval Employing Genetic Dissimilarity Weighting and Feature Space Transformation Functions" aceito para publicação no ACM - Symposium on Applied Computing (SAC), que acontecerá em março de 2012 na Itália. 



\section{Referências Bibliográficas}

Aksoy, S., Haralick, R. M., Cheikh, F. A., and Gabbouj, M. (2000). A weighted distance approach to relevance feedback. In Proceedings of the International Conference on Pattern Recognition (ICPRO0), pages 812-815.

Alemu, Y., bin Koh, J., Ikram, M., and Kim, D.-K. (2009). Image retrieval in multimedia databases: A survey. In International Conference on Intelligent Information Hiding and Multimedia Signal Processing, volume 0, pages 681-689, Los Alamitos, CA, USA. IEEE Computer Society.

Aslandogan, Y. and Yu, C. (1999). Techniques and systems for image and video retrieval. Knowledge and Data Engineering, IEEE Transactions on, 11(1):56 -63.

Avalhais, L. P. S., da Silva, S. F., Rodrigues Jr., J. F., and Traina, A. J. M. (2012). Image retrieval employing genetic dissimilarity weighting and feature space transformation functions. To Be Published on Inproceedings of ACM/SAC.

Berchtold, S., Bohm, C., and Kriegel, H.-P. (1998). The pyramid-tree: Breaking the curse of dimensionality. In ACM SIGMOD International Conference on Management of Data, pages 142-153, Seattle, WA.

Brandt, S. (1999). Use of shape features in content-based image retrieval. Master's thesis, Helsinki University of Technology.

Bruls, M., Huizing, K., and van Wijk, J. (2000). Squarified treemaps. In Proc. of Joint Eurographics and IEEE TCVG Symp. on Visualization (TCVG 2000), pages 33-42. IEEE Press.

Bugatti, P., Traina, A., and Traina, C. (2011). Improving content-based retrieval of medical images through dynamic distance on relevance feedback. In $C B M S$, pages $1-6$. 
Bugatti, P. H., Traina, A. J. M., and Traina, Jr., C. (2008). Assessing the best integration between distance-function and image-feature to answer similarity queries. In Proceedings of the 2008 ACM SAC, pages 1225-1230, New York, NY, USA.

Card, S. K., Mackinlay, J. D., and Shneiderman, B. (1999). Readings in information visualization: using vision to think. Morgan Kaufmann Publishers Inc., San Francisco, CA, USA.

Card, S. K., Newell, A., and Moran, T. P. (1983). The Psychology of Human-Computer Interaction. L. Erlbaum Associates Inc., Hillsdale, NJ, USA.

Catarci, T. (1997). Interacting with databases in the global information infrastructure. Cотmиnications Magazine, IEEE, 35(5):72-76.

Chávez, E., Navarro, G., Baeza-Yates, R., and Marroquín, J. L. (2001). Searching in metric spaces. ACM Comput. Surv., 33:273-321.

Chen, X., Ye, Y., Xu, X., and Huang, J. Z. (2012). A feature group weighting method for subspace clustering of high-dimensional data. Pattern Recogn., 45:434-446.

Chernoff, H. (1973). The use of faces to represent points in k-dimensional space graphically. Journal of the American Statistical Association, 8:361-368.

Chino, F. J. T. (2004). Visualizando a organização e o comportamento de estruturas métricas: aplicações em consultas por similaridade. Master's thesis, Instituto de Ciências Matemáticas e de Computação (ICMC).

Ciaccia, P. and Patella, M. (2002). Searching in metric spaces with user-defined and approximate distances. ACM Trans. Database Syst., 27:398-437.

Ciaccia, P., Patella, M., and Zezula, P. (1997). M-tree: An efficient access method for similarity search in metric spaces. In Jarke, M., editor, Proceedings of 23rd International Conference on Very Large Data Bases (VLDB), pages 426-435, Athens, Greece. Morgan Kaufmann Publishers.

da Silva, S. F. (2011). Seleção de características por meio de algoritmos genéticos para aprimoramento de rankings e de modelos de classificação. $\mathrm{PhD}$ thesis, Instituto de Ciências Matemáticas e de Computação (ICMC-USP).

da Silva, S. F., Ribeiro, M. X., do E.S. Batista Neto, J., Traina-Jr., C., and Traina, A. J. (2011). Improving the ranking quality of medical image retrieval using a genetic feature selection method. DSS, In Press:1-11.

de Oliveira, M. C. F. and Levkowitz, H. (2003). From visual data exploration to visual data mining: A survey. IEEE Transactions on Visualization and Computer Graphics, 9(3):378-394.

Faloutsos, C. and Lin, K.-I. (1995). Fastmap: A fast algorithm for indexing, data-mining and visualization of traditional and multimedia datasets. In Carey, M. J. and Schneider, D. A., editors, Proceedings of the 1995 ACM SIGMOD International Conference on Management of Data, San Jose, California, May 22-25, 1995, pages 163-174. ACM Press. 
Guldogan, E. and Gabbouj, M. (2008). Feature selection for content-based image retrieval. Signal Image and Video Processing, 2(3):241-250.

Haralick, R. M., Shanmugam, K., and Dinstein, I. (1973). Textural Features for Image Classification. IEEE/SMC, 3:610-621.

Holland, J. H. (1975). Adaptation in natural and artificial systems: An Introductory Analysis with Applications to Biology, Control and Artificial Intelligence. MIT Press, Cambridge, MA, USA.

Horowitz, E. and Sahni, S. (1974). Computing partitions with applications to the knapsack problem. J. ACM, 21:277-292.

Hotelling, H. (1933). Analysis of a complex of statistical variables into principal components. Journal of Educational Psychology, 24:417-441.

Huang, J., Kumar, S. R., and Mitra, M. (1997). Combining supervised learning with color correlograms for content-based image retrieval. In Multimedia 97: Proceedings of the fifth ACM international conference on Multimedia, pages 325-334, New York, NY, USA. ACM.

Inselberg, A. and Dimsdale, B. (1990). Parallel coordinates: a tool for visualizing multi-dimensional geometry. In VIS '90: Proceedings of the 1st conference on Visualization '90, pages 361-378, Los Alamitos, CA, USA. IEEE Computer Society Press.

Kandogan, E. (2000). Star coordinates: A multi-dimensional visualization technique with uniform treatment of dimensions. In In Proceedings of the IEEE Information Visualization Symposium, Late Breaking Hot Topics, pages 9-12.

Keim, D., Andrienko, G., Fekete, J.-D., Görg, C., Kohlhammer, J., and Melançon, G. (2008). Visual analytics: Definition, process, and challenges. In Information Visualization: Human-Centered Issues and Perspectives, pages 154-175. Springer-Verlag, Berlin, Heidelberg.

Keim, D. A. (1997). Visual database exploration techniques. In Tutorial KDD '97 at the International Conference on Knowledge Discovery and Data Mining.

Keim, D. A. (2002). Information visualization and visual data mining. IEEE Transactions on Visualization and Computer Graphics, 8(1):1-8.

Keim, D. A., Mansmann, F., Schneidewind, J., and Ziegler, H. (2006). Challenges in visual data analysis. In IV'06: Proceedings of the conference on Information Visualization, pages 9-16, Washington, DC, USA. IEEE Computer Society.

Lakdashti, A., Shahram Moin, M., and Badie, K. (2008). Semantic-based image retrieval: A fuzzy modeling approach. In AICCSA 2008. IEEE/ACS., pages 575-581.

Lawler, E. (1985). The Traveling Salesman Problem: A Guided Tour of Combinatorial Optimization. Wiley, New York. 
Li, J. and Wang, J. Z. (2003). Automatic linguistic indexing of pictures by a statistical modeling approach. IEEE/TPAMI, 25:1075-1088.

Loh, H.-H., Leu, J.-G., and Luo, R. (1988). The analysis of natural textures using run length features. Industrial Electronics, IEEE Transactions on, 35(2):323 -328.

López-Pujalte, C., Guerrero-Bote, V. P., and de Moya-Anegón, F. (2003). Order-based fitness functions for genetic algorithms applied to relevance feedback. J. Am. Soc. Inf. Sci. Technol., 54:152-160.

Lowe, D. G. (1999). Object recognition from local scale-invariant features. In ICCV, IEEE, volume 2, pages 1150-1157, Los Alamitos, CA, USA.

Ltifi, H., Ayed, M. B., Alimi, A. M., and Lepreux, S. (2009). Survey of information visualization techniques for exploitation in kdd. Computer Systems and Applications, ACS/IEEE International Conference on, 0:218-225.

MacArthur, S. D., Brodley, C. E., Kak, A. C., and Broderick, L. S. (2002). Interactive content-based image retrieval using relevance feedback. Comput. Vis. Image Underst., 88(2):55-75.

Nguyen, M.H., d. 1. T. F. (2010). Optimal feature selection for support vector machines. Pattern Recogn., 43:584-591.

Nocedal, J. and Wright, S. J. (2000). Numerical Optimization. Springer.

Oliva, A. and Torralba, A. (2001). Modeling the shape of the scene: A holistic representation of the spatial envelope. International Journal of Computer Vision, 42:145-175.

Paulovich, F. V., Nonato, L. G., Minghim, R., and Levkowitz, H. (2008). Least square projection: A fast high-precision multidimensional projection technique and its application to document mapping. IEEE Transactions on Visualization and Computer Graphics, 14(3):564-575.

Pearson, K. (1901). On lines and planes of closest fit to systems of points in space. Philosophical Magazine, 2(6):559-572.

Pickett, R. and Grinstein, G. (1988). Iconographic displays for visualizing multidimensional data. In Systems, Man, and Cybernetics, 1988. Proceedings of the 1988 IEEE International Conference on, volume 1, pages 514-519.

Rahman, M., Antani, S., and Thoma, G. (2011). A learning-based similarity fusion and filtering approach for biomedical image retrieval using svm classification and relevance feedback. Information Technology in Biomedicine, IEEE Transactions on, 15(4):640 -646.

Rao, R. and Card, S. K. (1994). The table lens: merging graphical and symbolic representations in an interactive focus + context visualization for tabular information. In CHI, pages 318-322.

Robertson, G. G., Mackinlay, J. D., and Card, S. K. (1991). Cone trees: animated 3D visualizations of hierarchical information. In CHI '91: Proceedings of the SIGCHI conference on Human factors in computing systems, pages 189-194, New York, NY, USA. ACM. 
Rocchio, J. (1971). Relevance Feedback in Information Retrieval, chapter x, pages 313-323. Prentice Hall.

Rodrigues Jr., J. F. (2003). Desenvolvimento de um framework para análise visual de informações suportando data mining. Master's thesis, Instituto de Ciências Matemáticas e de Computação (ICMC).

Rodrigues Jr., J. F., Traina, A. J. M., and Traina, Jr., C. (2005). Enhanced visual evaluation of feature extractors for image mining. In AICCSA '05: Proceedings of the ACS/IEEE 2005 International Conference on Computer Systems and Applications, pages 45-I, Washington, DC, USA. IEEE Computer Society.

Rodrigues Jr., J. F., Zaina, L. A. M., Romani, L. A. S., and Ciferri, R. R. (2009). Metricsplat - a platform for quick development, testing and visualization of content-based retrieval techniques. In Simpósio Brasileiro de Banco de Dados.

Salton, G. E. (1989). Automatic text processing. Addison-Wesley Longman Publishing Co., Inc., Boston, MA, USA.

Shneiderman, B. (1991). Tree visualization with tree-maps: A 2D space-filling approach. $A C M$ Transactions on Graphics, 11:92-99.

Shneiderman, B. (1996). The eyes have it: A task by data type taxonomy for information visualizations. Visual Languages, IEEE Symposium on, 0:336.

Shrinivasan, Y. B. and van Wijk, J. J. (2008). Supporting the analytical reasoning process in information visualization. In CHI '08: Proceeding of the twenty-sixth annual SIGCHI conference on Human factors in computing systems, pages 1237-1246, New York, NY, USA. ACM.

Siau, K. and Tan, X. (2006). Cognitive mapping techniques for user-database interaction. Professional Communication, IEEE Transactions on, 49(2):96-108.

Stricker, M. A. and Orengo, M. (1995). Similarity of color images. In Storage and Retrieval for Image and Video Databases, pages 381-392.

Sun, W. and Yuan, Y.-X. (2006). Optimization Theory and Methods: Nonlinear Programming. Springer.

Sun, Y. and Bhanu, B. (2010). Image retrieval with feature selection and relevance feedback. In Image Processing (ICIP), 2010 17th IEEE International Conference on, pages 3209 -3212.

Thomas, J. J. and Cook, K. A. (2005). Illuminating the Path: The Research and Development Agenda for Visual Analytics. National Visualization and Analytics Ctr.

Torres, R. d. S., Falcão, A. X., Gonçalves, M. A., Papa, J. a. P., Zhang, B., Fan, W., and Fox, E. A. (2009). A genetic programming framework for content-based image retrieval. Pattern Recogn., 42:283-292. 
Traina, A. J. M., Marques, J., and Jr., C. T. (2006). Fighting the semantic gap on cbir systems through new relevance feedback techniques. Computer-Based Medical Systems, IEEE Symposium on, 0:881-886.

Traina, Jr., C., Filho, R. F., Traina, A. J., Vieira, M. R., and Faloutsos, C. (2007). The omni-family of all-purpose access methods: a simple and effective way to make similarity search more efficient. The VLDB Journal, 16(4):483-505.

Traina, Caetano, J., Traina, A. J. M., Seeger, B., and Faloutsos, C. (2000a). Slim-trees: High performance metric trees minimizing overlap between nodes. In Zaniolo, C., Lockemann, P. C., Scholl, M. H., and Grust, T., editors, International Conference on Extending Database Technology (EDBT), volume 1777 of Lecture Notes in Computer Science, pages 51-65, Konstanz, Germany. Springer.

Traina, Caetano, J., Traina, A. J. M., Wu, L., and Faloutsos, C. (2000b). Fast feature selection using fractal dimension. In Medeiros, C. M. B. and Becker, K., editors, Brazilian Symposium on Databases (SBBD), pages 158-171, João Pessoa, PB.

Ward, M. (1994). Xmdvtool: integrating multiple methods for visualizing multivariate data. In Visualization, 1994., Visualization '94, Proceedings., IEEE Conference on, pages 326-333.

Wettschereck, D., Aha, D. W., and Mohri, T. (1997). A review and empirical evaluation of feature weighting methods for a class of lazy learning algorithms. Artificial Intelligence Review, 11:273-314.

Zezula, P., Amato, G., Dohnal, V., and Batko, M. (2006). Similarity Search: The Metric Space Approach, volume 32 of Advances in Database Systems. Springer.

Zhang, C., Meng, W., Zhang, Z., and Wu, Z. (2000). Webssql-a query language for multimedia web documents. In Advances in Digital Libraries, 2000. ADL 2000. Proceedings. IEEE, pages $58-67$.

Zhang, L., Coenen, F., and Leng, P. (2003). Setting attribute weights for k-nn based binary classification via quadratic programming. Intell. Data Anal., 7:427-441.

Zhou, X. and Huang, T. (2001). Exploring the nature and variants of relevance feedback. In Content-Based Access of Image and Video Libraries, 2001. (CBAIVL 2001). IEEE Workshop on, pages $94-101$. 


\section{APÊNDICE}

\section{$A$}

\section{Gráficos e Visualizações dos Resultados Experimentais}

Neste apêndice são apresentados os gráficos e as visualizações para os resultados discutidos no Capítulo 6.

\section{A.1 Gráficos de Precisão e Revocação e Número de Relevantes por Ciclo}

Os gráficos precisão vs. revocação e número de relevantes vs. ciclos construídos estão organizados de acordo com o conjunto de imagens. Para cada conjunto, primeiramente é mostrado o resultado da consulta inicial para cada extrator. São apresentados também os resultados obtidos após o décimo ciclo de realimentação, considerando cada método e ajuste do parâmetro $A$ da função de avaliação de ranking. 
Corel 1000

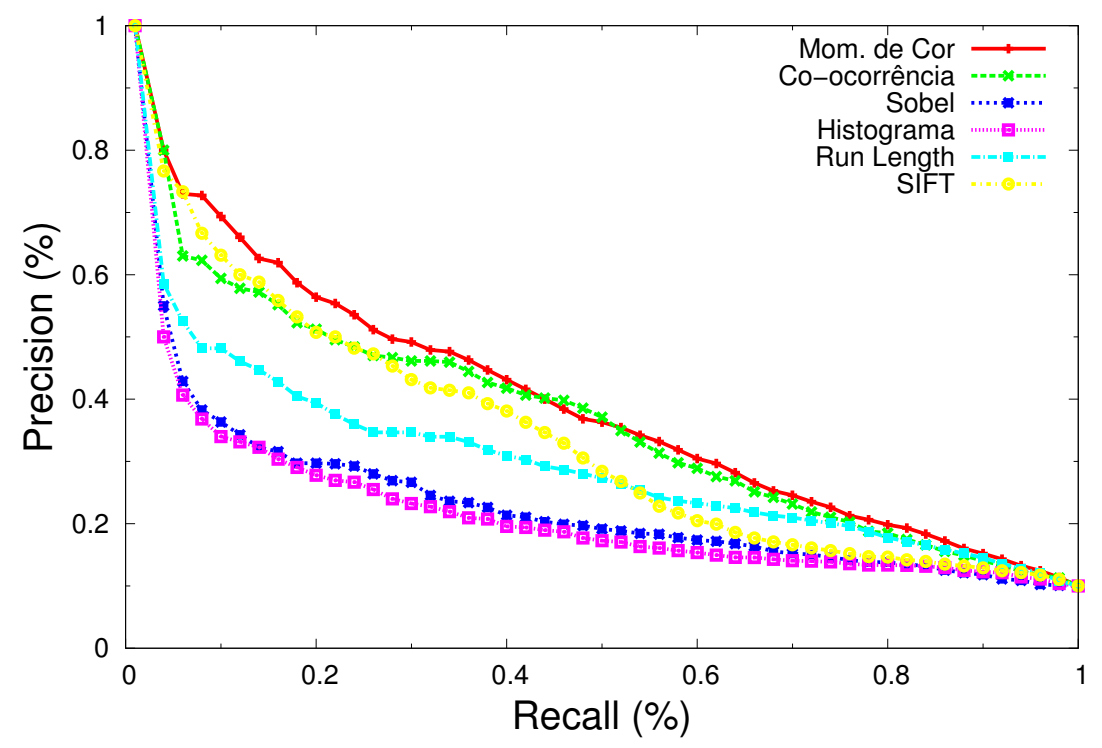

Figura A.1: Precisão vs. Revocação da consulta inicial para cada extrator. 


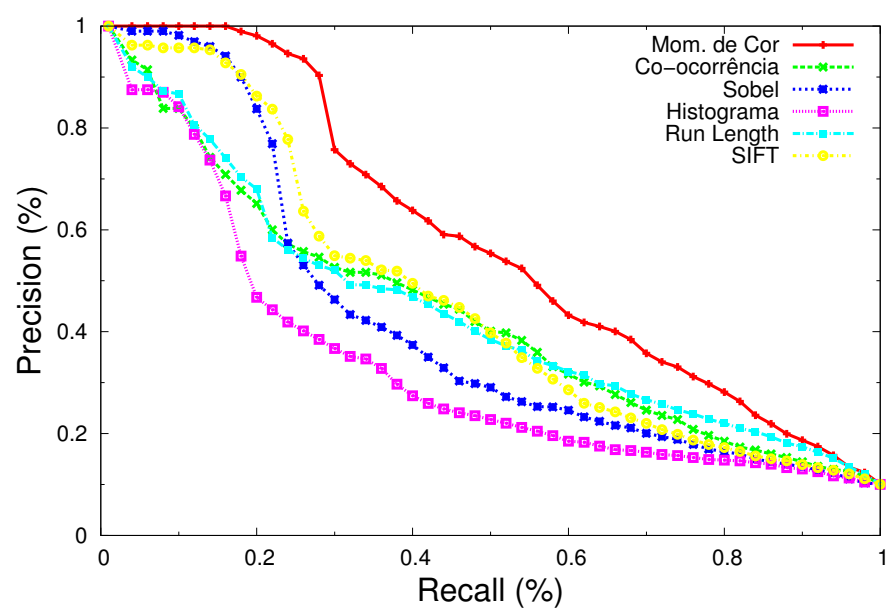

(a) WG, $A=10$.

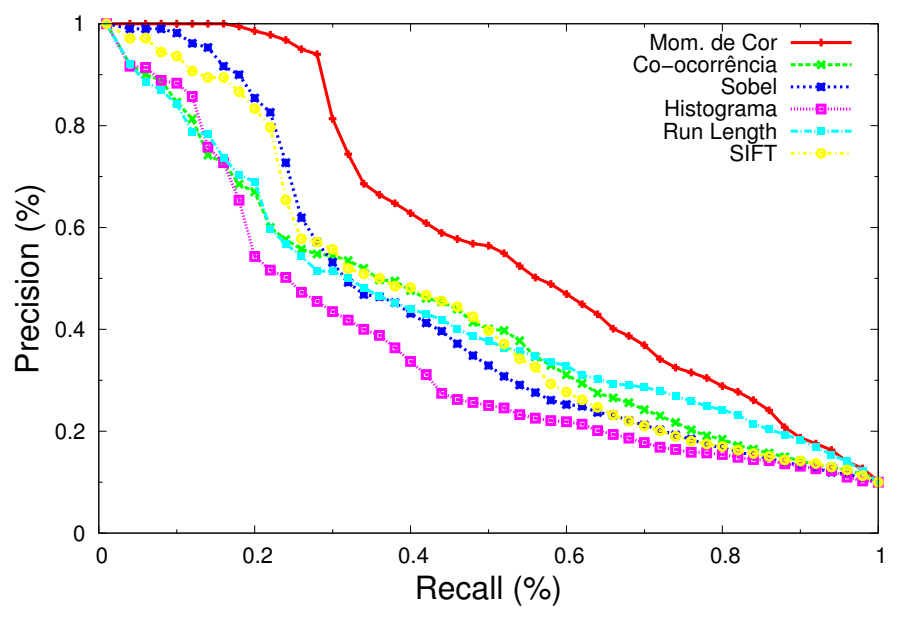

(b) WF, $A=10$.

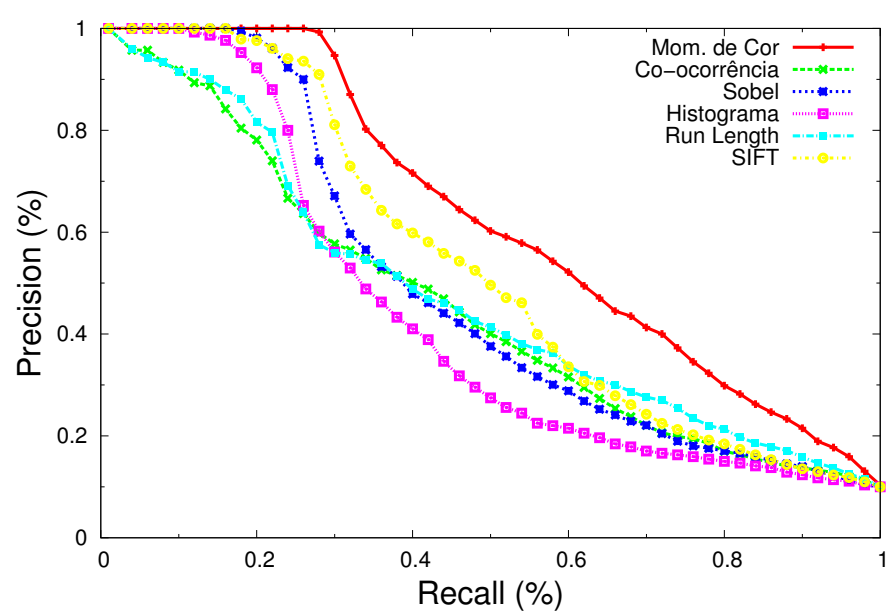

(c) $\mathrm{TF}, A=10$.

Figura A.2: Precisão vs. Revocação no ciclo 10, (a) WG, $A=2$ (b) WG, $A=10$ (c) WG, $A=20$ (d) WF, $A=2$ (e) WF, $A=10$ (f) WF, $A=20$ (g) TF, $A=2$ (h) TF, $A=10$ (i) TF, $A=20$. 
Corel 1000

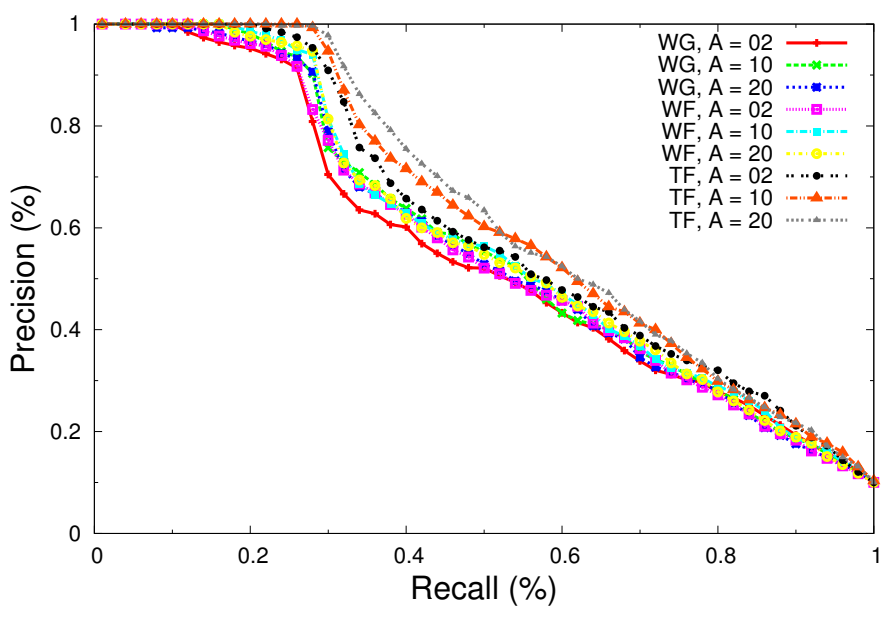

(a) Momentos de Cor.

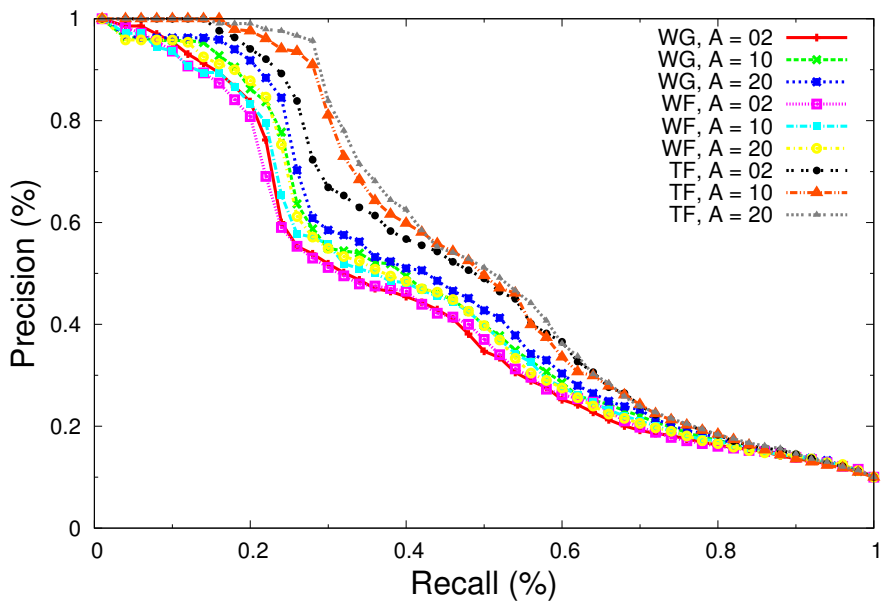

(b) SIFT.

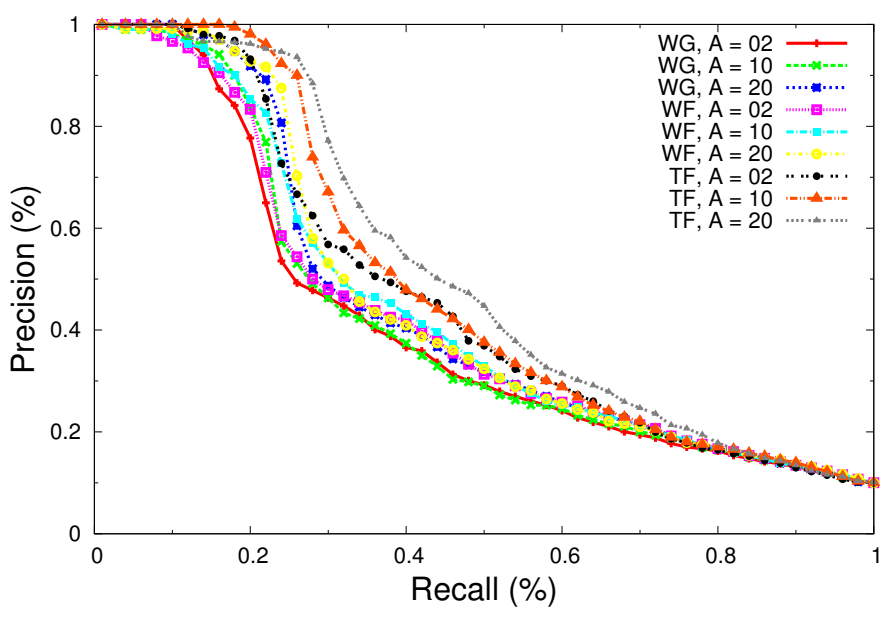

(c) Sobel.

Figura A.3: Precisão vs. Revocação para cada método e cada valor de $A$ utilizando os extratores (a) Momentos de Cor (b) SIFT (c) Sobel. 
Corel 1000

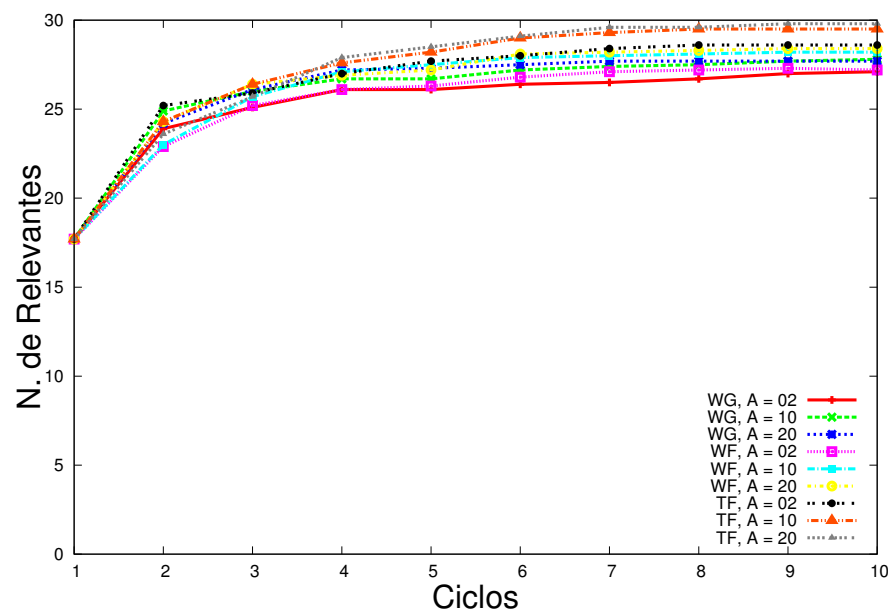

(a) Momentos de Cor.

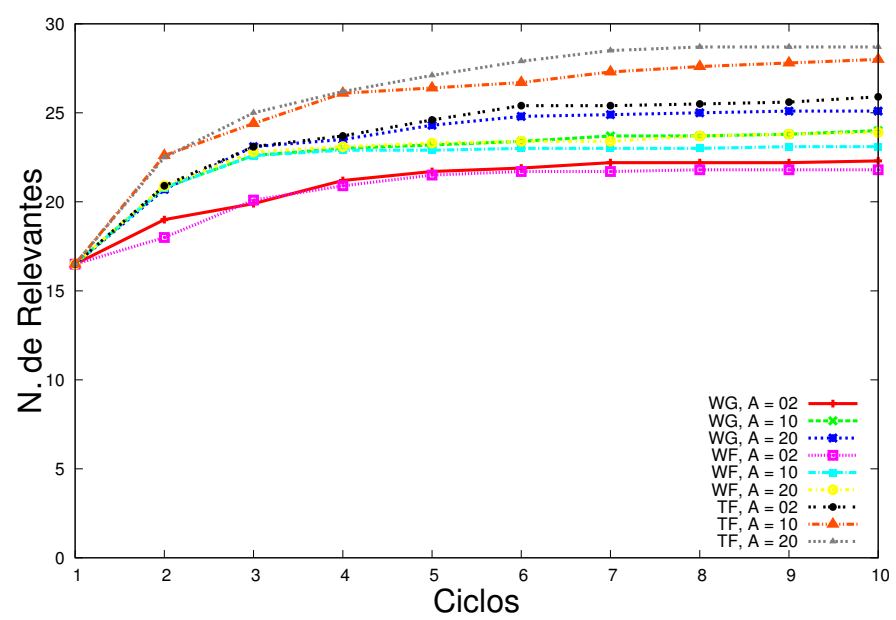

(b) SIFT.

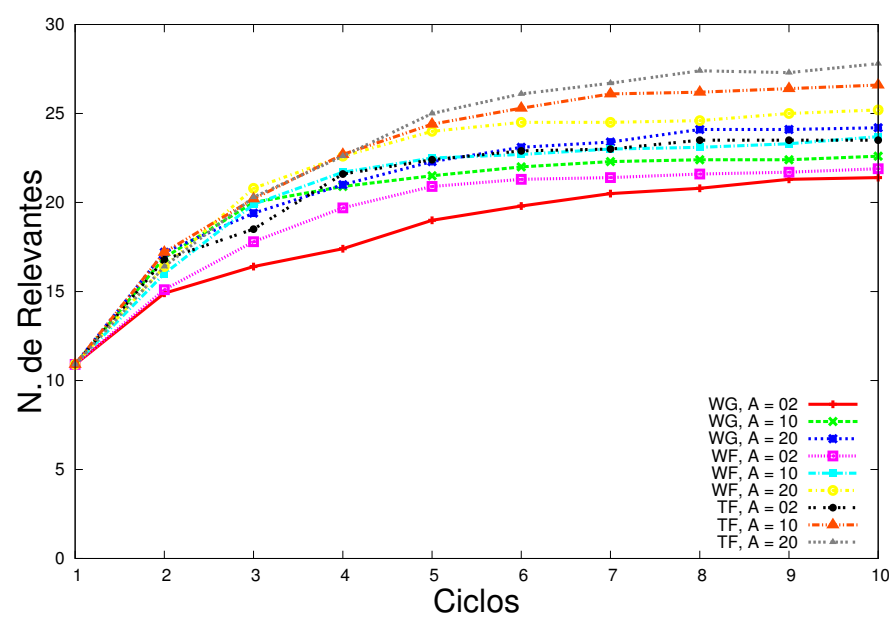

(c) Sobel.

Figura A.4: Número de Relevantes vs. Ciclos para cada método e cada valor de $A$ utilizando os extratores (a) Momentos de Cor (b) SIFT (c) Sobel. 
Corel 1000

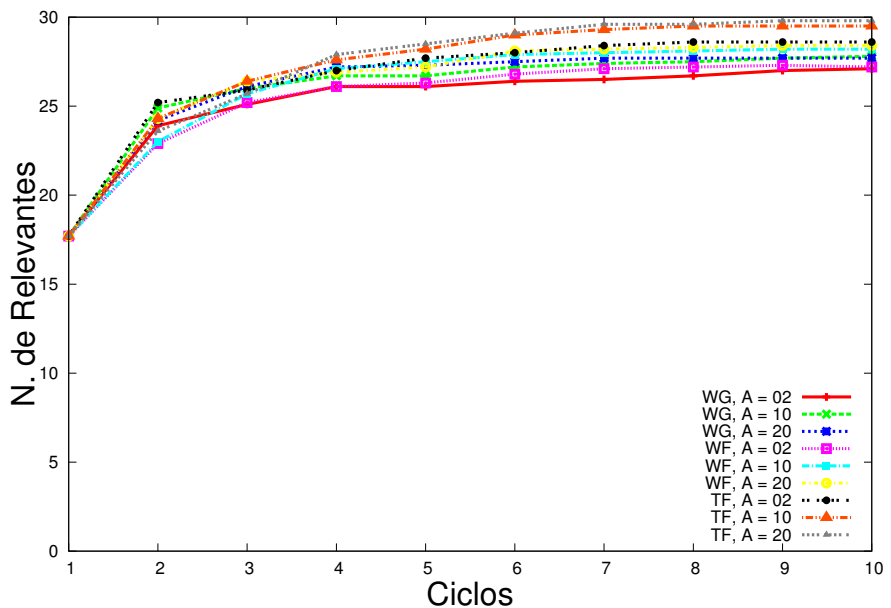

(a) Momentos de Cor.

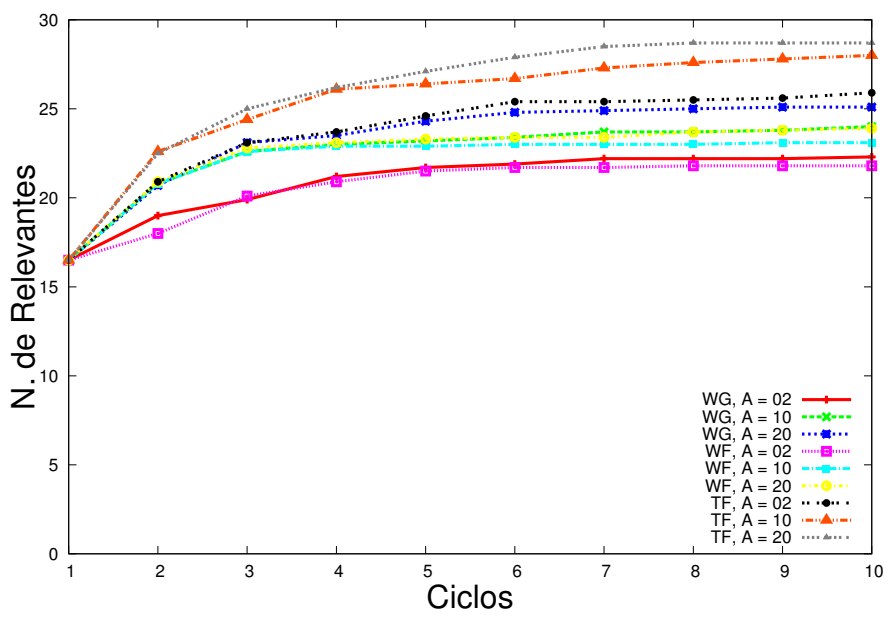

(b) SIFT.

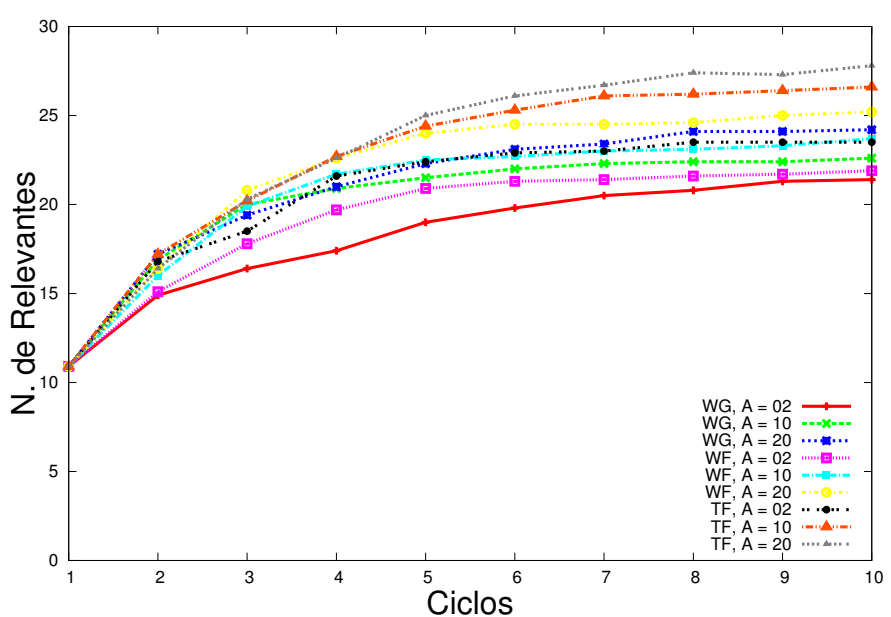

(c) Sobel.

Figura A.5: Número de Relevantes vs. Ciclos para cada método e cada valor de $A$ utilizando os extratores (a) Momentos de Cor (b) SIFT (c) Sobel. 


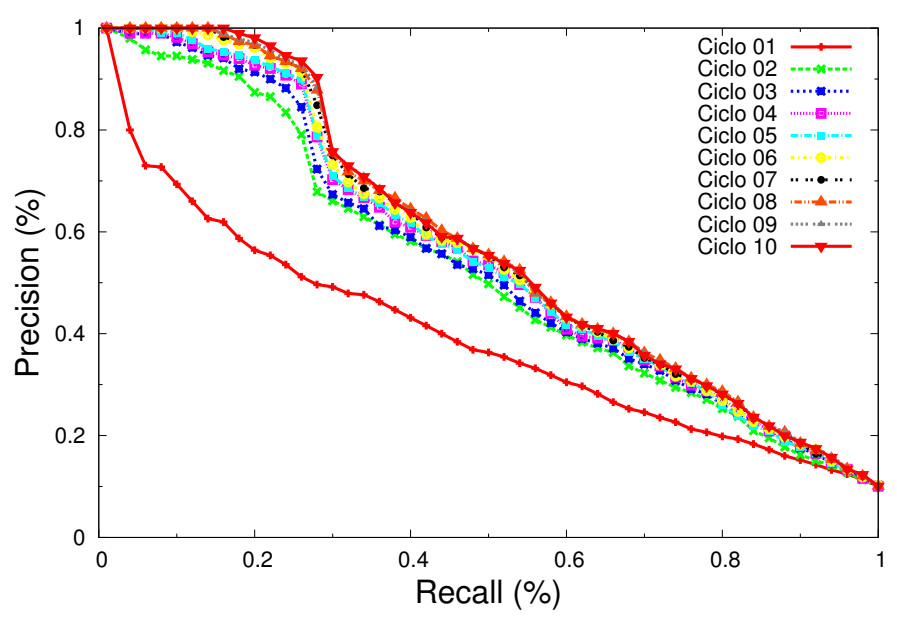

(a) WG, $A=10$.

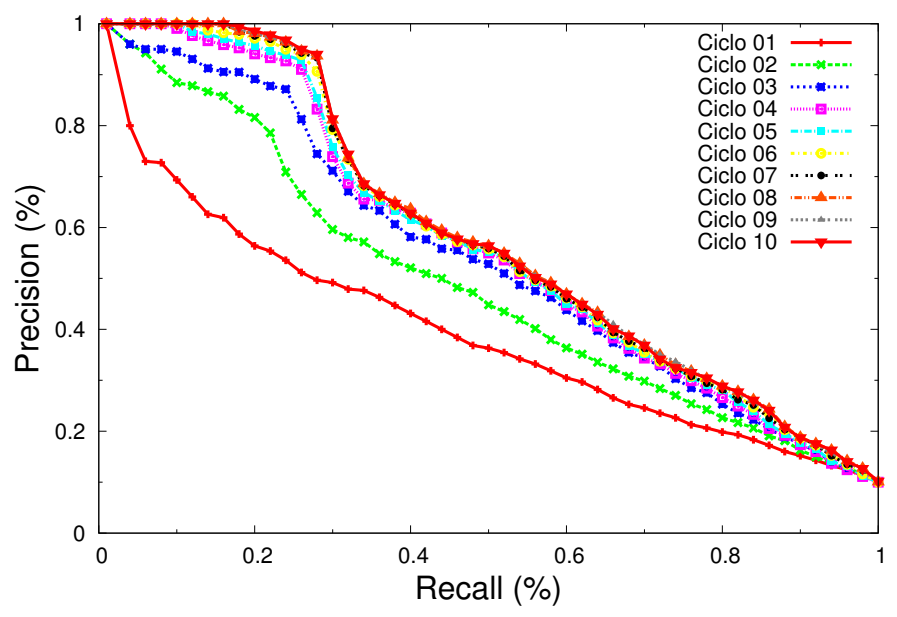

(b) WF, $A=10$.

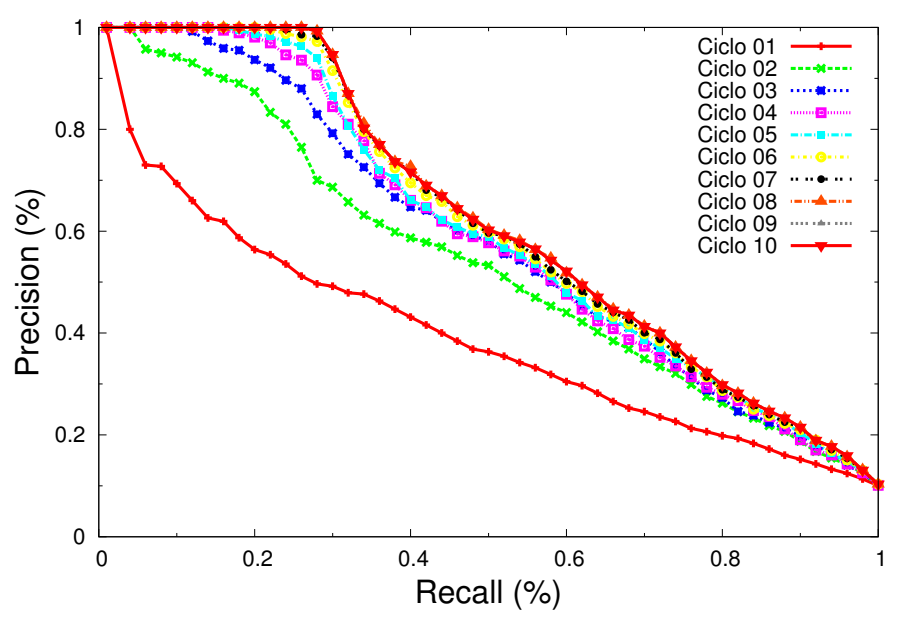

(c) $\mathrm{TF}, A=10$.

Figura A.6: Precisão vs. Revocação do ciclo 1 ao ciclo 10 considerando o extrator Momentos de Cor (a) WG, $A=10$ (b) WF, $A=10$, e (c) TF, $A=10$. 
Cenas

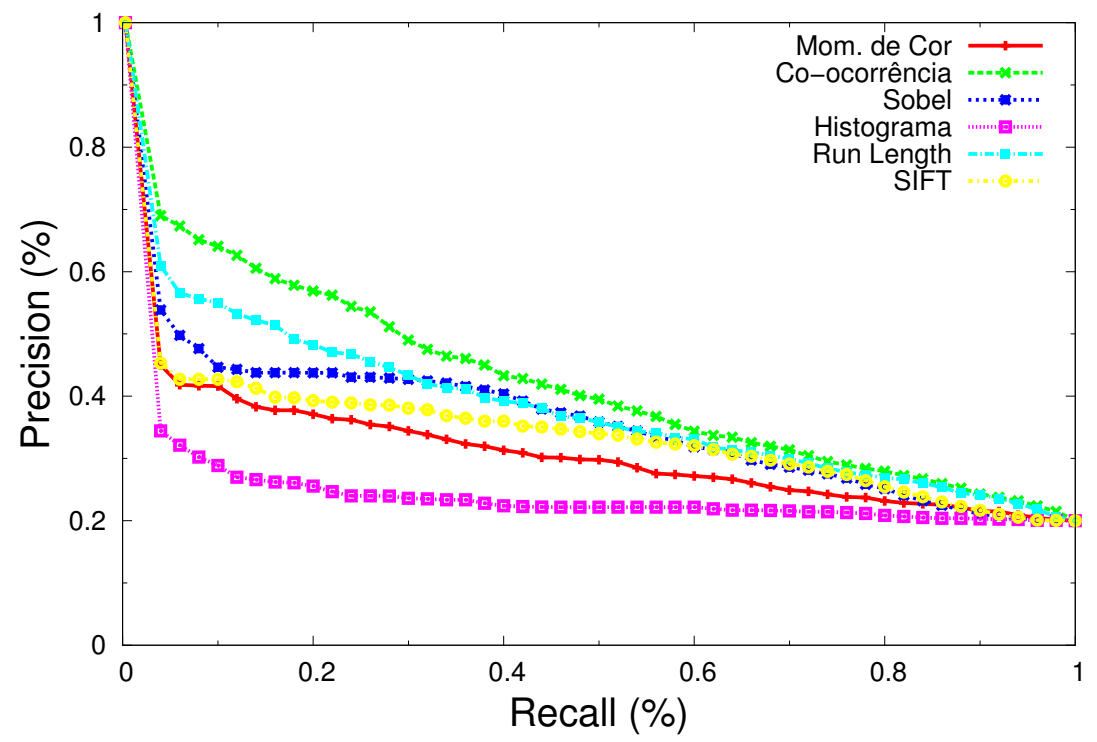

Figura A.7: Precisão vs. Revocação da consulta inicial para cada extrator. 
Cenas

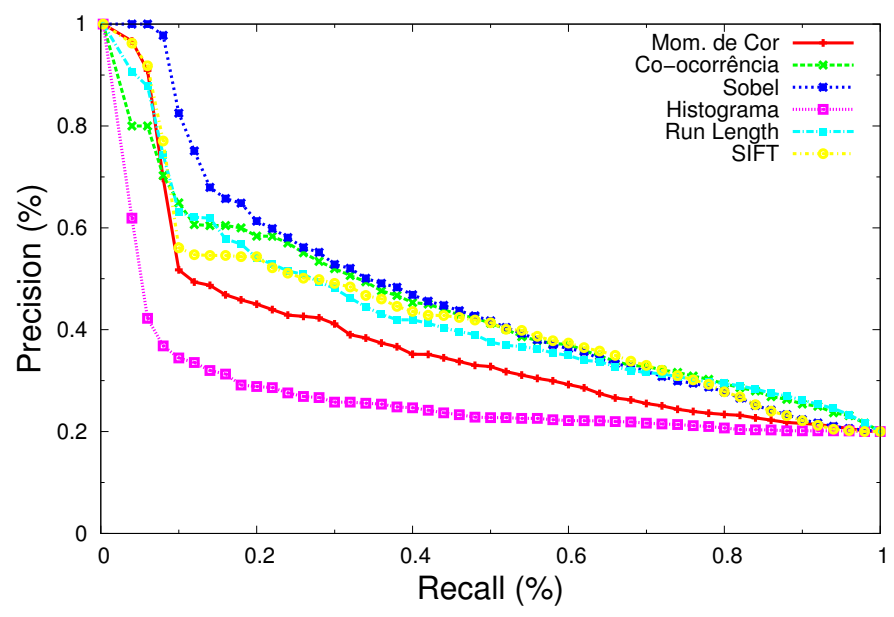

(a) WG, $A=20$.

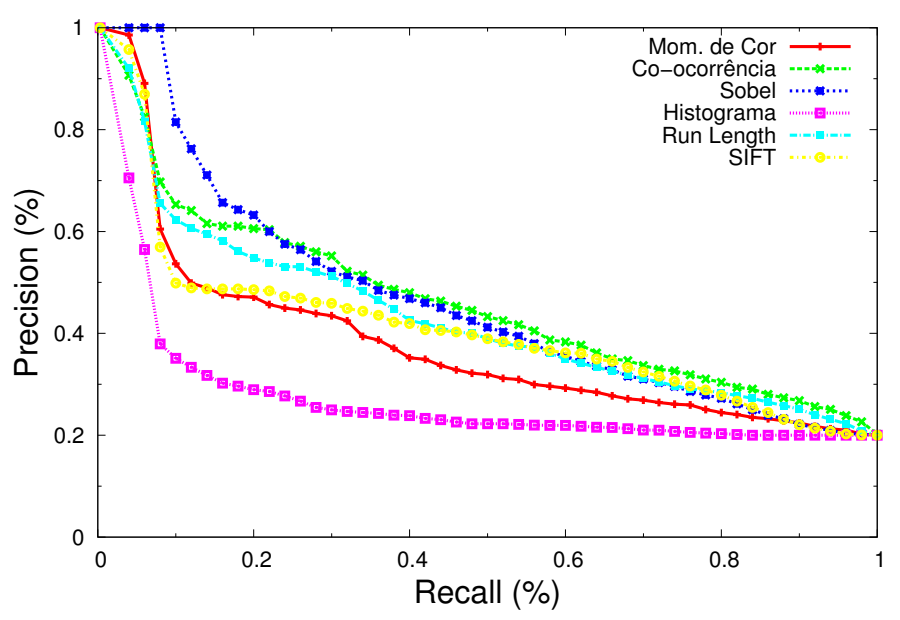

(b) WF, $A=10$.

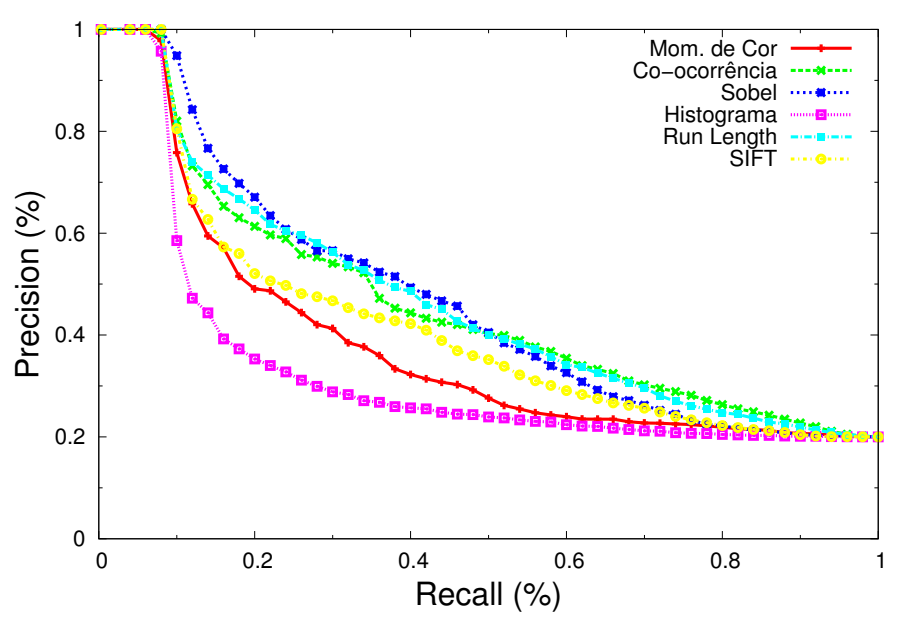

(c) $\mathrm{TF}, A=10$.

Figura A.8: Precisão vs. Revocação no ciclo 10, (a) WG, $A=2$ (b) WG, $A=10$ (c) WG, $A=20$ (d) WF, $A=2$ (e) WF, $A=10$ (f) WF, $A=20$ (g) TF, $A=2$ (h) TF, $A=10$ (i) TF, $A=20$. 
Cenas

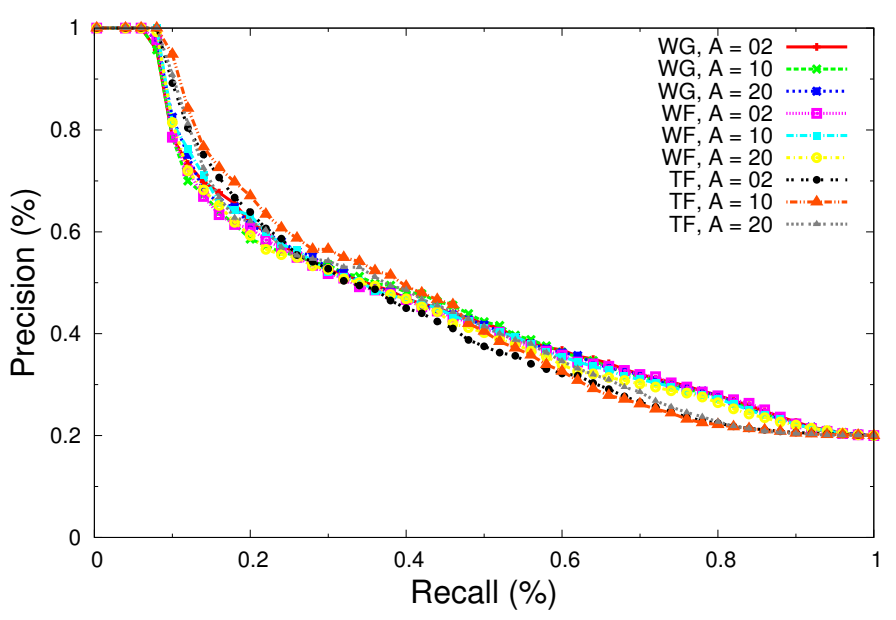

(a) Sobel.

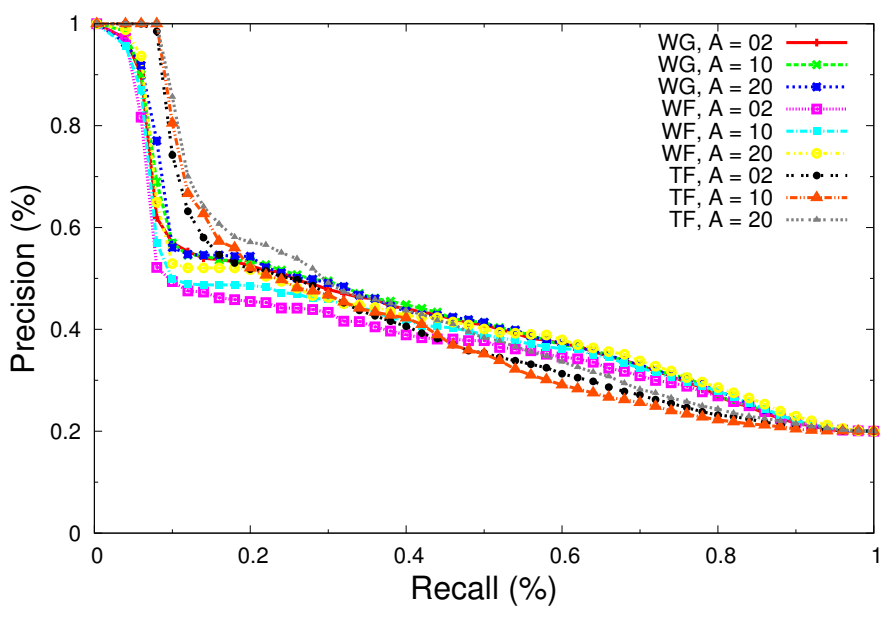

(b) SIFT.

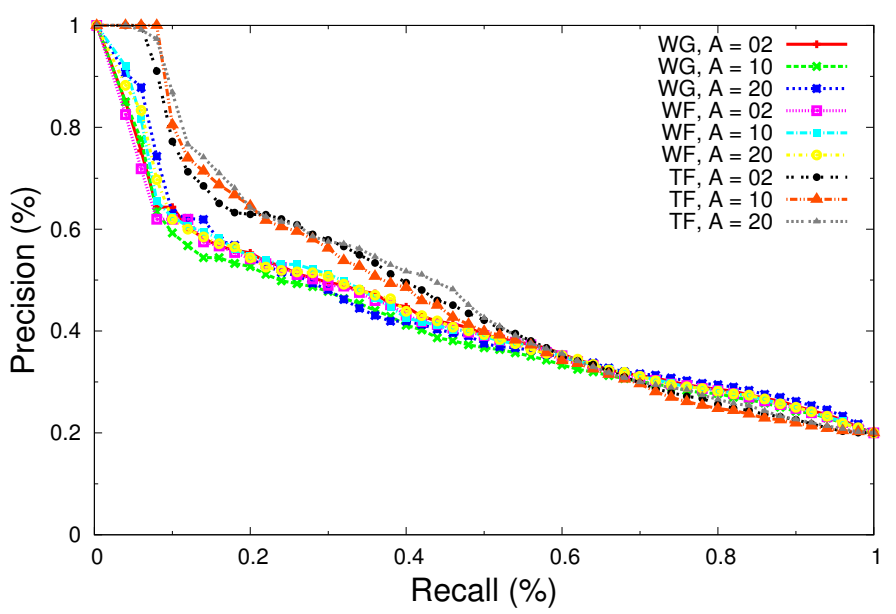

(c) Run Length.

Figura A.9: Precisão vs. Revocação para cada método e cada valor de $A$ (a) Sobel (b) SIFT (c) Run Length. 


\section{Cenas}

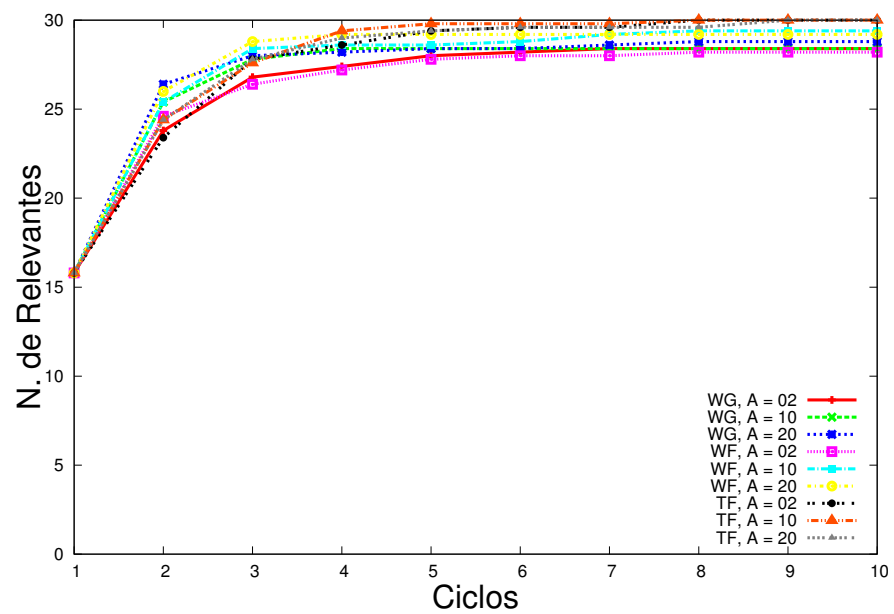

(a) Sobel.

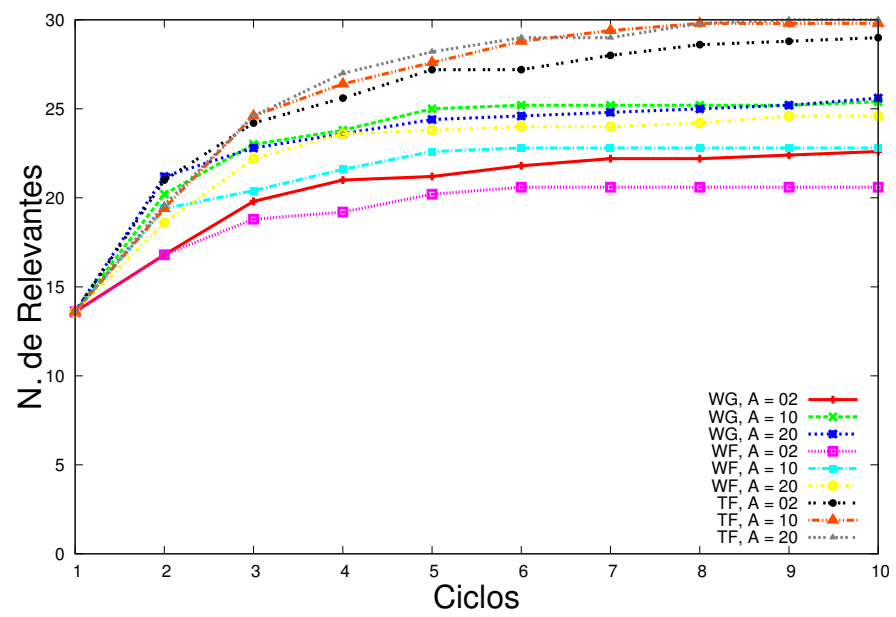

(b) SIFT.

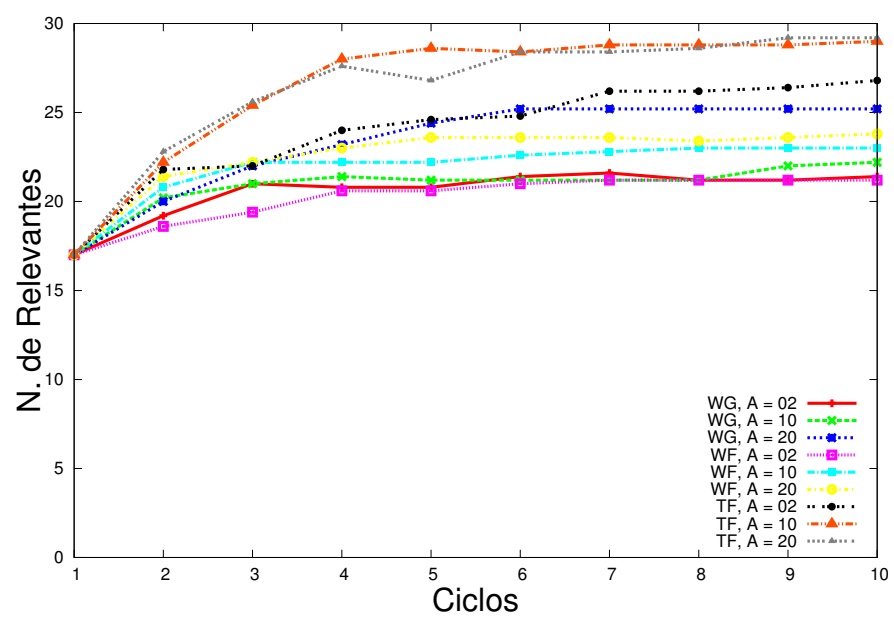

(c) Run Length.

Figura A.10: Número de Relevantes vs. Ciclos para cada método e cada valor de $A$ utilizando os extratores (a) Sobel (b) SIFT (c) Run Length. 


\section{Cenas}

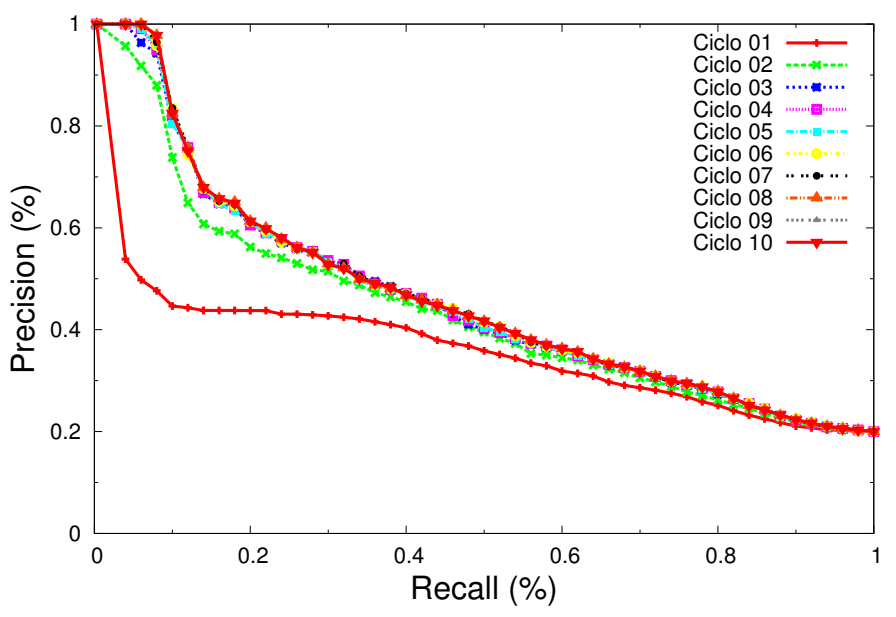

(a) WG, $A=20$.

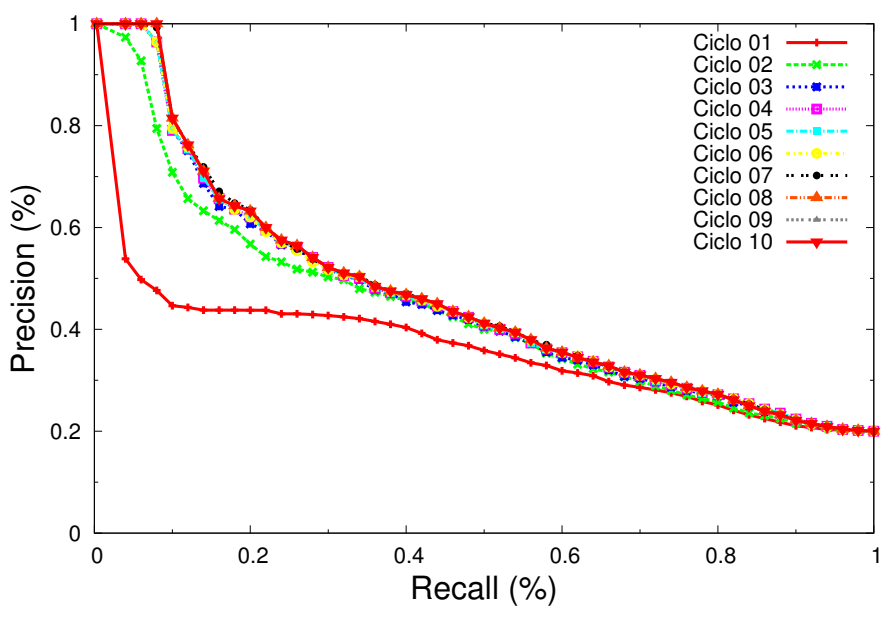

(b) WF, $A=10$.

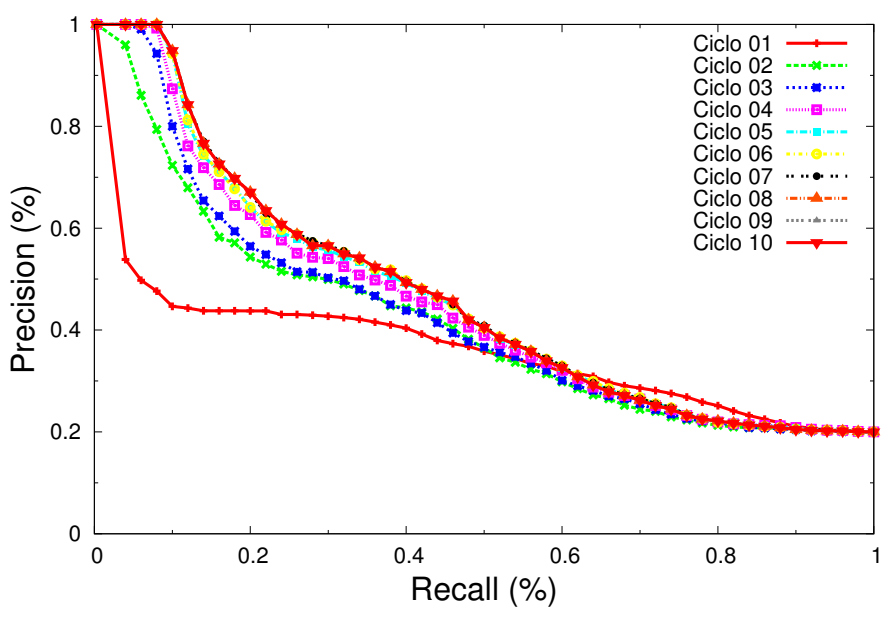

(c) TF, $A=10$.

Figura A.11: Precisão vs. Revocação do ciclo 1 ao ciclo 10 considerando o extrator Sobel (a) WG, $A=20$ (b) WF, $A=10$ e (c) TF, $A=10$. 


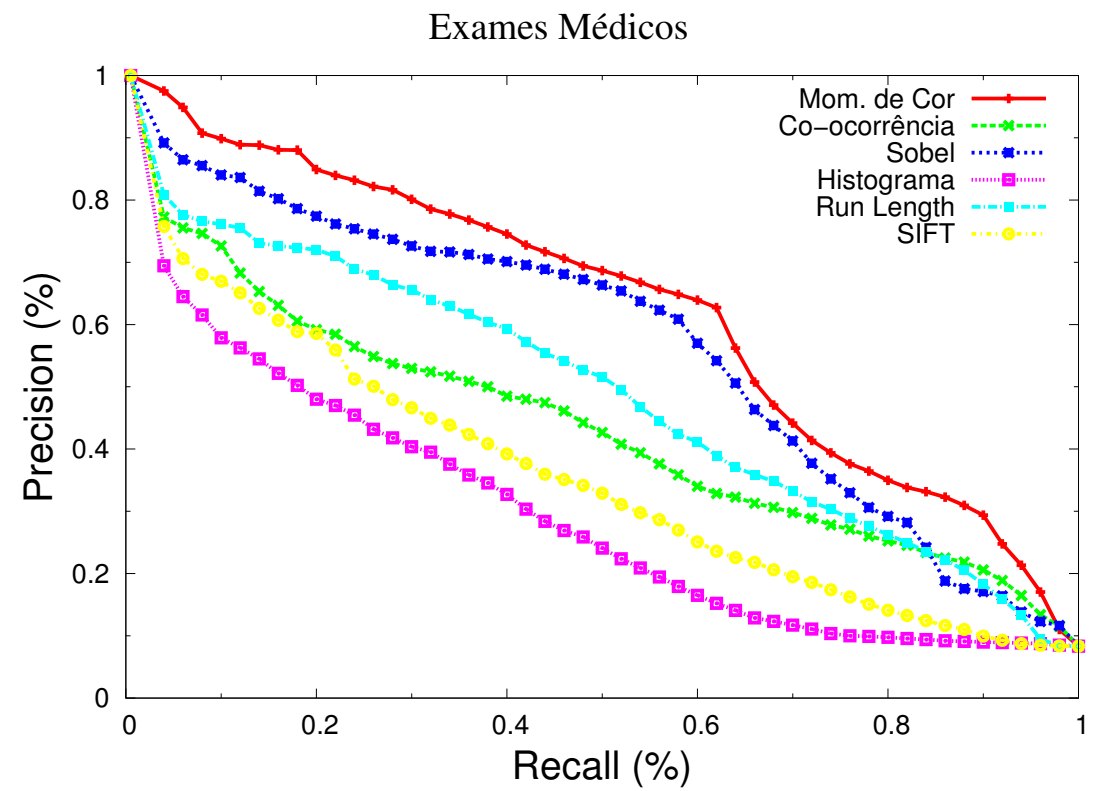

Figura A.12: Precisão vs. Revocação da consulta inicial para cada extrator. 
Exames Médicos

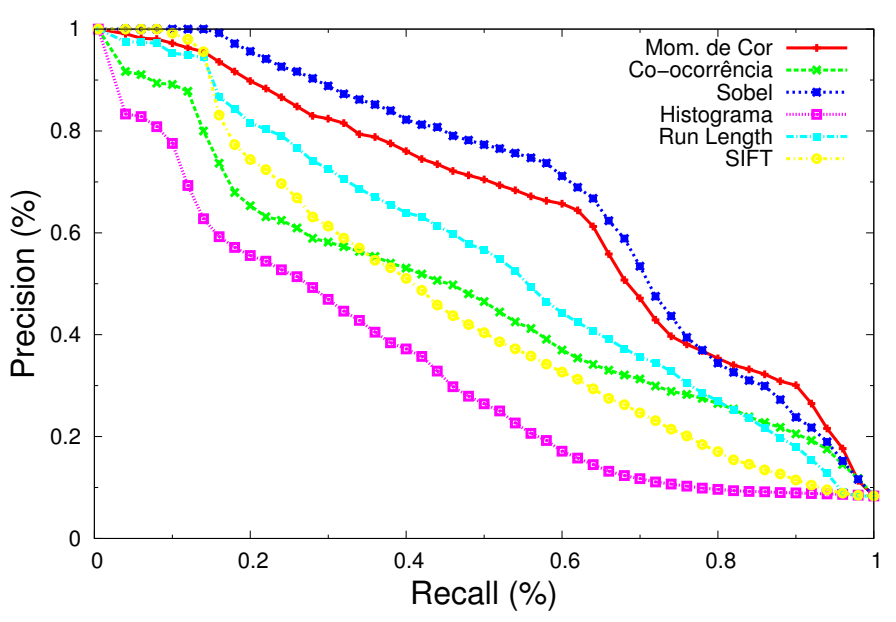

(a) WG, $A=20$.

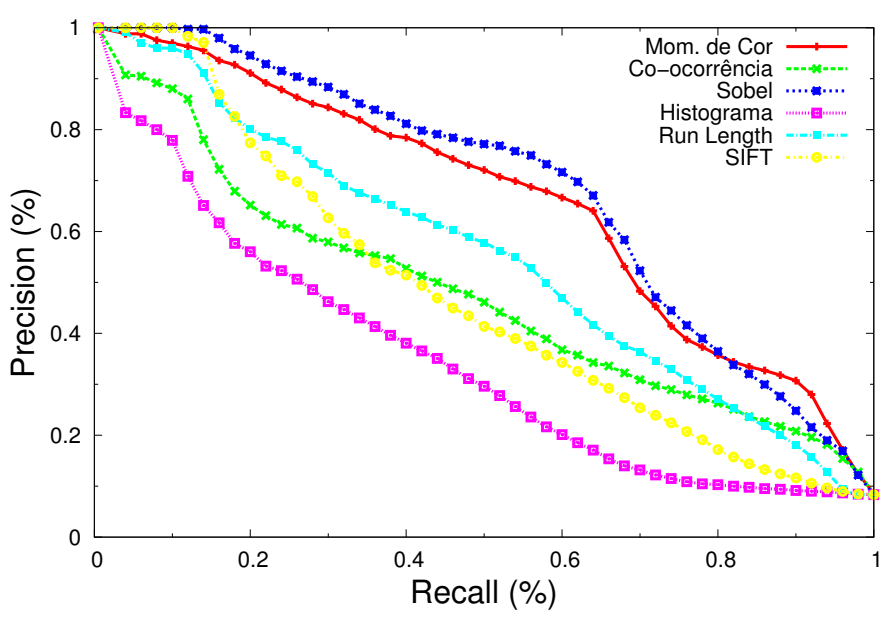

(b) WF, $A=10$.

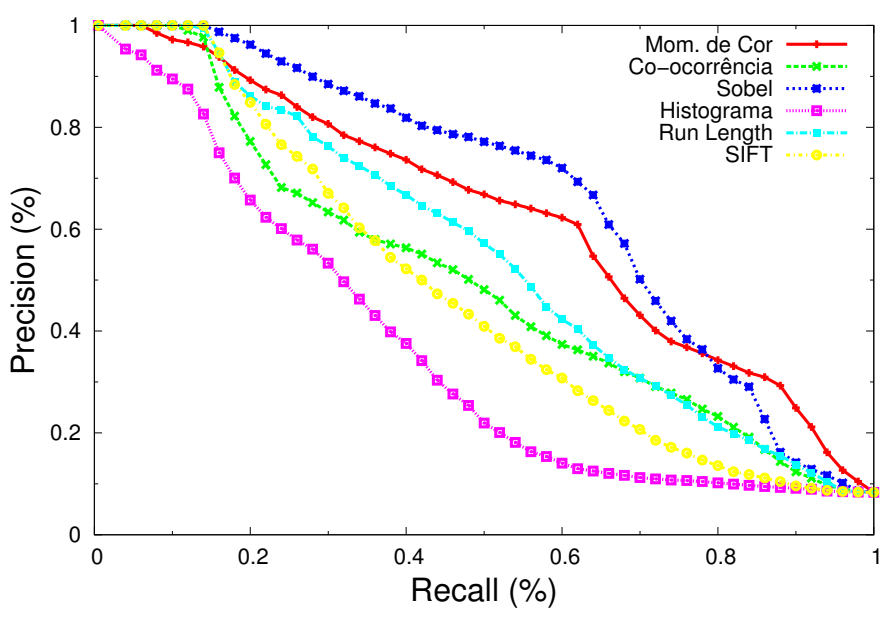

(c) $\mathrm{TF}, A=10$.

Figura A.13: Precisão vs. Revocação no ciclo 10, (a) WG, $A=2$ (b) WG, $A=10$ (c) WG, $A=20$ (d) WF, $A=2$ (e) WF, $A=10$ (f) WF, $A=20$ (g) TF, $A=2$ (h) TF, $A=10$ (i) TF, $A=20$. 
Exames Médicos

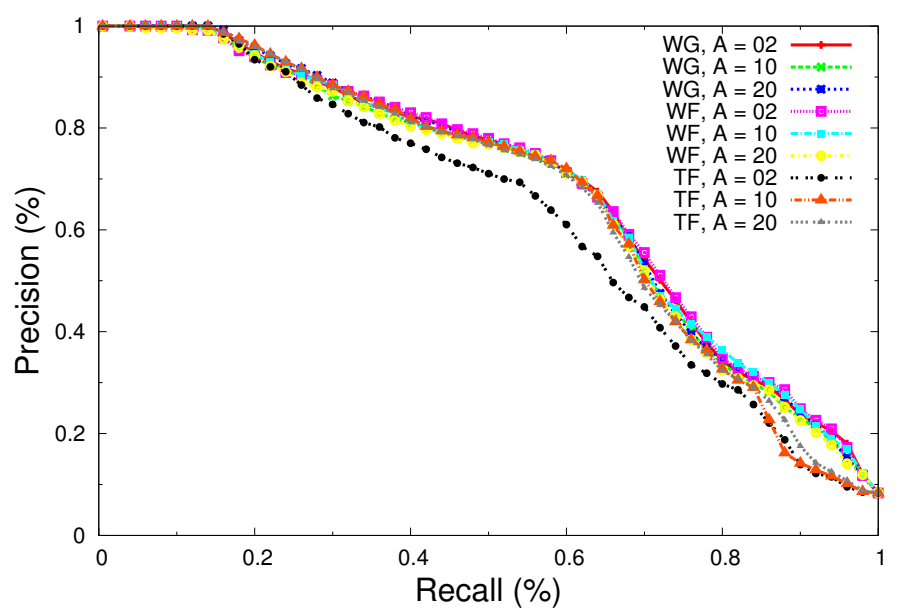

(a) Sobel.

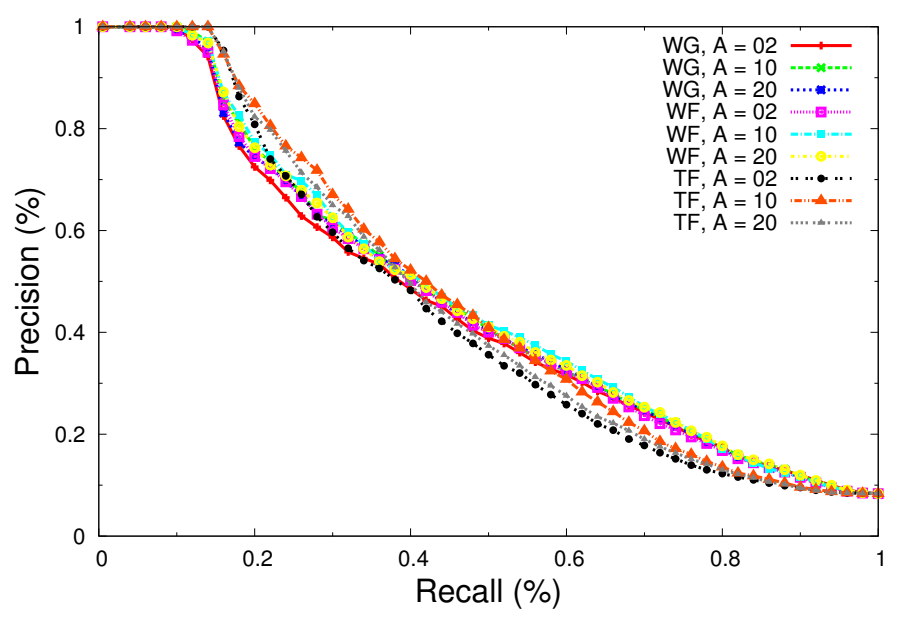

(b) SIFT.

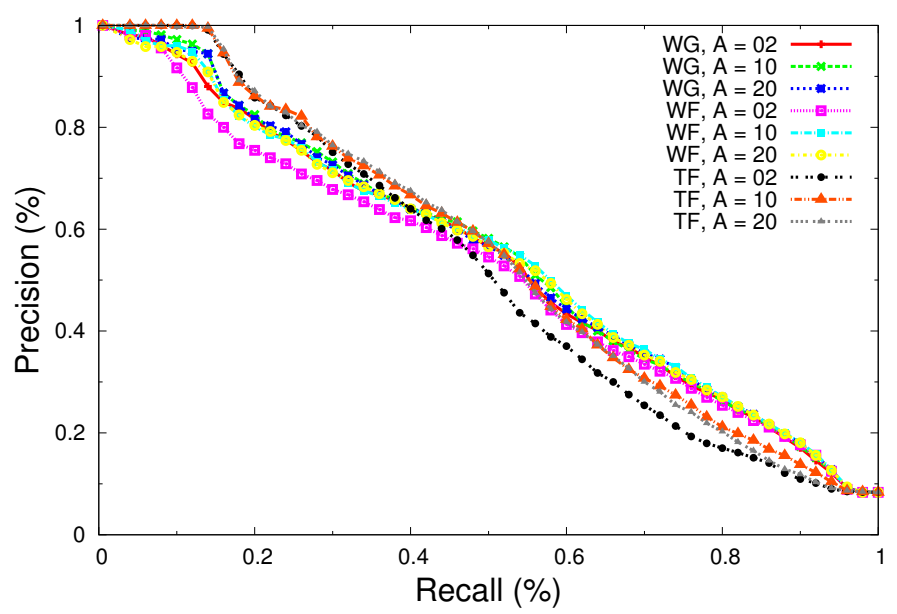

(c) Run Length.

Figura A.14: Precisão vs. Revocação para cada método e cada valor de $A$ utilizando os extratores (a) Sobel (b) SIFT (c) Run Length. 
Exames Médicos

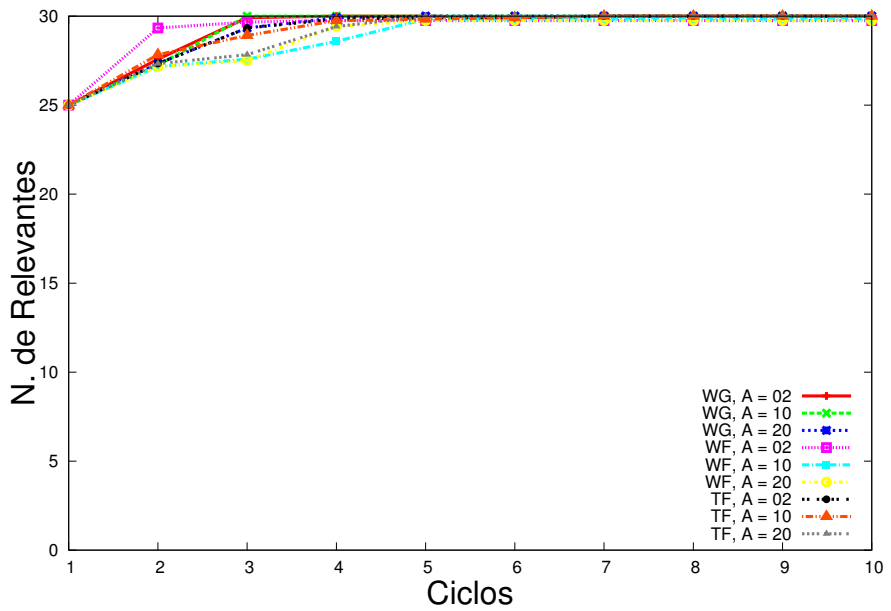

(a) Sobel.

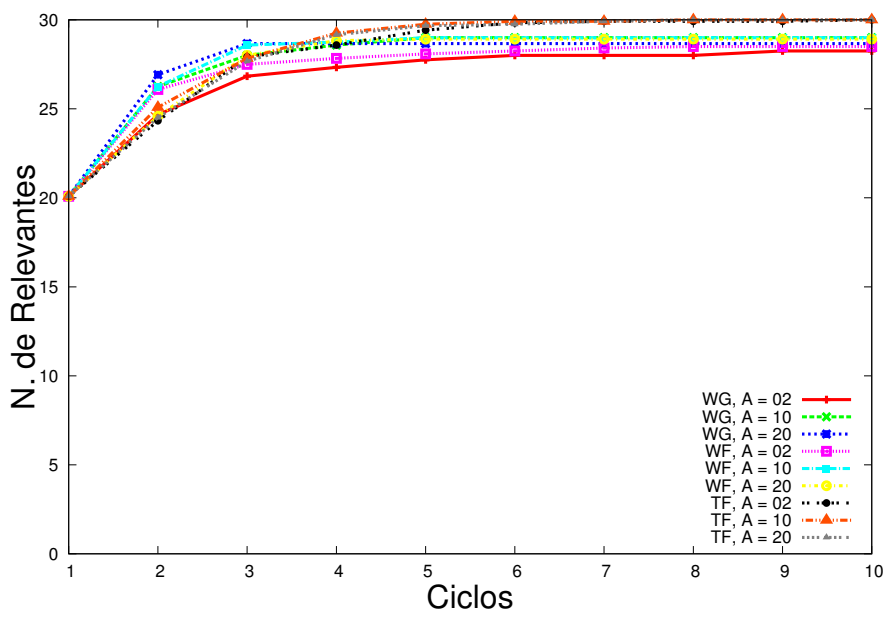

(b) SIFT.

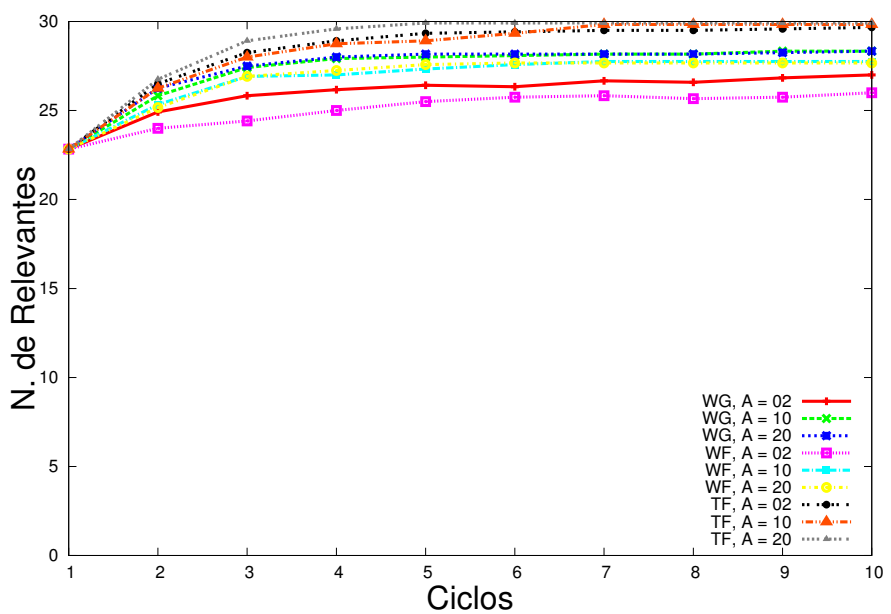

(c) Run Length.

Figura A.15: Número de Relevantes vs. Ciclos para cada método e cada valor de $A$ utilizando os extratores (a) Sobel (b) SIFT (c) Run Length. 


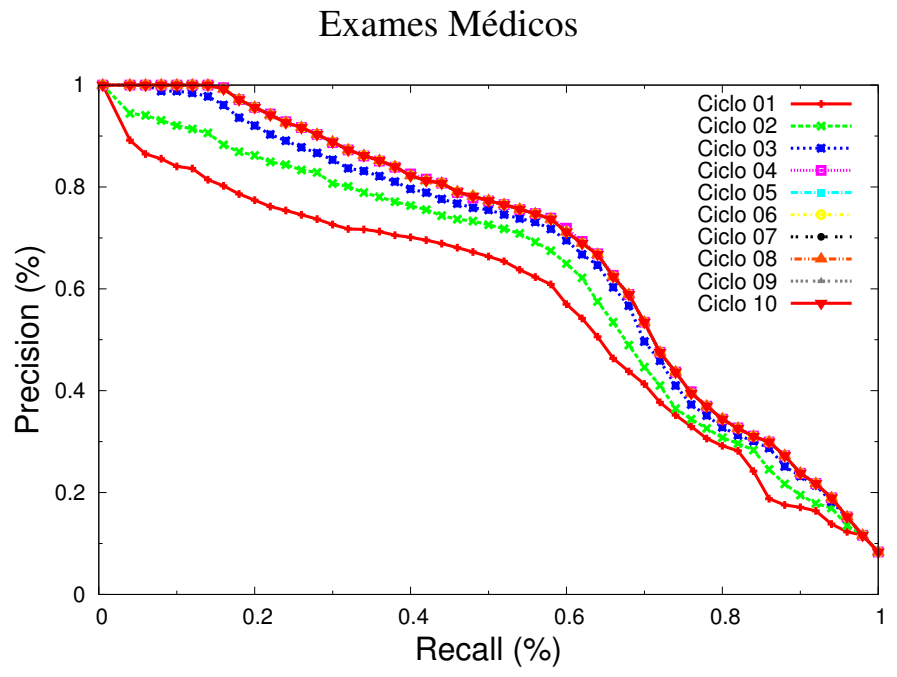

(a) WG, $A=20$.

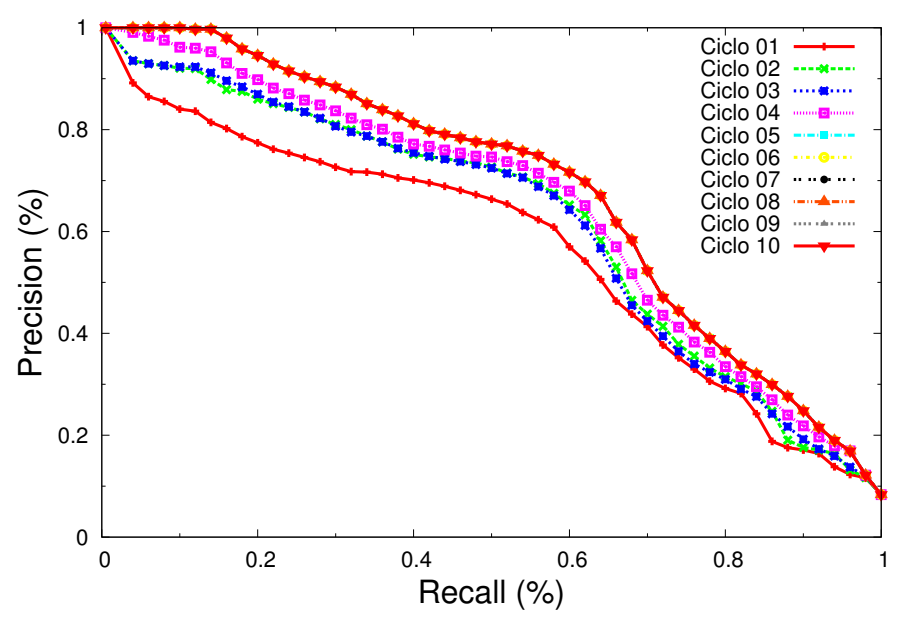

(b) WF, $A=10$.

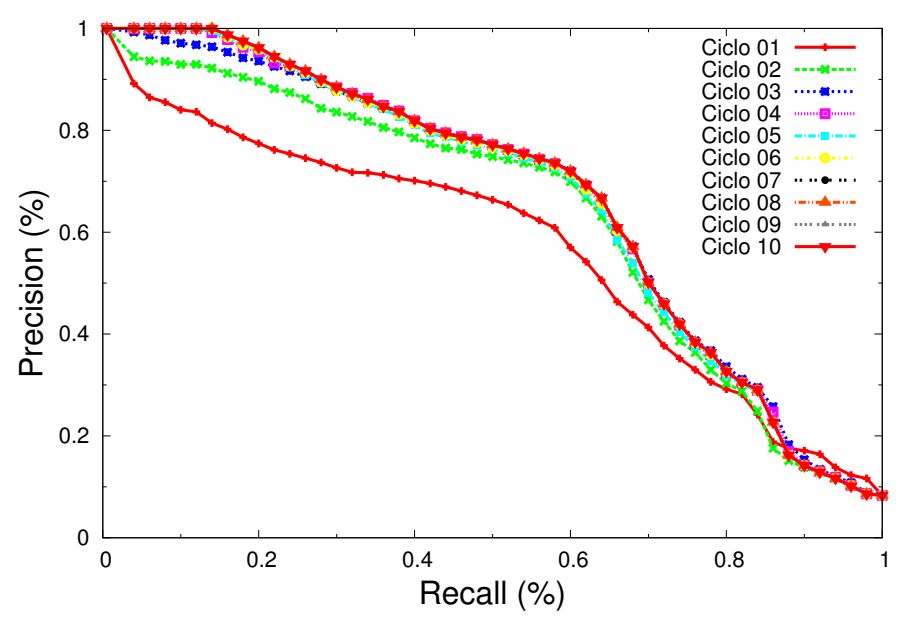

(c) $\mathrm{TF}, A=10$.

Figura A.16: Precisão vs. Revocação do ciclo 1 ao ciclo 10 considerando o extrator Sobel (a) WG, $A=20$ (b) WF, $A=10$ e (c) TF, $A=10$. 


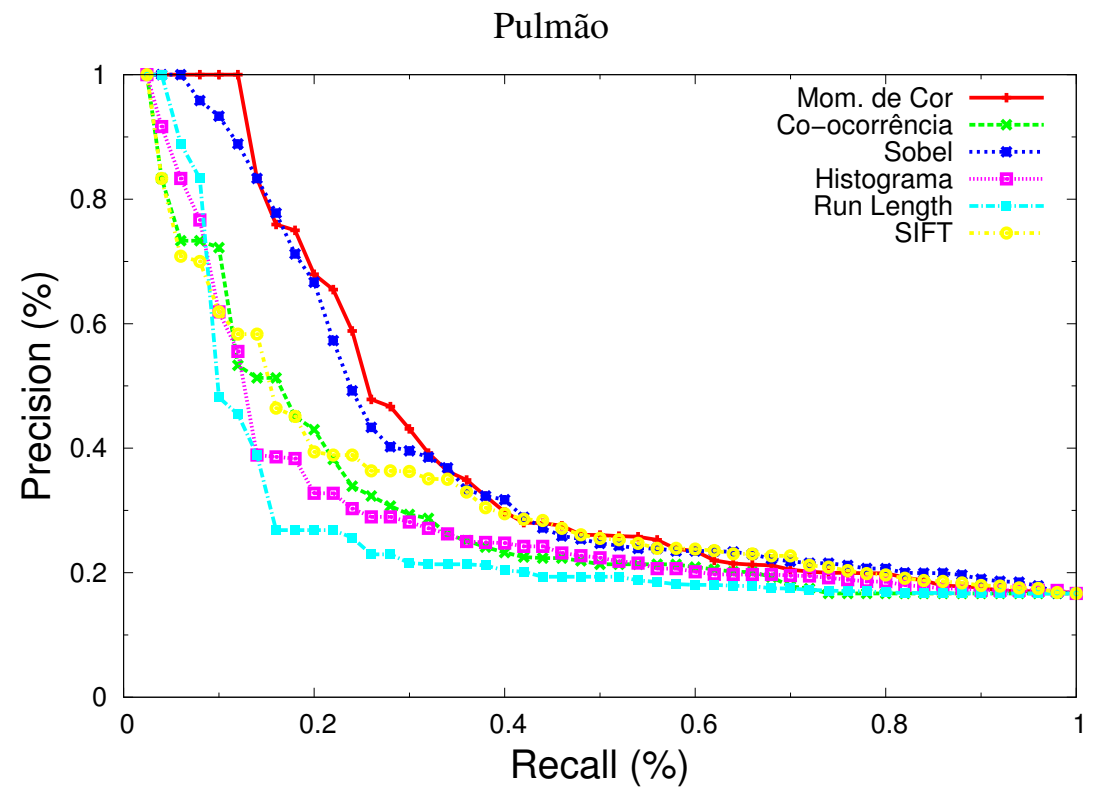

Figura A.17: Precisão vs. Revocação da consulta inicial para cada extrator. 
Pulmão

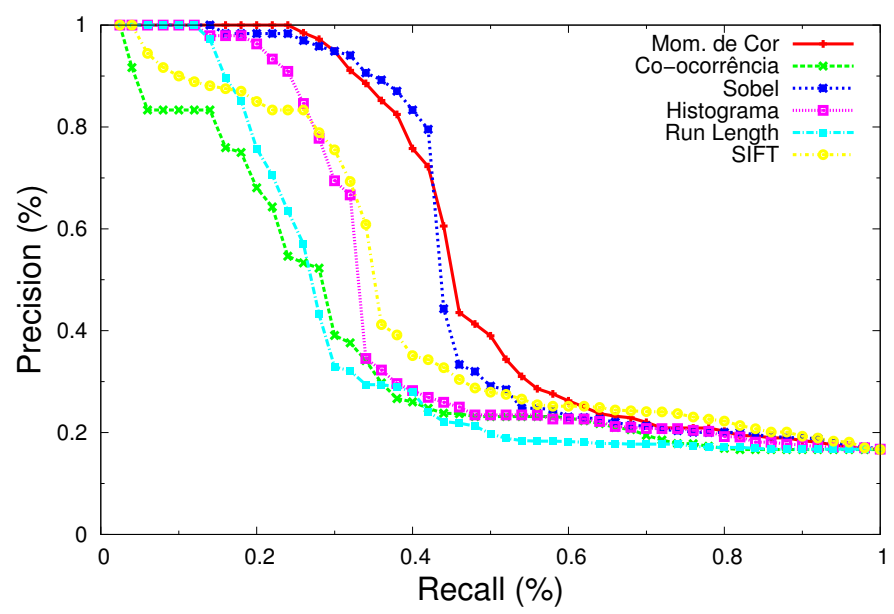

(a) WG, $A=2$.

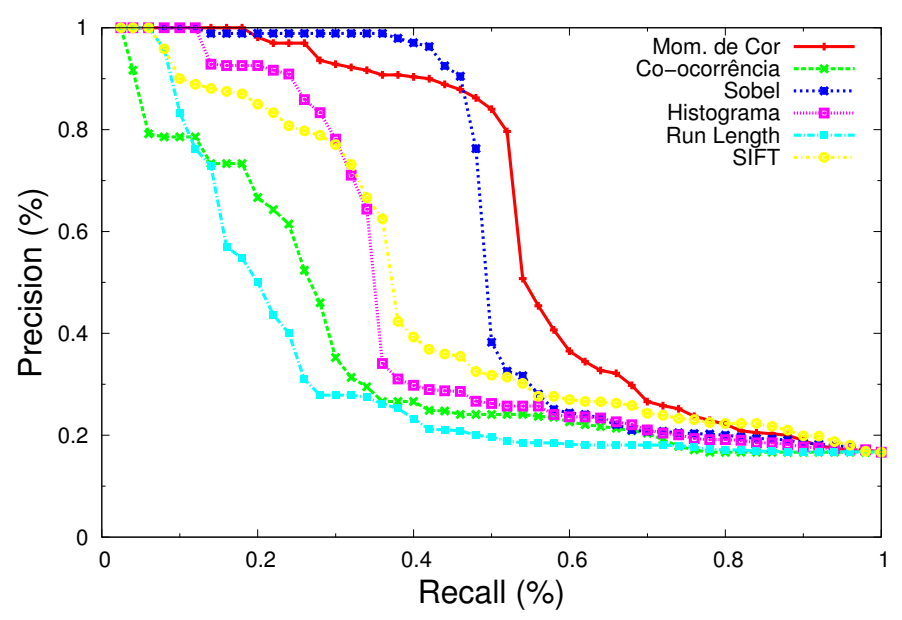

(b) WF, $A=10$.

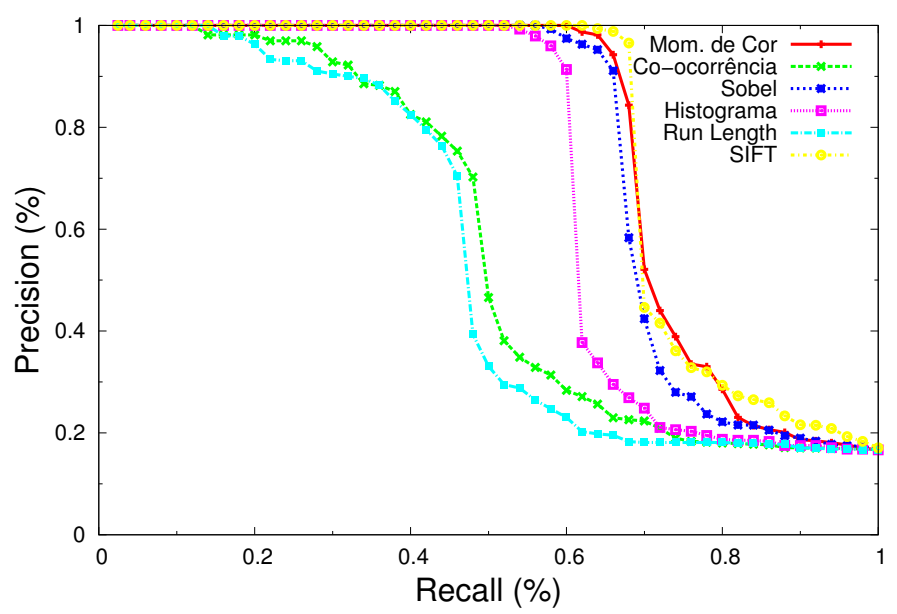

(c) $\mathrm{TF}, A=20$.

Figura A.18: Precisão vs. Revocação no ciclo 10, (a) WG, $A=2$ (b) WG, $A=10$ (c) WG, $A=20$ (d) WF, $A=2$ (e) WF, $A=10$ (f) WF, $A=20$ (g) TF, $A=2$ (h) TF, $A=10$ (i) TF, $A=20$. 
Pulmão

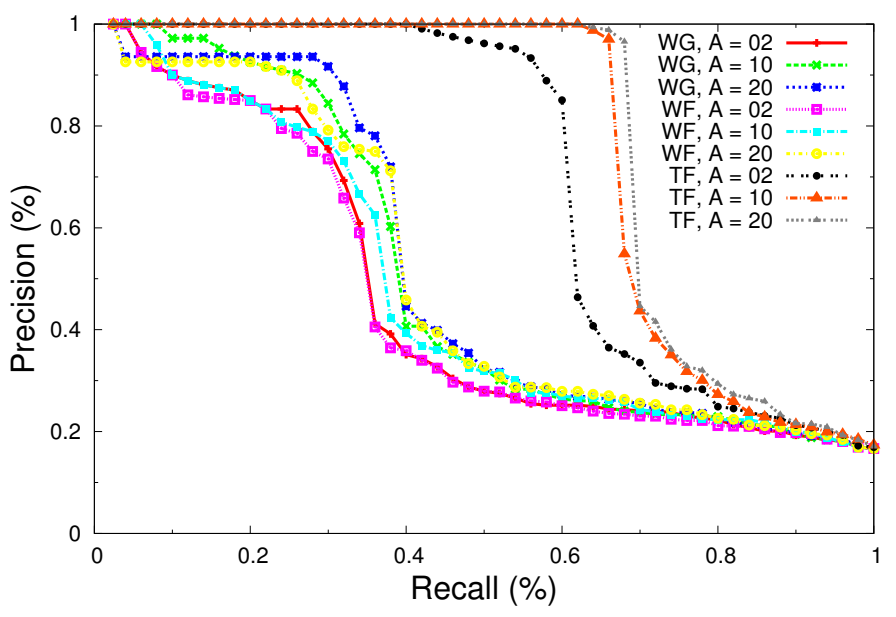

(a) SIFT.

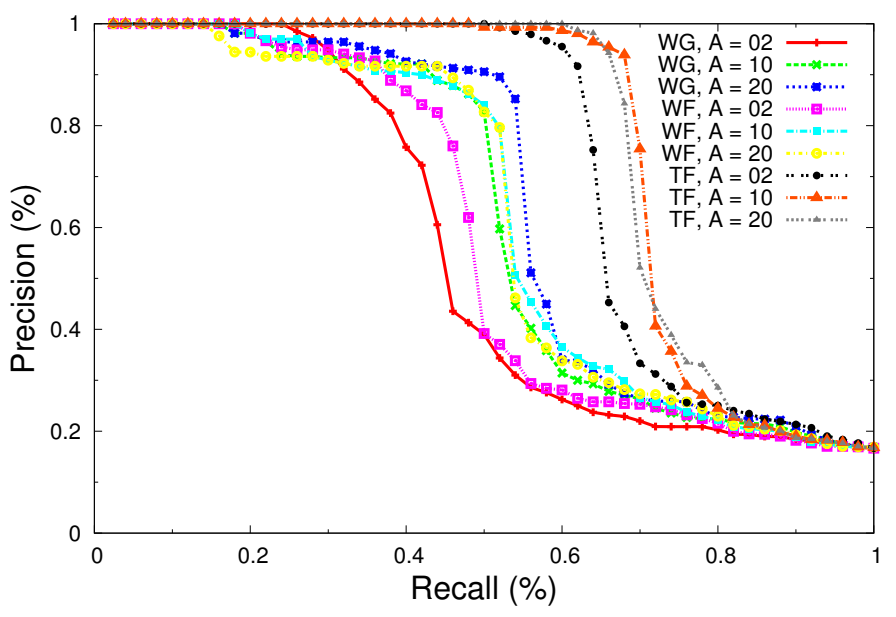

(b) Momentos de Cor.

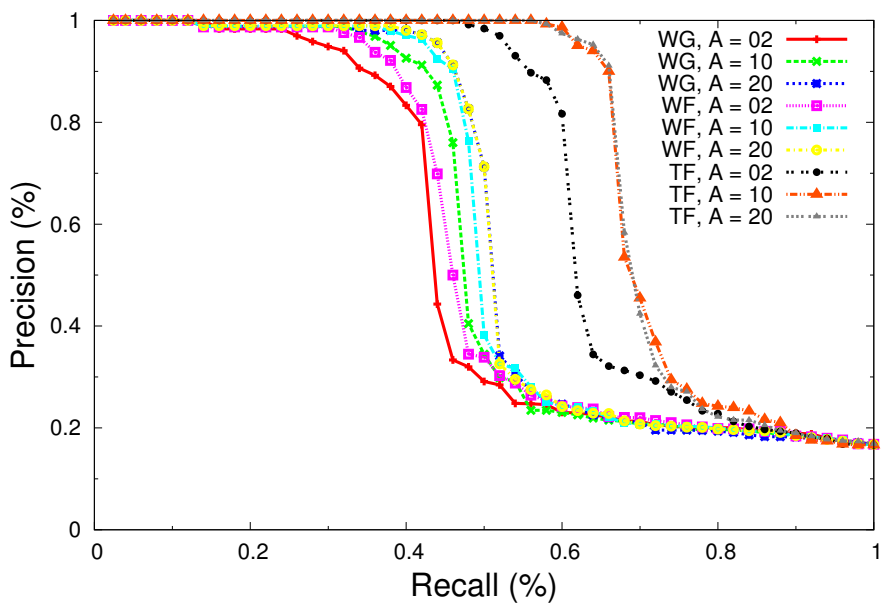

(c) Sobel.

Figura A.19: Precisão vs. Revocação para cada método e cada valor de $A$ utilizando os extratores (a) SIFT (b) Momentos de Cor (c) Sobel. 
Pulmão

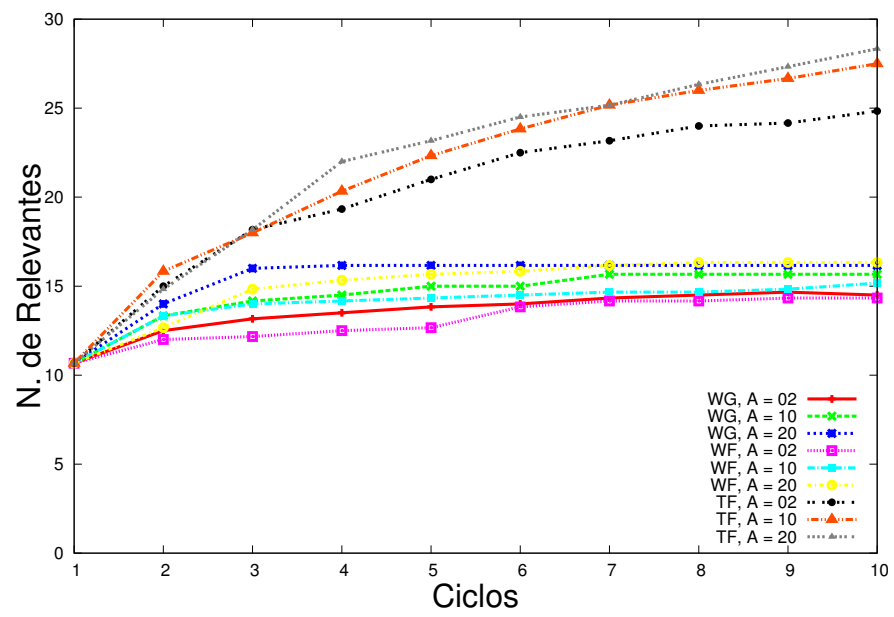

(a) SIFT,

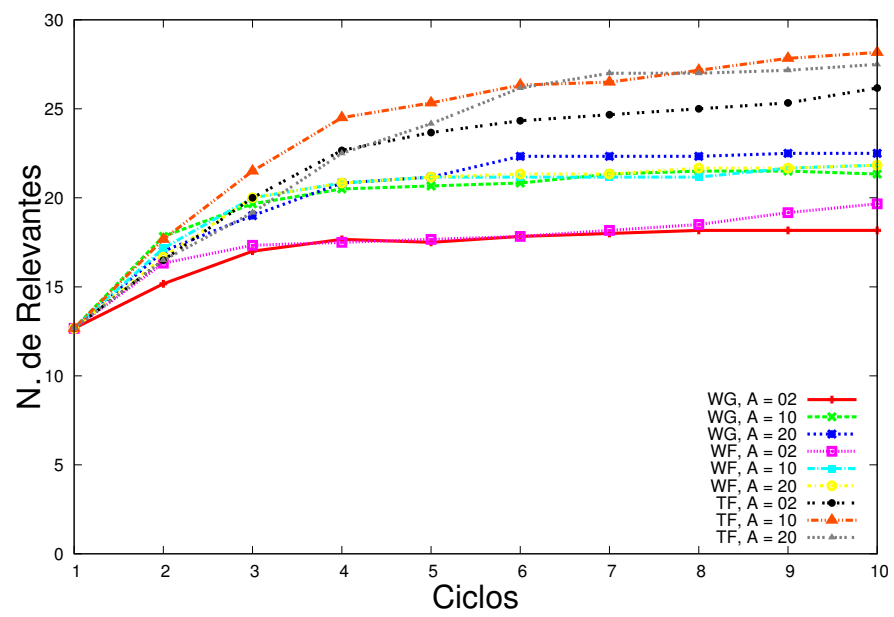

(b) Momentos de Cor.

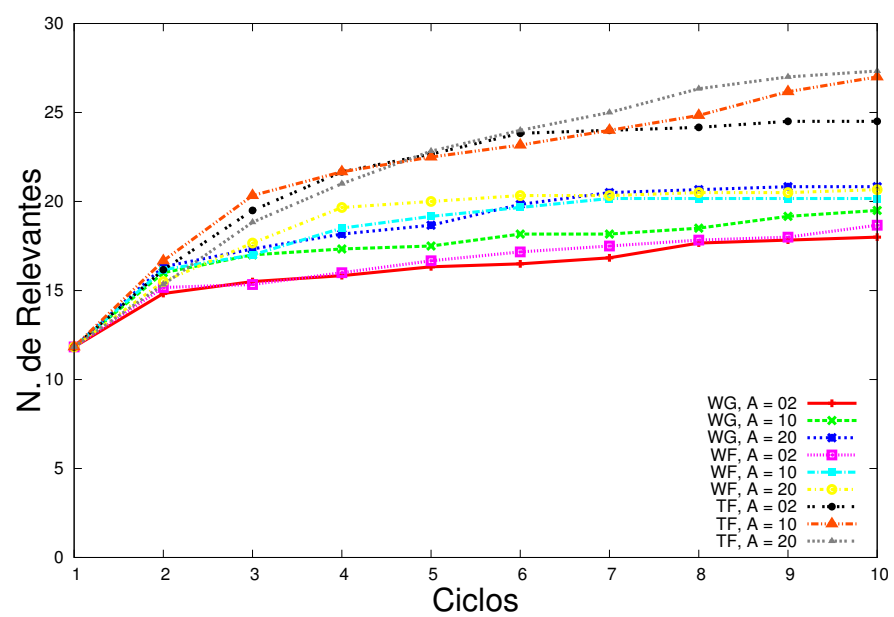

(c) Sobel.

Figura A.20: Número de Relevantes vs. Ciclos para cada método e cada valor de $A$ utilizando os extratores (a) SIFT (b) Momentos de Cor (c) Sobel. 
Pulmão

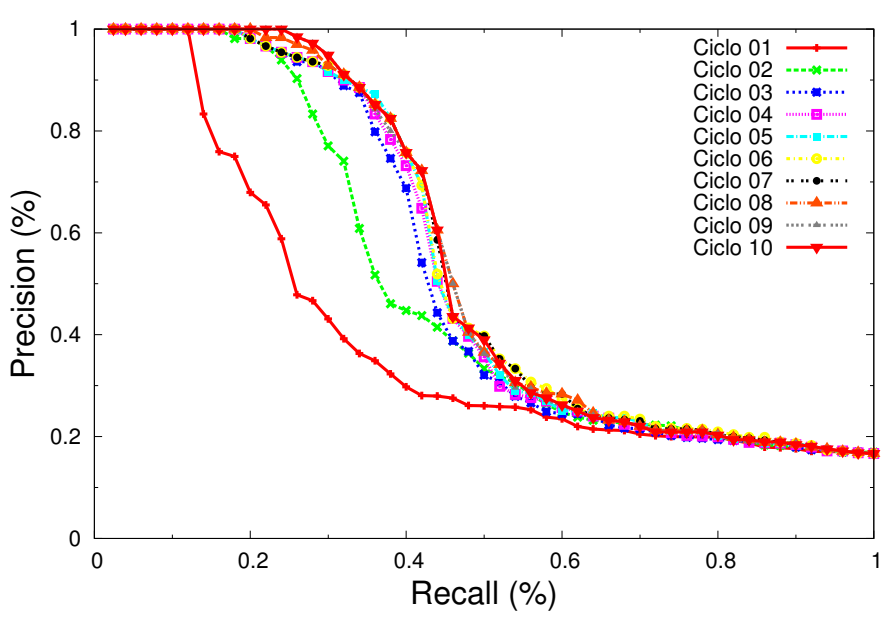

(a) WG, $A=2$, Momentos de Cor.

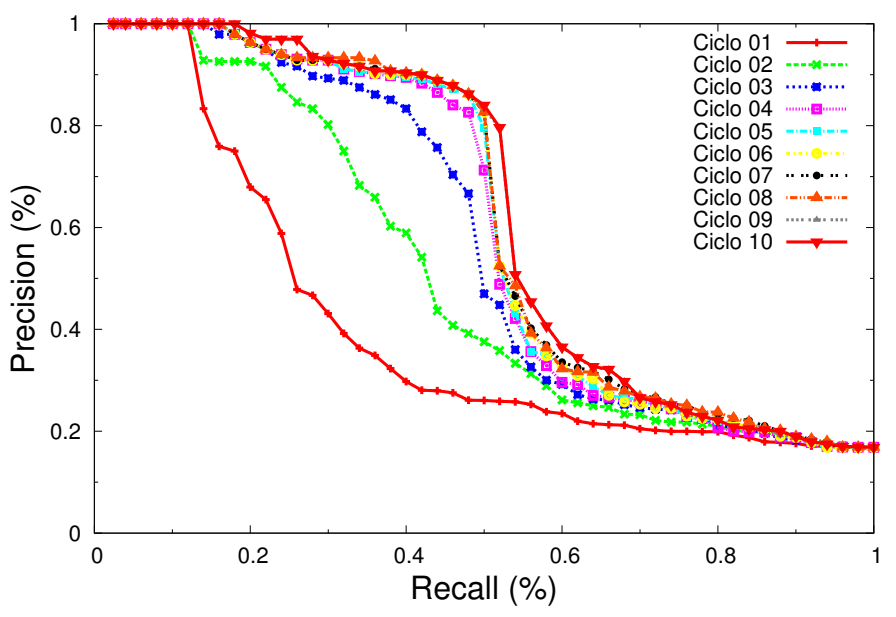

(b) WF, $A=10$, Momentos de Cor.

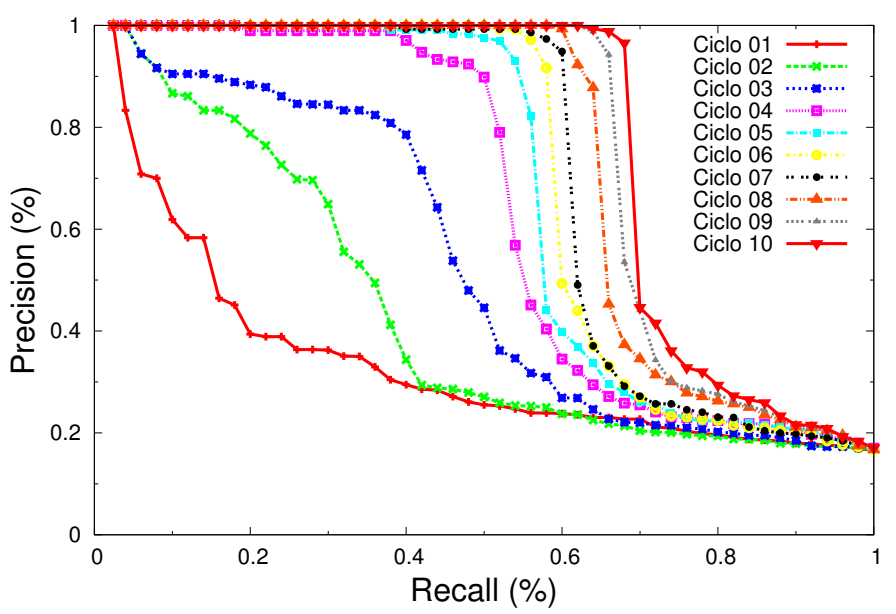

(c) TF, $A=20$, SIFT.

Figura A.21: Precisão vs. Revocação do ciclo 1 ao ciclo 10 considerando (a) WG, $A=2$, Momentos de Cor (b) WF, $A=10$, Momentos de Cor e (c) TF, $A=20$, SIFT. 


\section{A.2 Visualização}

Esta seção apresenta as visualizações geradas pela ferramenta MetricSplat, através da projeção por FastMap. A análise das visualizações para cada base são descritas no Capítulo 6.

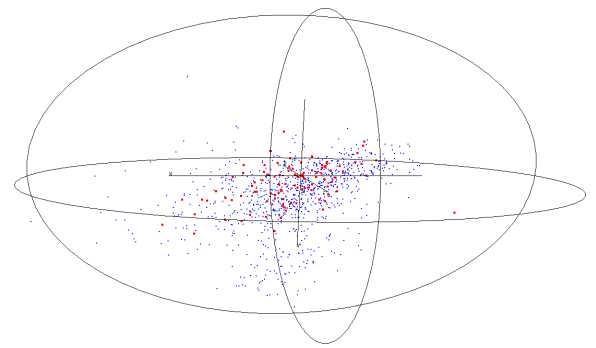

(a)

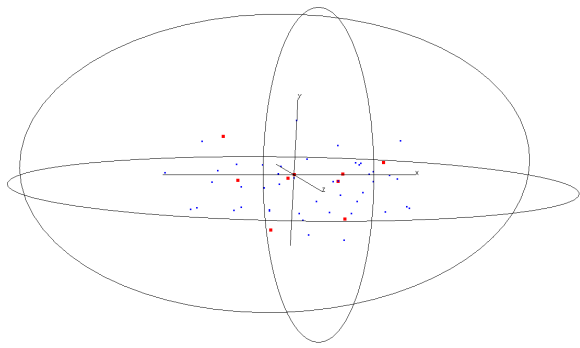

(b)

Figura A.22: Representação do espaço original da base Corel 1000 utilizando Mom. de Cor para (a) espaço completo (b) 50 elementos mais próximos ao centro de consulta.

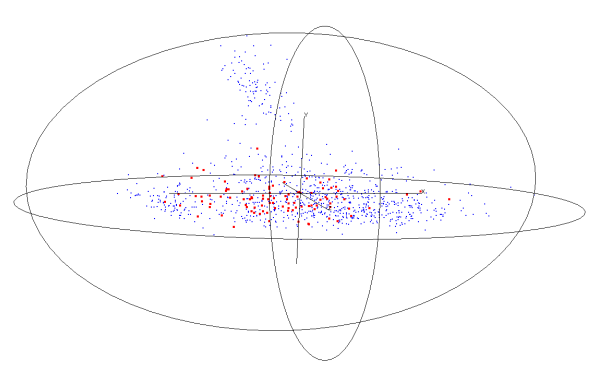

(a)

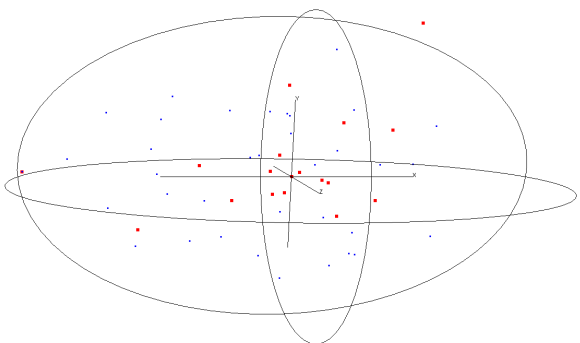

(b)

Figura A.23: Configuração do espaço da base Corel 1000 após o uso do método WG para (a) espaço completo (b) 50 elementos mais próximos ao centro de consulta.

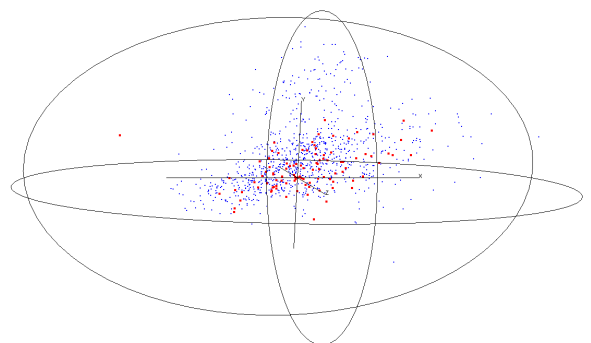

(a)

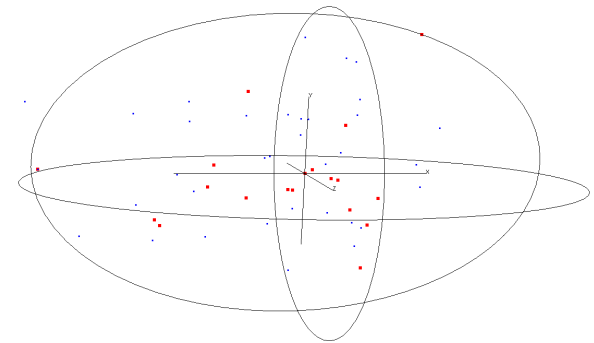

(b)

Figura A.24: Configuração do espaço da base Corel 1000 após o uso do método WF para (a) espaço completo (b) 50 elementos mais próximos ao centro de consulta. 


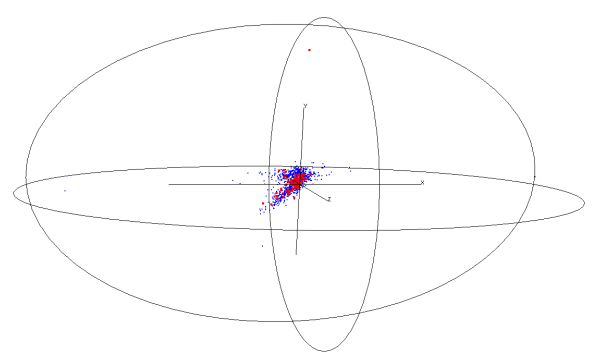

(a)

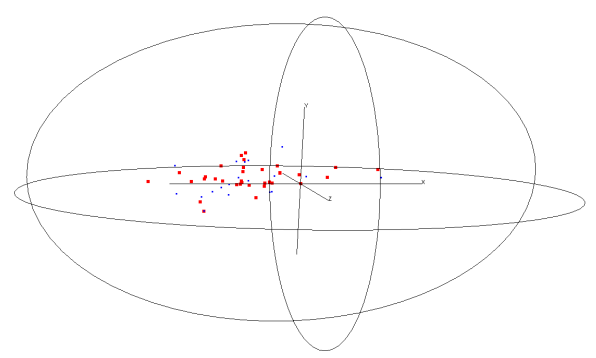

(b)

Figura A.25: Configuração do espaço da base Corel 1000 após o uso do método TF para (a) espaço completo (b) 50 elementos mais próximos ao centro de consulta.

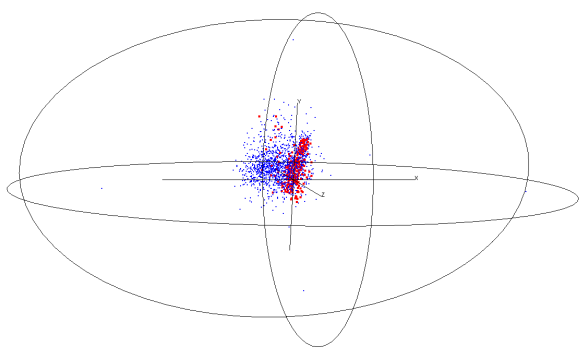

(a)

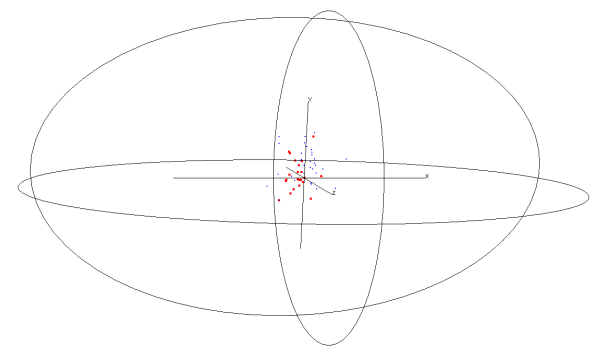

(b)

Figura A.26: Representação do espaço original da base Cenas utilizando Sobel para (a) espaço completo (b) 50 elementos mais próximos ao centro de consulta.

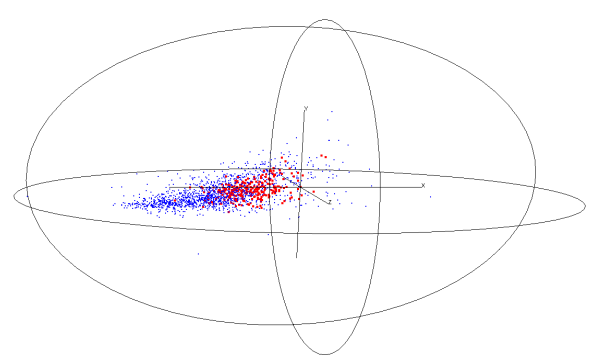

(a)

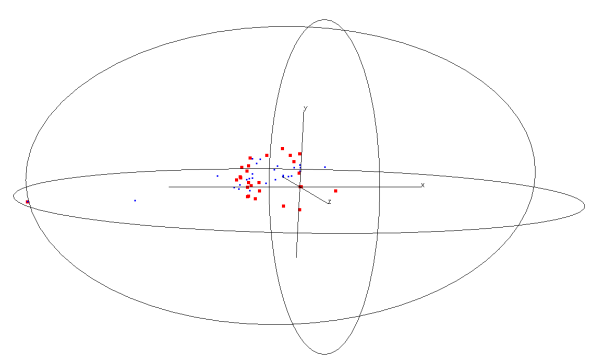

(b)

Figura A.27: Configuração do espaço da base Cenas após o uso do método WG para (a) espaço completo (b) 50 elementos mais próximos ao centro de consulta. 


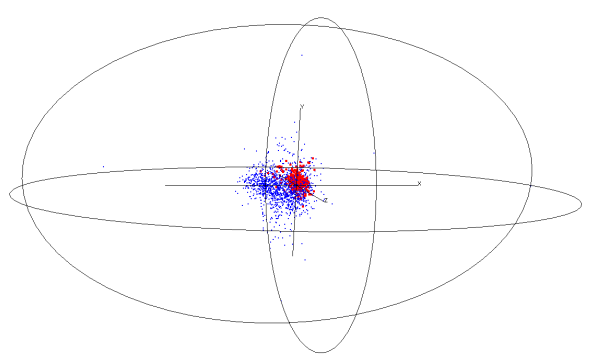

(a)

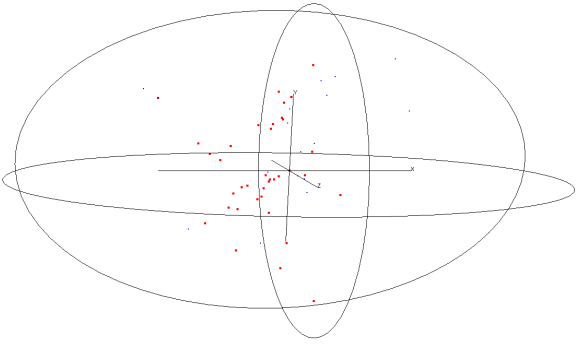

(b)

Figura A.28: Configuração do espaço da base Cenas após o uso do método WF para (a) espaço completo (b) 50 elementos mais próximos ao centro de consulta.

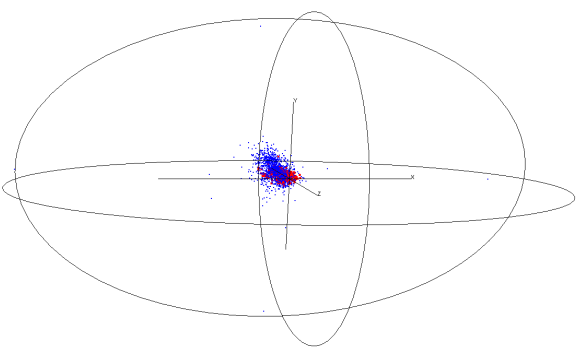

(a)

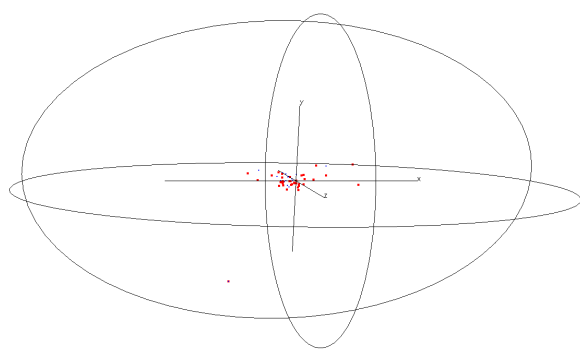

(b)

Figura A.29: Configuração do espaço da base Cenas após o uso do método TF para (a) espaço completo (b) 50 elementos mais próximos ao centro de consulta.

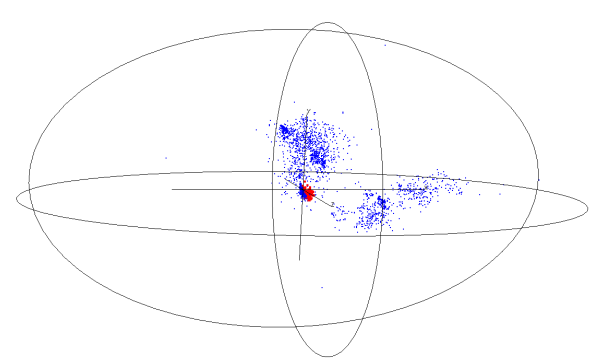

(a)

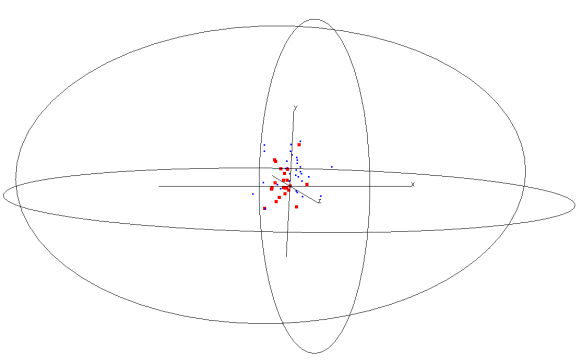

(b)

Figura A.30: Representação do espaço original da base Exames Médicos utilizando Sobel para (a) espaço completo (b) 50 elementos mais próximos ao centro de consulta. 


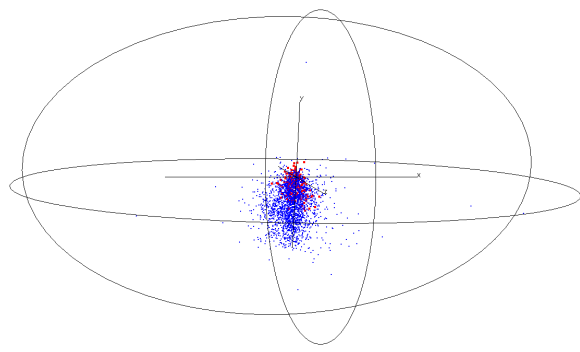

(a)

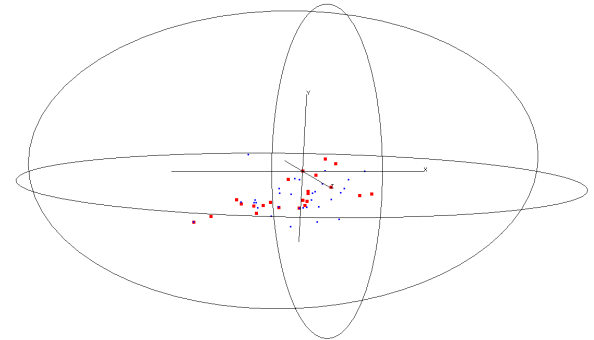

(b)

Figura A.31: Configuração do espaço da base Exames Médicos após o uso do método WG para (a) espaço completo (b) 50 elementos mais próximos ao centro de consulta.

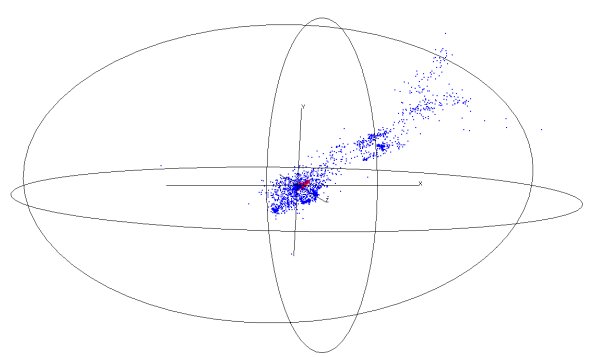

(a)

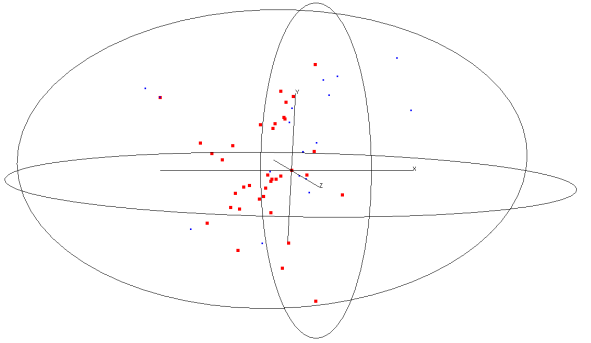

(b)

Figura A.32: Configuração do espaço da base Exames Médicos após o uso do método WF para (a) espaço completo (b) 50 elementos mais próximos ao centro de consulta.

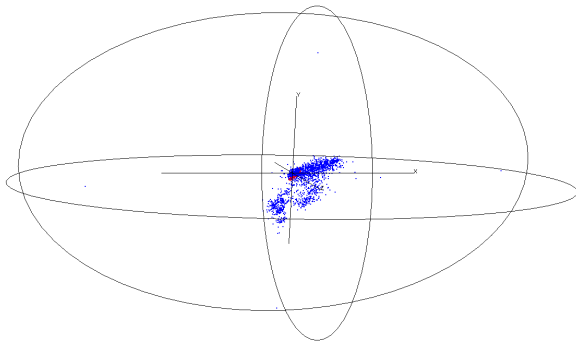

(a)

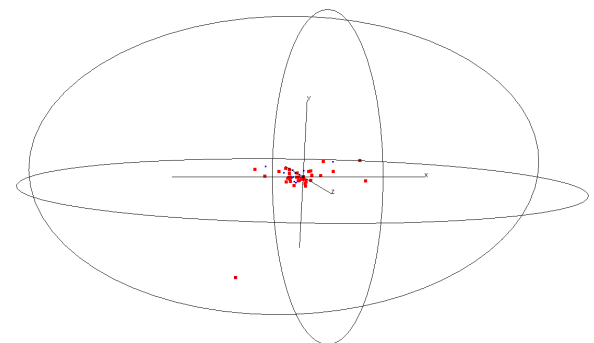

(b)

Figura A.33: Configuração do espaço da base Exames Médicos após o uso do método TF para (a) espaço completo (b) 50 elementos mais próximos ao centro de consulta. 


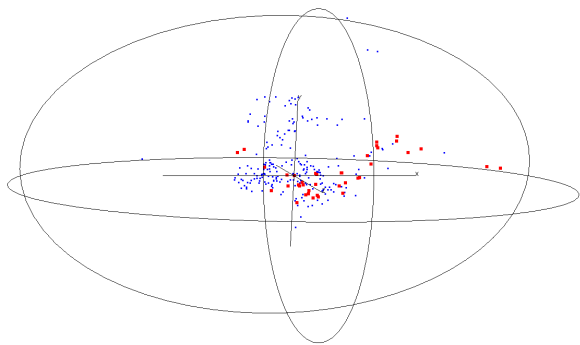

(a)

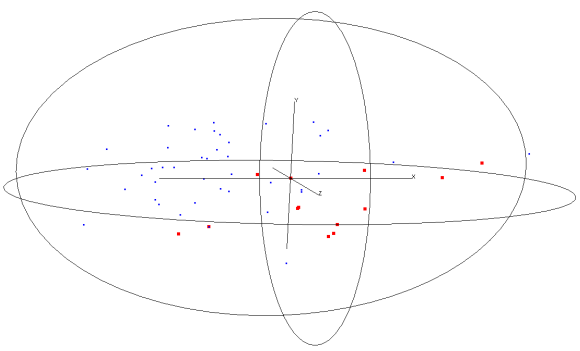

(b)

Figura A.34: Representação do espaço original da base Pulmão utilizando SIFT para (a) espaço completo (b) 50 elementos mais próximos ao centro de consulta.

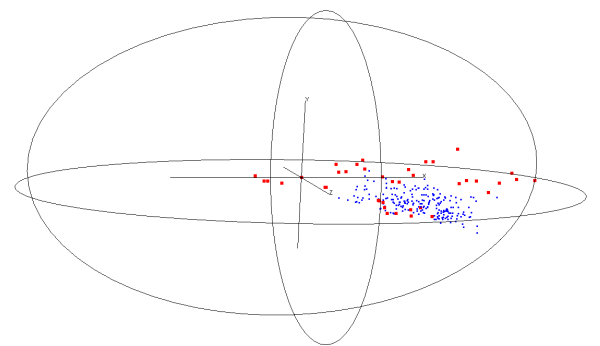

(a)

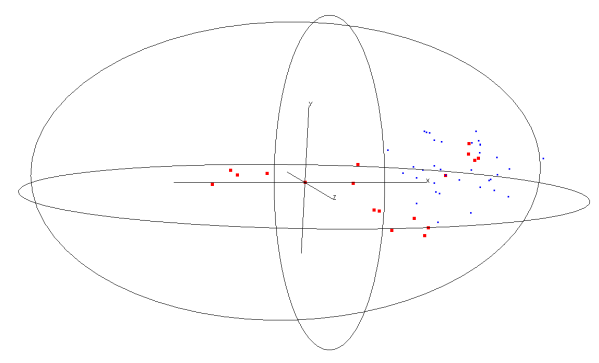

(b)

Figura A.35: Configuração do espaço da base Pulmão após o uso do método WG para (a) espaço completo (b) 50 elementos mais próximos ao centro de consulta.

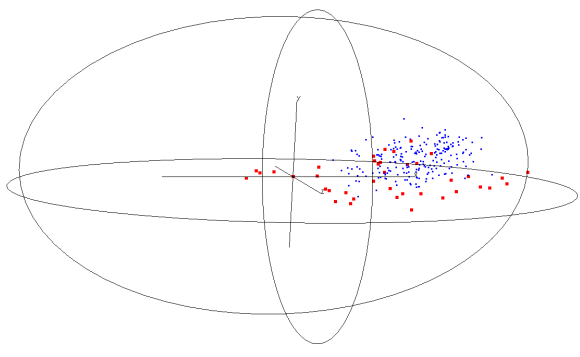

(a)

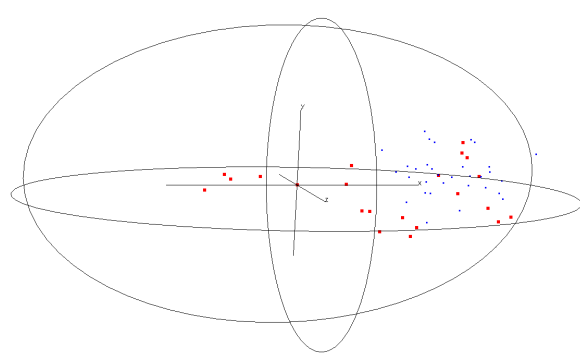

(b)

Figura A.36: Configuração do espaço da base Pulmão após o uso do método WF para (a) espaço completo (b) 50 elementos mais próximos ao centro de consulta. 


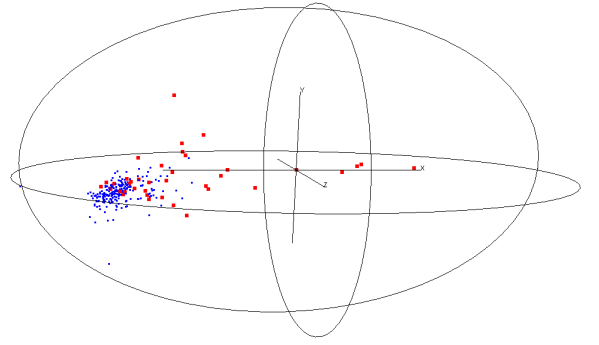

(a)

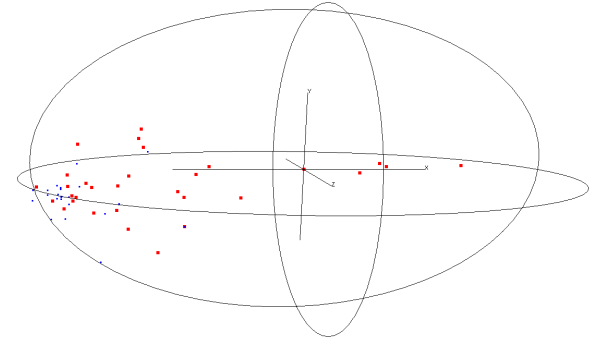

(b)

Figura A.37: Configuração do espaço da base Pulmão após o uso do método TF para (a) espaço completo (b) 50 elementos mais próximos ao centro de consulta. 